Pacific Northwest

National Laboratory

Operated by Battelle for the

U.S. Department of Energy

\section{Pipeline Cross-Site Transfer Assessment for Tank 241-SY-101}

\author{
Y Onishi \\ BE Wells \\ SA Hartley \\ SK Cooley
}

February 2002

Prepared for the U.S. Department of Energy under Contract DE-AC06-76RL01830 


\title{
DISCLAIMER
}

This report was prepared as an account of work sponsored by an agency of the United States Government. Neither the United States Government nor any agency thereof, nor Battelle Memorial Institute nor any of their employees makes any warranty, express or implied, or assumes any legal liability or responsibility for the accuracy, completeness, or usefulness of any information, apparatus, product, or process disclosed or represents that its use would not infringe privately owned rights. Reference herein to any specific commercial product, process, or service by trade name, trademark, manufacturer, or otherwise does not necessarily constitute or imply its endorsement, recommendation, or favoring by the United States Government or any agency thereof, or Battelle Memorial Institute. The views and opinions of authors expressed herein do not necessarily state or reflect those of the United States Government or any agency thereof.

\section{PACIFIC NORTHWEST NATIONAL LABORATORY \\ operated by \\ BATTELLE \\ for the \\ UNITED STATES DEPARTMENT OF ENERGY \\ under Contract DE-AC06-76RL01830}

\author{
Printed in the United States of America \\ Available to DOE and DOE contractors from the \\ Office of Scientific and Technical Information, \\ P.O. Box 62, Oak Ridge, TN 37831-0062; \\ ph: (865) 576-8401 \\ fax: (865) 576-5728 \\ email: reports@adonis.osti.gov
}

Available to the public from the National Technical Information Service,

U.S. Department of Commerce, 5285 Port Royal Rd., Springfield, VA 22161

$$
\begin{aligned}
& \text { ph: (800) 553-6847 } \\
& \text { fax: (703) 605-6900 }
\end{aligned}
$$

email: orders@ntis.fedworld.gov

online ordering: http://www.ntis.gov/ordering.htm 


\title{
Pipeline Cross-Site Transfer Assessment for Tank 241-SY-101 Waste
}

\author{
Y. Onishi \\ B.E. Wells \\ S.A. Hartley \\ S.K. Cooley
}

February 2002

Prepared for the U.S. Department of Energy under Contract DE-AC06-76RLO 1830

Pacific Northwest National Laboratory

Richland, WA 99352 


\section{Summary}

This study evaluated the feasibility of transferring waste stored in Hanford Tank 214-SY-101 (SY-101) in the 200 West Area to a storage tank in the 200 East Area through a 6.2-mile, 3-inchdiameter stainless steel pipeline. The Wasp slurry transport model was used for this assessment. We first conducted validation testing of the Wasp slurry pipe flow model, then applied the Wasp model to calculate the critical velocity and expected pressure drop to determine 1) whether current SY-101 waste can be transferred through the existing cross-site transfer pipeline without additional dilution with water or 2) how much dilution with water would be needed.

This evaluation was subject to the following restrictions:

Restriction 1: The slurry velocity must be greater than the critical velocity.

Restriction 2: The slurry flow must be turbulent.

Restriction 3: The pipeline pressure at the vent station must be less than 180 psi.

Restriction 4: The pipeline pressure must not exceed 400 psi in any part of the pipeline.

Restriction 5: The operating pressure of SY-101 transfer pump must not exceed 220 psi.

We evaluated 24 cases, combining the various sets of solid particle sizes, slurry velocities, and solid concentrations. A Monte Carlo simulation approach was used to account for uncertainties in the input parameters. Study results at the upper bound of the $95 \%$ confidence interval indicate that only the liquid waste can be transferred at or below $0.46 \mathrm{~m} / \mathrm{s}(1.5 \mathrm{ft} / \mathrm{sec})$ velocity without additional dilution with water. When the transferred SY-101 waste contains solids, the transfer velocity of $0.76 \mathrm{~m} / \mathrm{s}(2.5 \mathrm{ft} / \mathrm{sec})$ requires the least amount of dilution compared with the other two velocities of $1.2(4.5 \mathrm{ft} / \mathrm{s})$ and $0.46(1.5 \mathrm{ft} / \mathrm{s})$. The required dilution in this case ranges from 6.0 to 8.5 times, as shown in Table S.1. These results are subject to the uncertainty of the data used in the assessment, potential Wasp model prediction errors and limitations, potential unsteadiness of slurry bed load, current pipeline pressure restrictions, and the available head of the transfer pump already installed in Tank SY-101. If the transfer pump head limitation is eliminated, dilution requirements are reduced $0.79 \sim 4.7$ times, as shown in Table S.2, and restrictions 1 through 4 are optimally satisfied almost simultaneously.

Table S.1. Required SY-101 Slurry Conditions for Cross-Site Transfer

\begin{tabular}{|c|c|c|}
\hline $\begin{array}{c}\text { Solid concentration } \\
(\mathbf{v o l} \%)\end{array}$ & $\begin{array}{c}\text { Required water } \\
\text { dilution (volume } \\
\text { ratio) }\end{array}$ & $\begin{array}{c}\text { Slurry velocity } \\
(\mathbf{m} / \mathbf{s})\end{array}$ \\
\hline 0 (no sludge) & 0 & $\leq 0.46$ \\
\hline $5.67(1 / 3$ sludge) & 6.0 & \multirow{2}{*}{0.76} \\
\hline $11.3(2 / 3$ sludge) & 7.2 & \\
\hline 17.0 (sludge alone) & 8.5 & \\
\hline
\end{tabular}


Table S.2. Near-Optimal SY-101 Slurry Conditions for Cross-Site Transfer

\begin{tabular}{|c|c|c|}
\hline $\begin{array}{c}\text { Solid concentration } \\
\text { (vol \%) }\end{array}$ & $\begin{array}{c}\text { Required water } \\
\text { dilution (Volume } \\
\text { Ratio) }\end{array}$ & $\begin{array}{c}\text { Slurry velocity } \\
(\mathbf{m} / \mathbf{s})\end{array}$ \\
\hline 0 (no sludge) & 0 & $\leq 0.46$ \\
\hline $5.67(1 / 3$ sludge) & 0.79 & \multirow{2}{*}{0.76} \\
\hline $11.3(2 / 3$ sludge) & 3.0 & \\
\hline 17.0 (sludge only) & 4.7 & \\
\hline
\end{tabular}




\section{Contents}

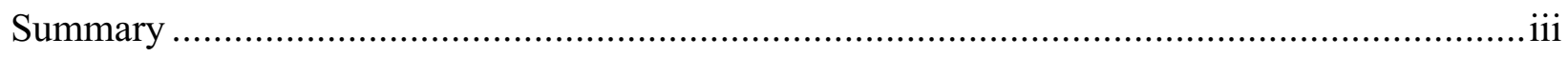

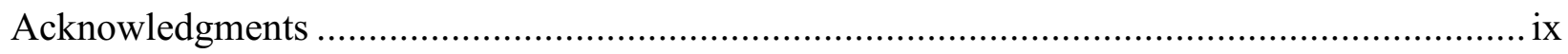

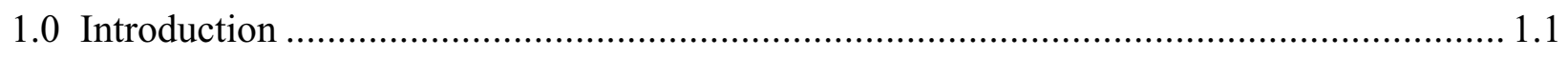

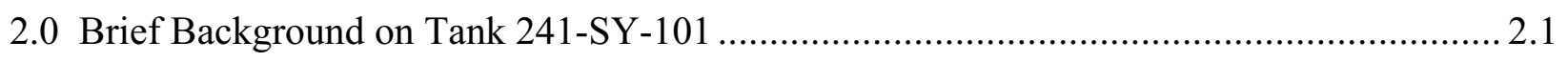

3.0 Wasp Slurry Pipeline Transport Model............................................................................ 3.1

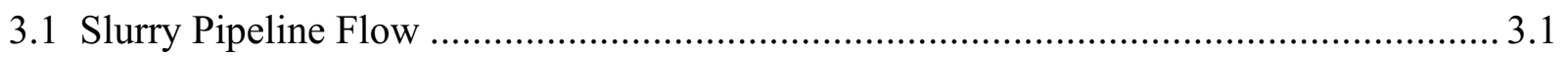

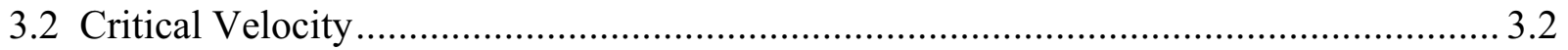

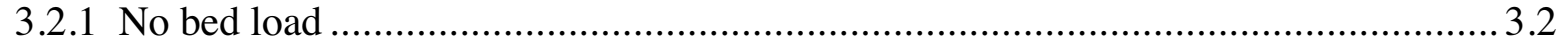

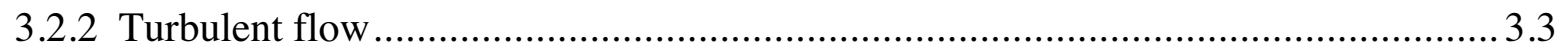

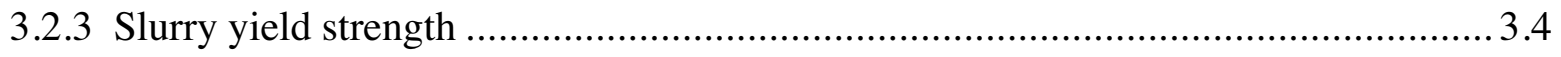

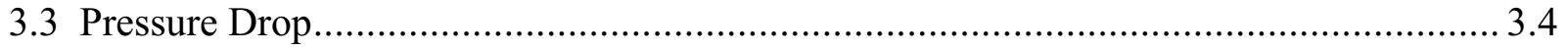

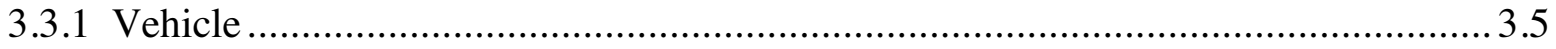

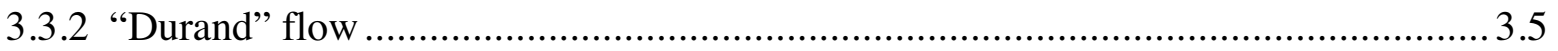

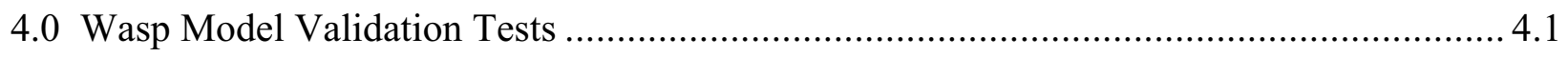

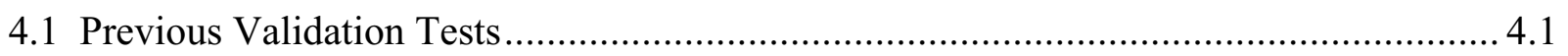

4.2 W-211 Pipeline Loop Tests ................................................................................. 4.5

4.2.1 Test loop and test conditions ........................................................................... 4.5

4.2.2 Wasp Model Validation to W-211 Test Loop Results ......................................... 4.7

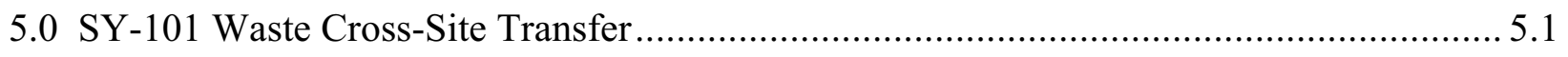

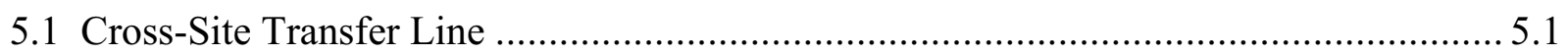

5.2 Liquid Waste Transfer Through the Cross-Site Transfer Line....................................... 5.2

5.3 Scoping Evaluation of Acceptable Waste Conditions for Cross-Site Transfer ................. 5.3

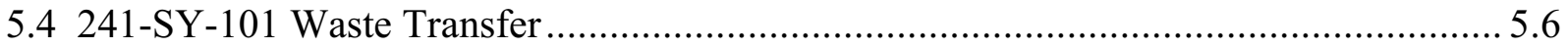

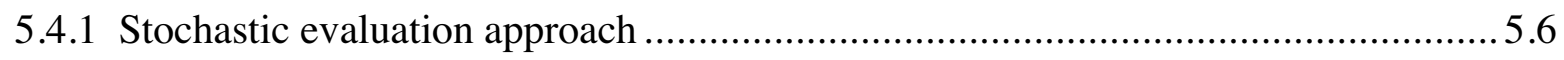

5.4.2 Specific waste properties for Tank 241-SY-101 ……..........................................5.6

5.4.3 Pipeline modeling results and evaluations .........................................................5.23

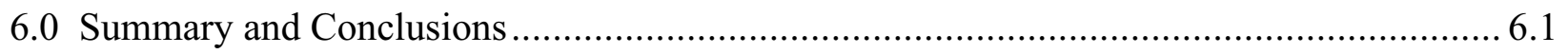

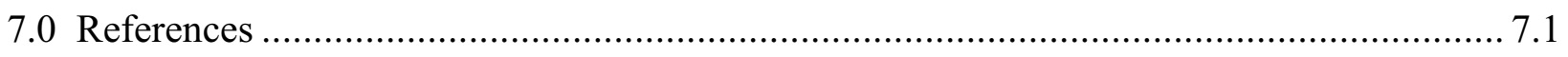




\section{Figures}

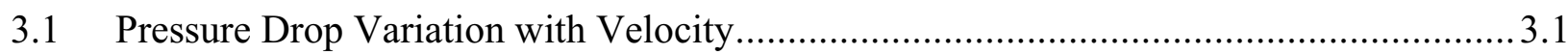

4.1 Comparison of Wasp Model Predictions and Measured Pressure Drops for Coal Slurry Transport.

4.2 Wasp Model Predictions and Measured Pressure Drop for Silica

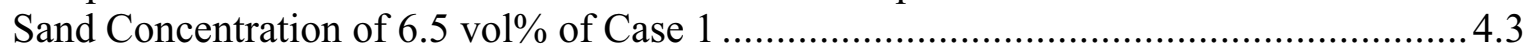

4.3 Wasp Model Predictions and Measured Pressure Drop for Simulant Solid Concentration of $7.8 \mathrm{vol} \%$ of Case 4 .........................................................................

4.4 Wasp Model Predictions and Measured Pressure Drop for Silica/Zircon

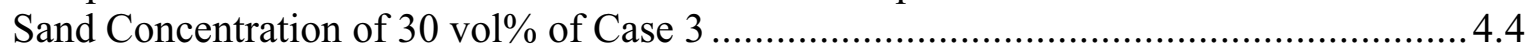

4.5 Measured and Wasp Model Results for W-211 Test Loop............................................. 4.8

4.6 Measured and Wasp Model Results for W-211 Test Loop.............................................4.9

4.7 Measured and Wasp Model Results for W-211 Test Loop (Thomas relation) ................ 4.12

4.8 Error Between the Measured and Wasp Model Results ................................................ 4.12

4.9 Wasp Model with Apparent Viscosity Error versus Measured Pressure Drop ................ 4.13

$5.1 \quad$ Schematic of Cross-Site Transfer Line .......................................................................

5.2 Normalized Viscosity as a Function of Temperature at Dilution....................................5.9

5.3 Normalized Viscosity as a Function of Dilution at Temperature...................................5.8

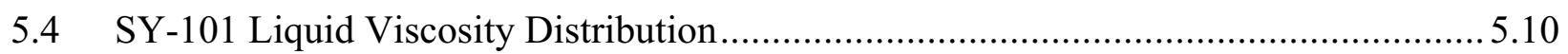

5.5 Identified Post-Mitigation SY-101 Solid Phases ......................................................... 5.11

5.6 Dry Solid Density as a Function of wHCS/wHL for Select Hanford Tanks .................. 5.13

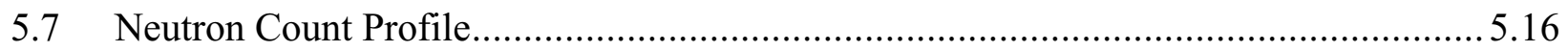

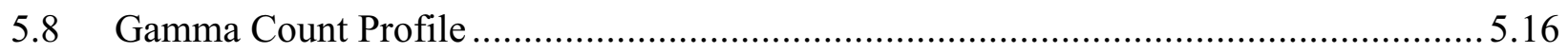

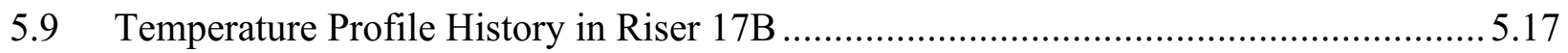

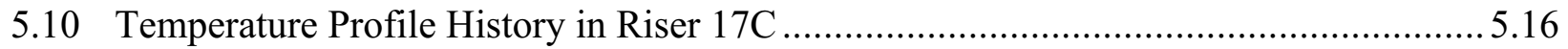

5.11 Normalized SY-101 Slurry Viscosity as a Function of Temperature.............................5.20

5.12 SY-101 Slurry Viscosity Distribution $(\gamma=1281 / \mathrm{s}, \mathrm{Cv}=0.155) \ldots \ldots \ldots \ldots \ldots \ldots \ldots \ldots \ldots \ldots \ldots . . .5 .21$

5.13 SY-101 Slurry Viscosity Distribution $(\gamma=801 / \mathrm{s}, \mathrm{Cv}=0.155) \ldots \ldots \ldots \ldots \ldots \ldots \ldots \ldots \ldots \ldots \ldots \ldots . . .5 .21$

5.14 SY-101 Slurry Viscosity Distribution $(\mathrm{g}=48 \mathrm{1} / \mathrm{s}, \mathrm{Cv}=0.155) \ldots \ldots \ldots \ldots \ldots \ldots \ldots \ldots \ldots \ldots \ldots \ldots . . .5 .21$

5.15 Example of Determination of Slurry Viscosity at Transfer Conditions .........................5.23 


\section{Tables}

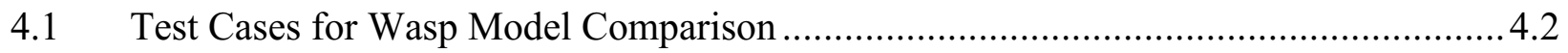

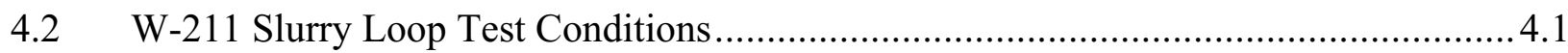

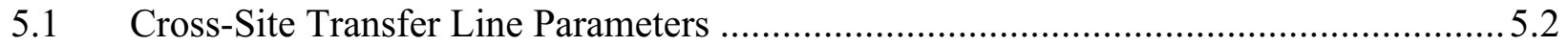

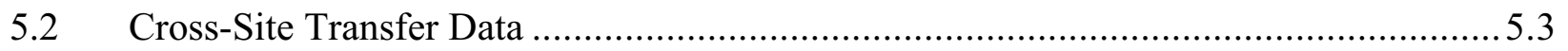

5.3 Ability to Transfer Water and SY-101 Liquid Waste to AP Tank Farm

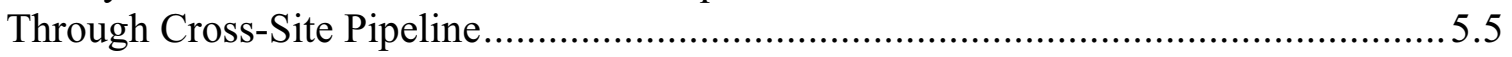

5.4 Some Examples of Acceptable Waste and Transport Conditions ...................................5.5

5.5 SY-101 Supernatant Liquid Viscosity at Dilution by Temperature.................................5.7

5.6 SY-101 Supernatant Liquid Viscosity at Temperature by Dilution...............................5.7

5.7 SY-101 Liquid Viscosity Values Extrapolated to Current Tank Conditions ................. 5.10

5.8 Dry Solid Particle Size Distribution from the PLM and SEM/EDS

Performed on the April/June 2000 SY-101 Samples ................................................... 5.14

5.9 Dry Solid Particle Size Distribution from Window E SY-101 Samples........................5.14

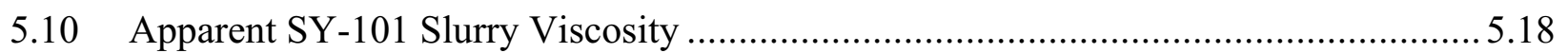

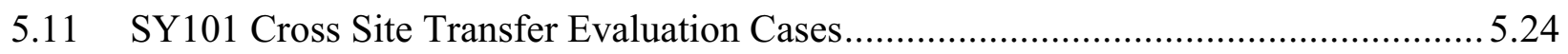

5.12 Monte Carlo Simulation Results for Test Cases 1 through 4 ......................................25

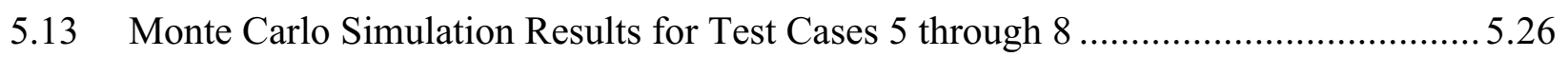

5.14 Monte Carlo Simulation Results for Test Cases 9 through 12 .................................. 5.27

5.15 Monte Carlo Simulation Results for Test Cases 13 Through 16 ....................................27

5.16 Monte Carlo Simulation Results for Test Cases 17 through 20 .................................5.28

5.17 Monte Carlo Simulation Results for Test Cases 21 through 24 ................................... 5.28

5.18 Cross Site Transferability of SY-101 Waste Without Additional Dilution....................5.29

5.19 Required Water Dilution and Slurry Operational Conditions for Cases 1-4 ...............5.31

5.20 Required Water Dilution and Slurry Operational Conditions for Cases 7-8 …...........5.31

5.21 Required Water Dilution and Slurry Operational Conditions for Cases 10-12 ...........5.31

5.22 Required Water Dilution and Slurry Operational Conditions for Cases 13-16 ...........5.32

5.23 Required Water Dilution and Slurry Operational Conditions for Cases 19-20 ...........5.32

5.24 Required Water Dilution and Slurry Operational Conditions for Cases 23-24 ...........5.32

5.25 Summary of SY-101 Waste Transferable Conditions................................................5.33

5.26 Near-Optimal SY-101 Slurry Conditions for Cross-Site Transfer ...............................5.34 


\section{Acknowledgments}

The authors express appreciation to Carl W. Enderlin for his assistance in estimating the SY-101 waste viscosity based on the mixer-pump performance and SY-101 to SY-102 waste transfers and for providing us with the cross-site transfer pipeline descriptions. We thank Judith A. Bamberger for providing the W-211 pipeline loop experimental data in electronic form to make the Wasp model validation efforts much easier. Judith also provided the experimentally measured viscosity plots. We thank Ms. Catherine A. Majumder, who calculated the slurry viscosity from the plots of the W-211 loop experiments to provide us the viscosity values for the model testing. And thanks to Ms. Sheila Bennett for her excellent editorial support. 


\subsection{Introduction}

The objective of this study was to evaluate the feasibility of transferring waste currently stored in double-shell Tank 241-SY-101 (SY-101) in the 200 West Area of the Hanford Site in eastern Washington State to a storage tank in the 200 East Area through a 6.2-mile, 3-inchdiameter stainless steel pipeline. Specifically, the study was performed to determine 1) whether current SY-101 waste can be transferred through the pipeline without additional dilution with water and 2) if that is not possible, how much dilution is needed.

SY-101 had a series of flammable gas release events in the past (Stewart et al. 1995), and as a result its waste has been studied extensively. Recently, a portion of the SY-101 waste was transferred to neighboring Tank 241-SY-102, and water was added to remedy SY-101's level growth and gas release problems (Johnson et al. 2000). The cross-site transfer of SY-101 waste is the next step to further remove waste from SY-101.

We used the Wasp pipeline slurry transport model (Wasp 1963) to determine the critical slurry velocity and pressure drop and thus to identify acceptable SY-101 waste properties and operational conditions for pipeline transfer. The Wasp model was developed with industrial coal slurry transport data and is used extensively for sand and coal slurry transfer by water (Wasp et al. 1977). The density of coal is $1,350 \mathrm{~kg} / \mathrm{m}^{3}$, and its particles tend to be a few hundred microns in size, while sand has a density of $2,650 \mathrm{~kg} / \mathrm{m}^{3}$ and a medium particle size of $250 \sim 500 \mu \mathrm{m}$. Because these conditions may be significantly different from expected Hanford conditions, we tested the Wasp model with experimental data (Reynolds et al. 1996) to evaluate its applicability to the transfer of the much finer-particle waste before applying it to the SY-101 cross-site transfer conditions.

Section 2 presents background information on Tank SY-101. The Wasp model is described in Section 3, and results of past and current validation testing are given in Section 4. Section 5 describes the cross-site pipeline and its pressure restrictions, application of the Wasp model to the recent SY-102 cross-site transfer, the scoping evaluation, SY-101 waste characterization, and cross-site transfer evaluation results. The summary and conclusions are presented in Section 6, and cited references are listed in Section 7. 


\subsection{Brief Background on Tank 241-SY-101}

An excellent condensed history of Tank 241-SY-101 (SY-101) is presented in Johnson et al. (2000):

Between 1977 and 1980, Tank 241-SY-101 was filled with waste that was the most concentrated material produced by the evaporators. Subsequent waste additions included concentrated complexant waste containing significant organic complexant concentrations. The waste in 241-SY-101 was observed to generate a flammable mixture of gases, retain the gas mixture within the waste, and spontaneously release large volumes of the gas mixture in what are understood to be buoyant displacement gas release events (BD-GREs). While periodic in nature, the amount and timing of waste gas releases could neither be accurately predicted nor controlled. Three of the largest BD-GREs resulted in the tank domespace exceeding the lower flammability limit (LFL).

In 1990, this behavior was declared an Unreviewed Safety Question (USQ). In order to control waste gas release and reduce the flammability hazard, a mixer pump was installed in 1993. Routine pump operations prevented the buildup and release of large volumes of flammable gas. An unanticipated consequence of mixer pump operations and mitigation of the large gas releases was an excessive growth of a gas-retaining crust on the waste surface. The waste surface change (level rise) caused by accumulation of gas and solids within this crust resulted in declaration of a USQ in 1998. Between December 18, 1999 and March 15, 2000, a series of waste transfers and water dilution of the remaining 241-SY-101 waste dissolved most of the soluble sodium salts, significantly improving the waste characteristics.

The Flammable Gas Safety Issue was closed and SY-101 was removed from the "watch list" in January 2001 as a direct result of this mitigation campaign. ${ }^{(a)}$

(a) Department of Energy Memorandum DOE F 1325.0, CL Huntoon to H Boston, January 11, 2001. Subject: Approval to Close the Flammable Gas Safety Issue for Tank 241-SY-101 and Remove the Tank from the Watch List. 


\subsection{Wasp Slurry Pipeline Transport Model}

\subsection{Slurry Pipeline Flow}

The pressure drop of slurry flow in a pipeline varies with flow velocity. However, unlike a pure liquid flow, it is not monotonic (Vanoni 1975; Govier and Aziz 1977), as shown in Figure 3.1.

At sufficiently high velocity, all solids are suspended and their distributions are vertically homogeneous. As the velocity decreases below a certain point, $U_{1}$ (see Figure 3.1) (Govier and Aziz 1977), all of the solids are still suspended, but their distribution becomes vertically heterogeneous. As the velocity further decreases to the critical velocity $\mathrm{U}_{2}$, some solids start to move (e.g., sliding, hopping, jumping) along the pipe bottom as a "bed load." At this point, the pressure drop usually becomes the minimum. As the velocity decreases further, fewer solids move as the suspended load, and more solids are transported as the bed load. At further reduced velocity, $\mathrm{U}_{3}$, the bed load starts to generate the bed form. The bed form further increases the apparent pipe fraction factor, resulting in increased pressure drop. Finally, at further reduced velocity $\mathrm{U}_{4}$, all solids stop moving.

Thus, at critical velocity, $\mathrm{U}_{2}$, the slurry operation is optimized and requires minimum pump pressure. However, once some solids start to move as bed load, more pressure is required to move them. The danger of plugging the pipeline arises if the pump does not have enough extra pressure to overcome this added pressure drop requirement or if the pipeline strength cannot accommodate this additional pressure requirement. Thus, to avoid potential pipeline plugging, waste transfer through the pipeline must be operated above the critical velocity, $\mathrm{U}_{2}$.

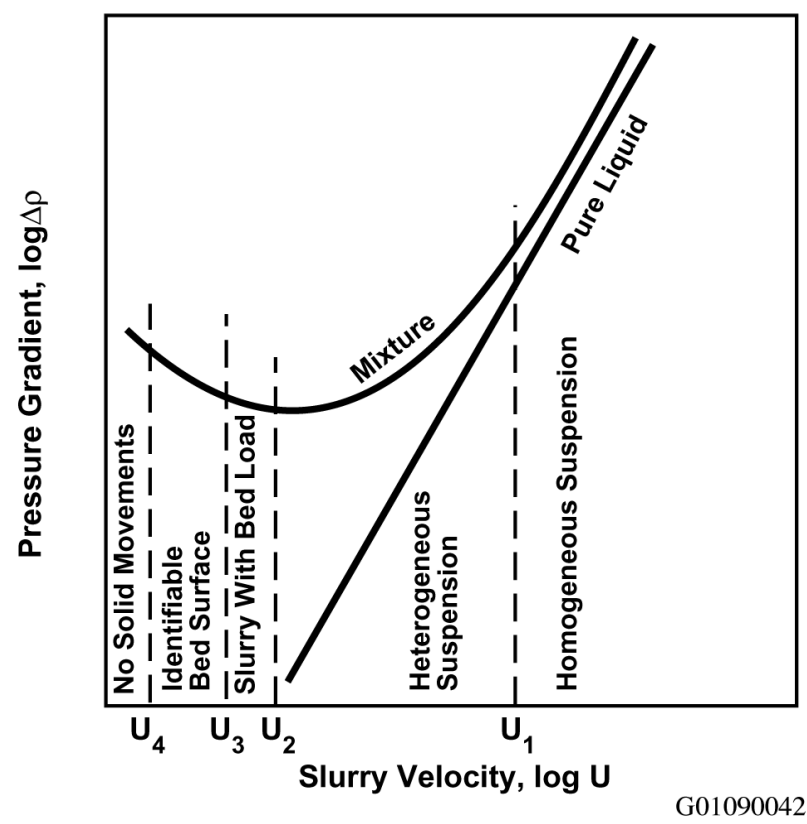

Figure 3.1. Pressure Drop Variation with Velocity 
There have been many slurry pipeline transport models developed to calculate the critical velocity and the pressure drop since Durand first developed a model based on experiments with closely sized, coarse particles (100 $\mu \mathrm{m}$ to $25 \mathrm{~mm}$ particles of coal, sand, pebbles, and gravel) carried by water (Durand 1953a,b; Govier and Aziz 1989). These models include Spell (1955), Sinclair (1962), Wasp (1963), Condolois and Chapus (1963), Thomas (1965), Zandi and Govatas (1967), Rose and Duckworth (1969), Shook (1969), Oroskar and Turain (1980), Wani (1982), and Hanks (1986).

Wasp's model (1963) is "probably the best method at present" (Wasp et al. 1977). Wasp's contribution to slurry pipeline transport assessment was to introduce explicitly the concept of two-phase flow to the slurry pipeline transport. Based on coal slurry data accumulated over 13 years of experiments and actual 102-mile pipeline transport, he proposed to separate the slurry flow into two components: a vertically homogeneous slurry flow called a "vehicle" and a vertically heterogeneous slurry flow called a "Durand" flow (Wasp 1963). We now briefly describe his model, which predicts the critical velocity and the pressure drop.

\subsection{Critical Velocity}

The slurry pipe flow must be above the critical velocity based on the following conditions:

- It must be above $\mathrm{U}_{2}$ (see Figure 3.1) to have all solids suspended (no bed load, as discussed above)

- It must be turbulent (for a pipe flow, Reynolds number of above 2,100 2,400)

- It must overcome the yield strength of the slurry, if any.

\subsubsection{No bed load}

Wasp proposed the following model to calculate the minimum velocity required to suspend all solids by expanding the Durand model to better represent the solid concentrations and the mean particle size for more widely varied particle sizes:

where

$$
\mathrm{U}_{\mathrm{c}}=3.116 \mathrm{C}_{\mathrm{V}}^{0.186}\left[2 \mathrm{gD}\left(\frac{\rho_{\mathrm{S}}-\rho_{\mathrm{L}}}{\rho_{\mathrm{L}}}\right)\right]^{\frac{1}{2}}\left(\frac{\mathrm{d}}{\mathrm{D}}\right)^{\frac{1}{6}}
$$

$\mathrm{C}_{\mathrm{V}}=$ total solid volume fraction

$\mathrm{D}=$ pipe diameter

$\mathrm{d}=$ particle diameter (weighted mean diameter for mixed sizes)

$\mathrm{g}=$ gravitational acceleration

$\mathrm{U}_{\mathrm{C}}=$ critical velocity

$\rho_{\mathrm{L}}$ and $\rho_{\mathrm{s}}=$ liquid and solid densities, respectively.

Any consistent units of metric or English system can be used for Equation (3.1) and all other equations used in Section 3. 


\subsubsection{Turbulent flow}

The acceptable slurry Reynolds number, $\operatorname{Re}_{\mathrm{M}}$ must be

$$
\operatorname{Re}_{M}=\frac{d U_{C} \rho_{M}}{\mu_{M}} \geq 2,300
$$

where

$$
\begin{aligned}
& \mu_{M}=\text { slurry viscosity } \\
& \rho_{M}=\text { slurry density. }
\end{aligned}
$$

The slurry density may be estimated by

$$
\rho_{M}=\left(1-C_{V}\right) \rho_{L}+C_{V} \rho_{S}
$$

The slurry viscosity may be estimated by several different equations. Einstein expressed the mixture viscosity of laminar slurry as

$$
\mu_{\mathrm{M}}=\mu_{\mathrm{L}}\left(1+2.5 \mathrm{C}_{\mathrm{V}}\right)
$$

where $\mu_{\mathrm{L}}$ is the liquid viscosity (Wasp et al. 1977). Equation (3.4) is not valid for solid concentrations much greater than $1 \mathrm{vol} \%$. There are many slurry viscosity formulas for more concentrated suspensions (e.g., Landel et al. 1963; Wasp et al. 1977), including those of polynomial expressions of the form

$$
\mu_{\mathrm{M}}=\mu_{\mathrm{L}}\left(1+\mathrm{a}_{1} \mathrm{C}_{\mathrm{V}}+\mathrm{a}_{2} \mathrm{C}_{\mathrm{V}}^{2}+\mathrm{a}_{3} \mathrm{C}_{\mathrm{V}}^{3}+\mathrm{a}_{4} \mathrm{C}_{\mathrm{V}}^{4}+\ldots\right)
$$

where $\mathrm{a}_{1}, \mathrm{a}_{2}, \mathrm{a}_{3}$, and $\mathrm{a}_{4}$ are constants. Thomas (1965) developed the following more commonly used expression by modifying Einstein's formula:

$$
\mu_{\mathrm{M}}=\mu_{\mathrm{L}}\left(1+2.5 \mathrm{C}_{\mathrm{V}}+10.05 \mathrm{C}_{\mathrm{V}}^{2}+0.00273 \mathrm{e}^{16.6 \mathrm{C}}\right)
$$

We use this Einstein formula modified by Thomas (Equation 3.6) in the Wasp model as a default. However, if slurry viscosity values for a specific application are available, it is better to use them (see Section 4) than to use the slurry viscosity values obtained from various equations discussed above. In this study, we used either the measured values themselves (for the Wasp model validation tests described in Section 4) or case-specific equations developed using the measured slurry viscosity values for the SY-101 waste cross-site transfer assessment discussed in Section 5.4. 


\subsubsection{Slurry yield strength}

If the slurry has yield strength, the pipe flow must overcome the yield strength. Thomas (1965) proposed the critical velocity to be Equation (3.7) with the pipeline Reynolds number set to 2100 to have transition to turbulence:

$$
\mathrm{U}_{\mathrm{c}}=\sqrt{\frac{\operatorname{Re}_{\mathrm{M}}}{6}} \sqrt{\frac{\tau_{\mathrm{O}}}{\rho_{\mathrm{M}}}}
$$

where $\tau_{0}$ is the slurry yield strength. Wasp et al. (1977) recommends the slurry (effective) viscosity to be

$$
\mu_{\mathrm{eff}}=\frac{\tau_{\mathrm{o}} \mathrm{D}}{6 \mathrm{U}_{\mathrm{c}}}
$$

Thus Equation (3.7) becomes

$$
\mathrm{U}_{\mathrm{c}}=19 \sqrt{\frac{\tau_{\mathrm{o}}}{\rho}}
$$

If the slurry has no yield strength, as in the case of SY-101 slurry, $\tau_{0}$ is zero. Thus, $\mathrm{U}_{\mathrm{C}}$ also becomes zero. The actual critical velocity must be the largest $\mathrm{U}_{\mathrm{C}}$ obtained from Equations (3.1), (3.2), and (3.9).

\subsection{Pressure Drop}

To handle the widely varying particle sizes present in real industrial slurry transport conditions, Wasp proposed to separate the slurry flow into "vehicle" (homogeneous) and "Durand" flow (heterogeneous) components. The overall pressure drop of the slurry flow is the sum of the pressure drops due to vehicle and "Durand" flow components:

$$
\Delta \mathrm{P}_{\text {total }}=\Delta \mathrm{P}_{\text {vehicle }}+\Delta \mathrm{P}_{\text {Durand }}
$$

The Wasp model determines which portion of the slurry is in the "vehicle" and which is in the "Durand" flow portion via the following relationships:

$$
\mathrm{C}_{\mathrm{V}, \text { vehicle }}=\mathrm{C}_{\mathrm{V}, \text { total }}\left(\frac{\mathrm{C}}{\mathrm{C}_{\mathrm{A}}}\right)
$$

and

$$
\mathrm{C}_{\mathrm{V}, \text { Durand }}=\mathrm{C}_{\mathrm{V} \text {,total }}-\mathrm{C}_{\mathrm{V} \text {,vehicle }}
$$


where $\mathrm{C} / \mathrm{C}_{\mathrm{A}}$ is calculated with Equation (3.13) developed by Ismail (1952):

$$
\frac{\mathrm{C}}{\mathrm{C}_{\mathrm{A}}}=10^{\left(\frac{-1.8 \mathrm{w}}{\beta \kappa \mathrm{u}_{*}}\right)}
$$

where the friction velocity is given by

$$
\mathrm{u}_{*}=\mathrm{U}_{\sqrt{\frac{\mathrm{f}}{2}}}
$$

and

$\mathrm{C}$ and $\mathrm{C}_{\mathrm{A}}=$ solid volume fractions at $8 \%$ of the diameter from the top of the pipe and at the middle, respectively

$\mathrm{w}=$ solid settling velocity

$\beta=$ constant $(=1)$

$\kappa=$ Von Kerman constant $(=0.35$ for a slurry flow $)$

$\mathrm{f}=$ the friction factor.

\subsubsection{Vehicle}

For the "vehicle" component, Wasp's model treats the slurry as if it is a liquid with density and viscosity accounting for the true carrying liquid and homogeneous portion of the solids. The pressure drop per unit pipe length due to the "vehicle" is thus calculated by

$$
\frac{\Delta \mathrm{P}_{\text {vehicle }}}{\mathrm{L}}=4 \frac{\mathrm{f}}{\mathrm{D}} \frac{\mathrm{U}^{2}}{2 \mathrm{~g}}
$$

The friction factor $\mathrm{f}$ can be obtained from the Moody diagram or, equivalently, in the turbulent regime, may be expressed as

$$
\frac{1}{\sqrt{f}}=4 \log \frac{D}{2 \varepsilon}+3.48-4 \log \left(1+9.35 \frac{D}{2 \varepsilon \operatorname{Re} \sqrt{f}}\right)
$$

where

$$
\begin{aligned}
& \operatorname{Re}=\text { Reynolds number of the vehicle } \\
& \varepsilon \quad=\text { pipe roughness }
\end{aligned}
$$

\subsection{2 "Durand" flow}

The Wasp model uses the Durand formula for calculating the pressure drop due to the "Durand" (heterogeneous) slurry flow component. This is expressed as 


$$
\frac{\Delta \mathrm{P}_{\text {Durand }}}{\mathrm{L}}=82\left(\frac{\Delta \mathrm{P}_{\text {water }}}{\mathrm{L}}\right) \mathrm{C}_{\mathrm{v}, \text { Durand }}\left(\frac{\mathrm{gD}\left(\frac{\rho_{\mathrm{S}}}{\rho_{\mathrm{L}}}-1\right)}{\mathrm{U}^{2} \sqrt{\mathrm{C}_{\mathrm{D}}}}\right)^{1.5}
$$

where

$\mathrm{C}_{\mathrm{D}} \quad=$ drag coefficient

$\mathrm{C}_{\mathrm{V} \text {,Durand }}=$ volume fraction of solids in the Durand (heterogeneous) portion of the slurry flow.

The pressure drop of a water flow, $\Delta \mathrm{P}_{\text {water }}$, can be obtained in the same manner as $\Delta \mathrm{P}_{\text {vehicle }}$ with Equation (3.15). These calculations are iterated until there is no measurable change for the calculated friction factor and resultant pressure drop. 


\subsection{Wasp Model Validation Tests}

The Wasp model was developed with coarse particles, mostly of coal, and applied to coal and sand transports, as were all other slurry pipeline flow models. These conditions are potentially quite different from Hanford waste conditions, including SY-101 wastes. Thus, before applying the Wasp model to an SY-101 cross-site transfer, we needed to perform some model testing with measured results. In this section, we will discuss our Wasp model testing with fine particle data, as well as those studies conducted by other researchers.

\subsection{Previous Validation Tests}

Wasp himself tested his model for predicted pressure drop against those for actual commercial coal slurry transport systems (Wasp et al. 1977). The density of coal is approximately $1,350 \mathrm{~kg} / \mathrm{m}^{3}$. The pipe inside diameter was $30.5 \mathrm{~cm}$; the coal particle sizes varied from approximately 1 to $5 \mathrm{~mm}$. The slurry had coal concentrations varying from 38.1 to 53.5 wt $\%$, and the pipeline velocities were 0.91 to $2.2 \mathrm{~m} / \mathrm{s}$. Figure 4.1 shows 19 cases of predicted pressure drops compared with the measured values. Because the Wasp model was developed with extensive coal slurry transport data, it produced reasonable accuracy, with errors of $-21 \%$ to $+17 \%$ and an average error of $7 \%$.

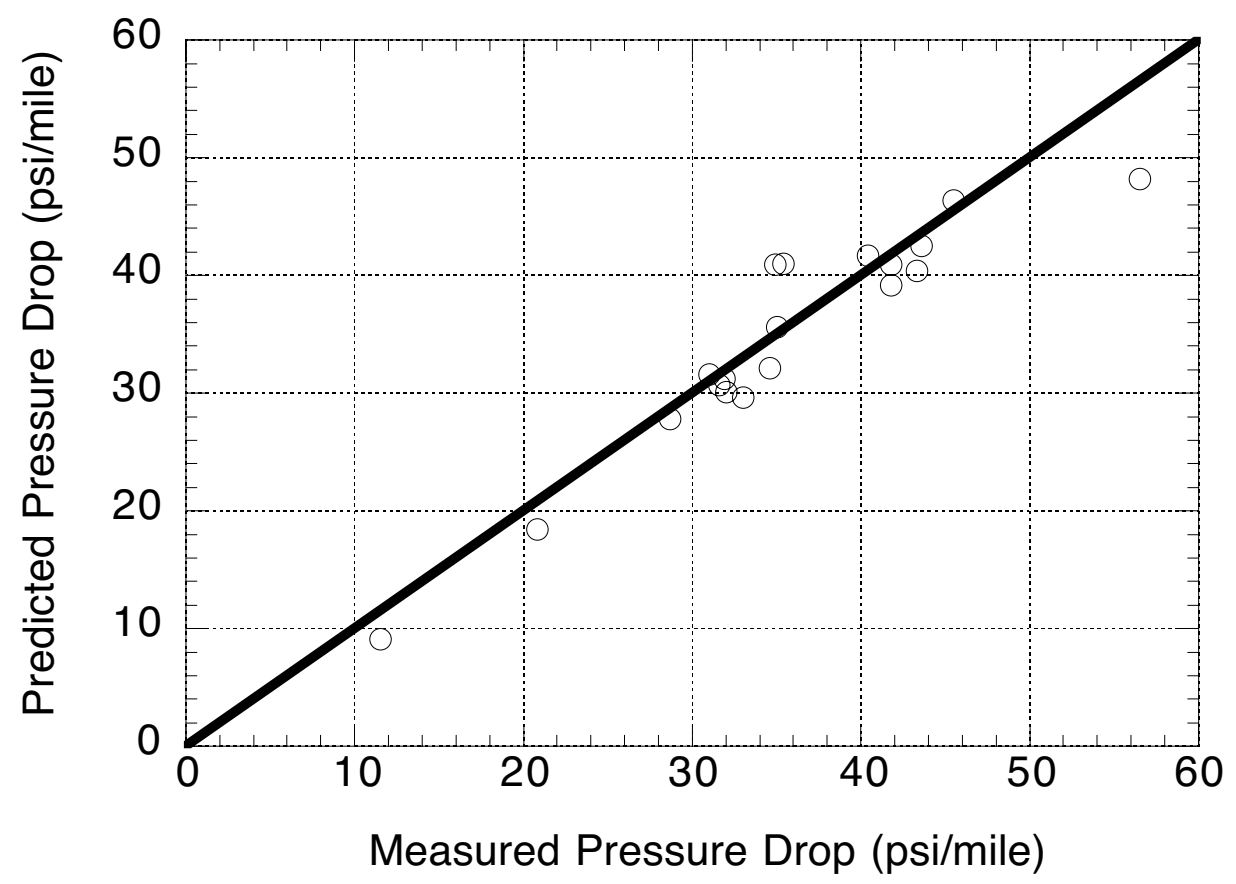

Figure 4.1. Comparison of Wasp Model Predictions and Measured Pressure Drops for Coal Slurry Transport (data from Wasp et al. 1977) 
Florida International University has conducted extensive slurry pipe flow experiments with water as a carrier fluid. They compared some of their results with Wasp model predictions (Ebadian et al. 2001). The pressure drops of these experiments were measured in a 5.9-m horizontal section of the pipe flow loop, which consists of $30 \mathrm{~m}$ of 2.21-cm (0.87-in.) stainless steel. Results from the four cases presented in Table 4.1 were used to compare it with the Wasp model.

Table 4.1. Test Cases for Wasp Model Comparison

\begin{tabular}{|c|c|c|c|c|c|}
\hline $\begin{array}{c}\text { Test } \\
\text { Cases }\end{array}$ & $\begin{array}{c}\text { Solid } \\
\text { Type }\end{array}$ & $\begin{array}{c}\text { Solid Density } \\
\left(\mathbf{k g} / \mathbf{m}^{\mathbf{3}}\right)\end{array}$ & $\begin{array}{c}\text { Particle Size } \\
(\boldsymbol{\mu m})\end{array}$ & $\begin{array}{c}\text { Volume Fraction } \\
(\mathbf{v o l} \%)\end{array}$ & $\begin{array}{c}\text { Pipe Flow } \\
\text { Velocity } \\
(\mathbf{m} / \mathbf{s})\end{array}$ \\
\hline 1 & Silica sand & 2,380 & $75-150$ & $10-28$ & $0.4-2.5$ \\
\hline 2 & Zircon sand & 4,232 & $75-150$ & $6-27$ & $0.4-2.5$ \\
\hline 3 & Silica/zircon & $3,400-3,565$ & $75-150$ & $6-30$ & $0.4-2.5$ \\
\hline 4 & $\begin{array}{c}\text { Tank waste } \\
\text { simulant }\end{array}$ & Avg 3,090 & $\begin{array}{c}2-157 \\
(\text { avg 19.5) }\end{array}$ & 5.2 and 7.8 & $0.4-2.5$ \\
\hline
\end{tabular}

The tank waste simulant for Case 4 is a mixture of $\mathrm{Fe}_{2} \mathrm{O}_{3}, \mathrm{Al}_{2} \mathrm{O}_{3}, \mathrm{MnO}_{2}, \mathrm{Ni}_{2} \mathrm{O}_{3}$, and $\mathrm{SiO}_{2}$ to resemble a tank waste at the U.S. Department of Energy Savannah River Site.

Ebadian et al. (2001) used three different equations to calculate the viscosity of slurry mixture in the Wasp Model. The first is the Thomas equation (Equation 3.6), and the second is Landel's equation (Landel et al. 1963), given as

$$
\mu_{\mathrm{M}}=\mu_{\mathrm{L}}\left(1-\frac{\mathrm{C}_{\mathrm{V}}}{\mathrm{C}_{\mathrm{V} \max }}\right)^{-2.5}
$$

The third equation represents a Bingham flow and is expressed as

$$
\tau=\tau_{0}+K \gamma
$$

where

$$
\begin{array}{ll}
\gamma & =\text { strain rate } \\
\mathrm{K} & =\text { consistency } \\
\tau & =\text { shear stress } \\
\tau_{0} & =\text { slurry yield strength. }
\end{array}
$$

The parameter values in Equation (4.2) were determined by the pipeline experiments. Thus the apparent slurry viscosity may be expressed by

$$
\mu_{\mathrm{M}}=\mathrm{K}+\frac{\tau_{0}}{\gamma}
$$


The Wasp model with the Thomas and Landel equations had predictions that matched the measured pressure drop well for low solid volume fractions, as shown in Figure 4.2 for Case 1 with solid concentration of $6.5 \mathrm{vol} \%$, for example. However, the consistency (Equations 4.2 and 4.3) obtained by the experiments almost always overpredicted the pressure drop.

This is also true for Case 4. The comparison was better for the 5.2-vol\% condition than for the 7.8 vol\% condition. The comparison of the 7.8-vol\% condition is shown in Figure 4.3. As the solid concentration increases further, the discrepancy between the Wasp prediction and the measured pressure drops increases, as Figure 4.4 (for Case 3 with 30 vol\%) indicates.

The study of Ebadian et al. (2001) indicates that the Wasp model generally works well with the Thompson or Landel viscosity equations for relatively low solid concentrations (below $10 \mathrm{vol} \%$ in their test cases), but the model did not reproduce the pressure drop well when the solid concentration increased further. Because the Wasp model was developed with data from industrial coal slurry operations, it was expected to predict the pressure drop of Cases 1 through 3 reasonable well. The difference between Wasp's results and Ebadian's studies may be due to the potential inaccuracy of estimating slurry viscosity from the various equations. It may also be due to Wasp's dealing with coal and Ebadian et al. using sand. Thus, it is useful to test the Wasp model with actual measured slurry viscosity for high solid concentrations, as well as those with fine solid particles, because many of the Hanford solids are expected to be in the several micron range (DiCenso et al. 1995; Ryan 1995; Whyatt et al. 1996; Herting 1997, 1998). Section 4.2 discusses these points as they pertain to our current study.

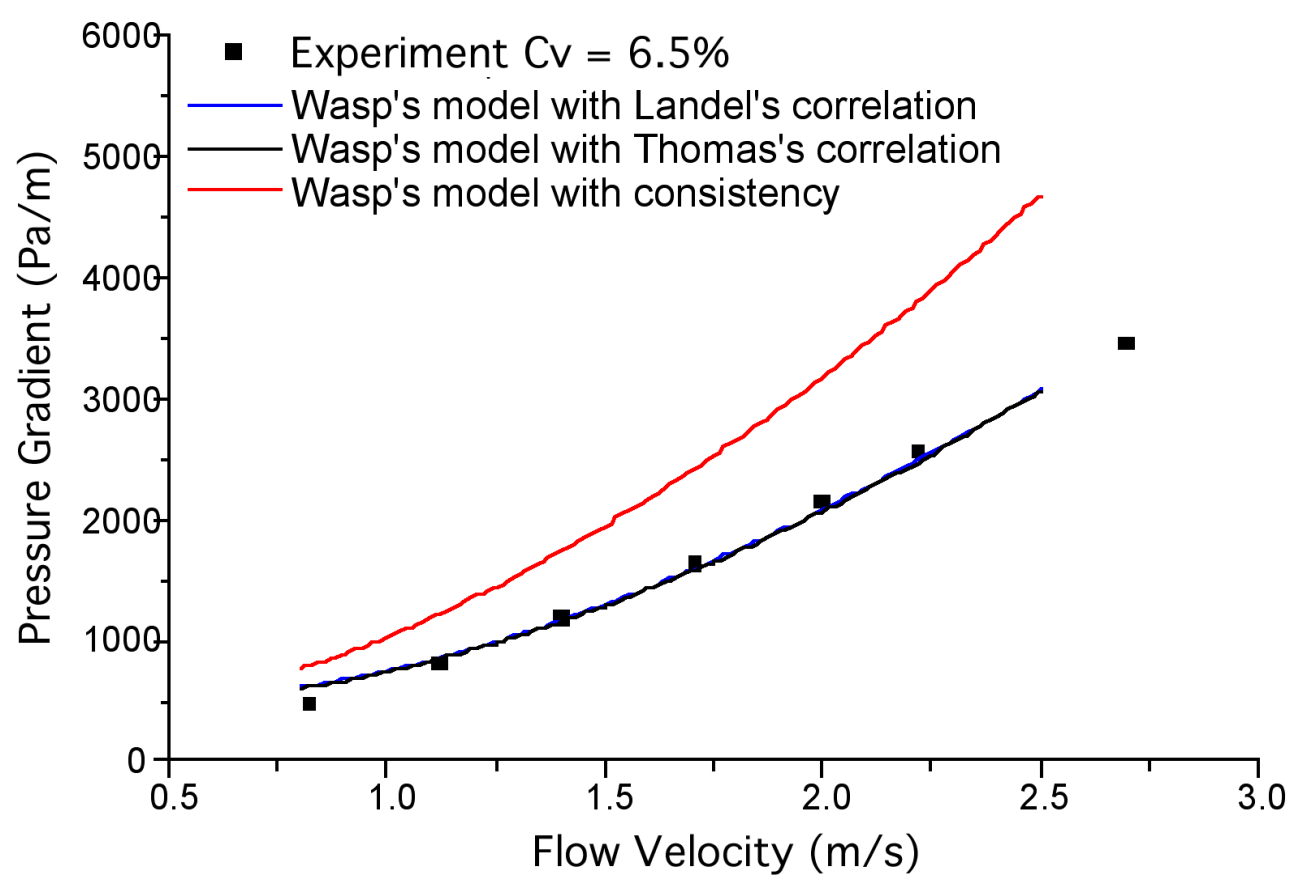

Figure 4.2. Wasp Model Predictions and Measured Pressure Drop for Silica Sand Concentration of 6.5 vol\% of Case 1 (Ebadian et al. 2001) 


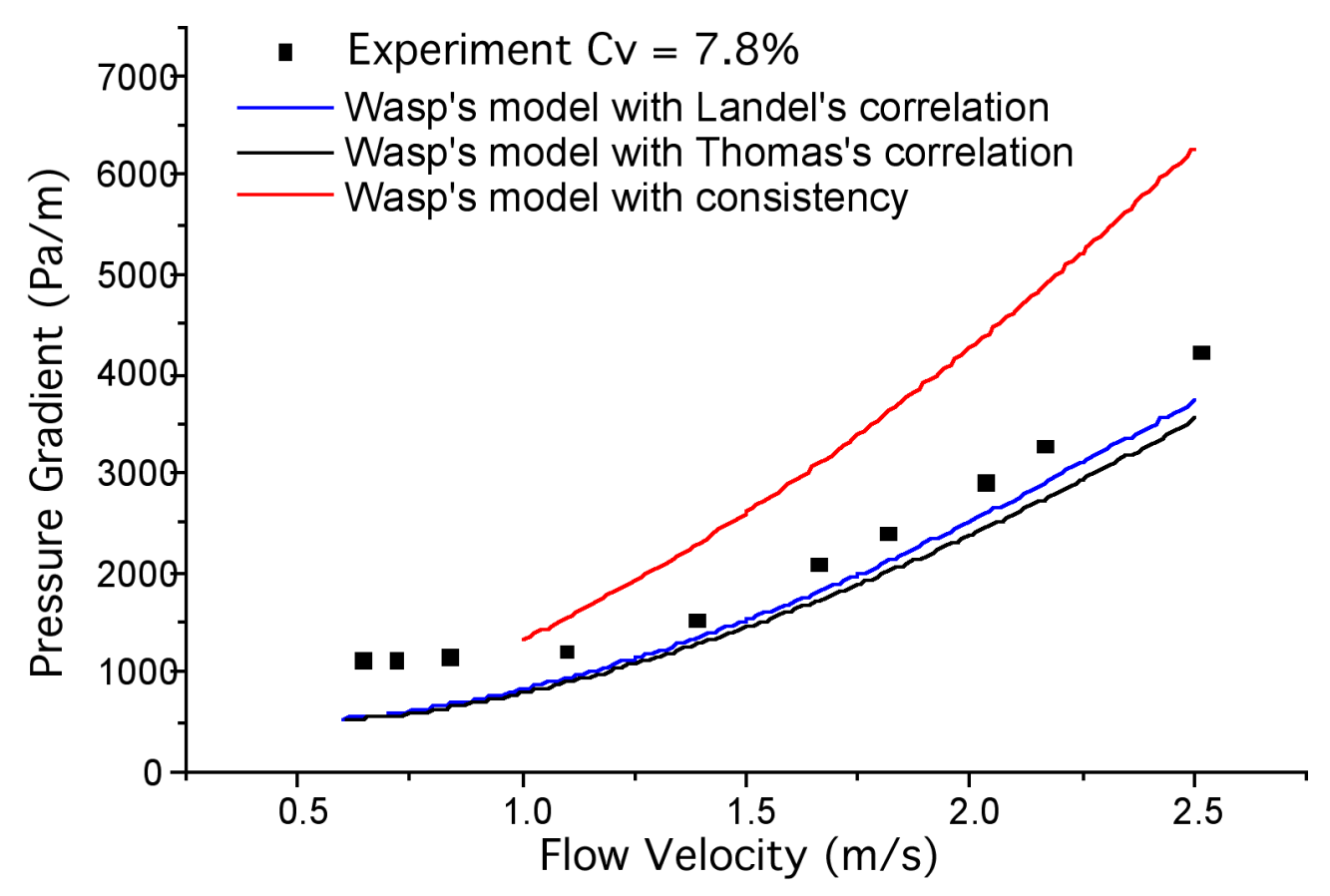

Figure 4.3. Wasp Model Predictions and Measured Pressure Drop for Simulant Solid Concentration of 7.8 vol\% of Case 4 (Ebadian et al. 2001)

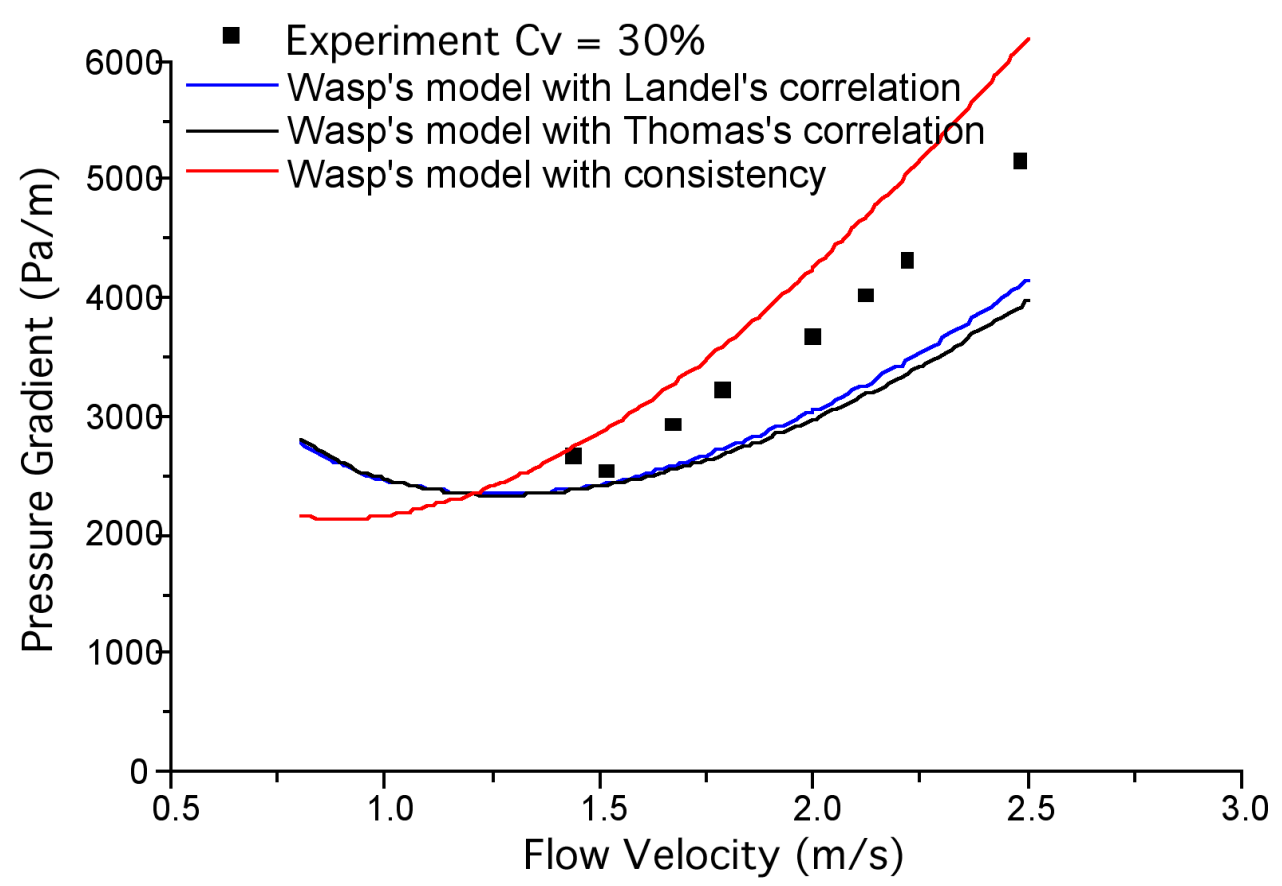

Figure 4.4. Wasp Model Predictions and Measured Pressure Drop for Silica/Zircon Sand Concentration of 30 vol\% of Case 3 (Ebadian et al. 2001) 


\subsection{W-211 Pipeline Loop Tests}

The W-211 project is responsible for providing system capabilities to remove waste from 10 of the Hanford double-shell tanks. They are also responsible for measuring tank waste properties before the waste slurry is introduced into pipeline systems. To support these efforts, Pacific Northwest National Laboratory (PNNL) constructed and operated an Instrument Validation Facility (IVF) test loop to determine whether the selected instruments function as intended to measure slurry characteristics and ensure that the waste can be pumped (Reynolds et al. 1996).

\subsubsection{Test loop and test conditions}

The pressure drop section of the test loop is pertinent to the current investigation. This straight, horizontal pipe section, measuring $3.03 \mathrm{~m}$ between the pressure transducers, was constructed of 3-inch-diameter, schedule-40 stainless steel. The pressure differential was measured with a Rosemount 3051CD transmitter with a remote seal assembly with 0.25 inches of water accuracy.

The IVF is a slurry test loop capable of pumping slurry of varied physical properties at various flow rates. The slurry characteristics of the test cases considered are given in Table 4.2. Actual particle size distribution data are available for Tests 3 through 8 and 10 through 24 . Water is the base fluid in each case. The slurry characteristics represent the average of all test runs (typically seven to ten) at similar conditions.

The yield stress in shear of the slurry mixture was measured outside of the test loop with a Haake rheometer. The slurry viscosity was determined as the derivative of the equation describing the yield stress in shear as a function of the strain rate evaluated at the average strain rate of the flow for each test. For the majority of the available data, these measurements were taken at temperatures that varied significantly from the reported flow conditions. The viscosity for water (Tests 1 and 2) differs from the handbook values. The viscosity was almost $18 \%$ high for Test 1 and 32\% high for Test 2 at the measurement temperature. It was $40 \%$ high for Test 1 and $9 \%$ low for Test 2 at the temperature of the test flow (see water viscosity and slurry viscosity in Table 4.2), revealing the degree of accuracy of the rheology measurements.

Computing the pressure drop for the pipe section from the energy equation using the Moody diagram for the conditions of Tests 1 and 2 (water viscosity taken from the handbook values) gave a pressure drop of approximately 6.10 inches of water. As will be shown in Section 4.2.2, the Wasp model gave identical results. The pressure drops computed with the measured viscosity are approximately 6.37 inches of water for Test 1 and 6.05 inches of water for Test 2 . These results illustrate the sensitivity of the pressure drop calculations to the viscosity of the flow. Comparing these calculated results with the reported pressure drops (5.36 and 2.8 inches of water for Tests 1 and 2, respectively) indicates a potential for errors of up to 54\% in the measured pressure drop from the test loop for water.

The viscosity of the slurry mixture used in this analysis may also contain some error. Typically, the viscosity of a mixture will increase with increasing solid volume fraction and 


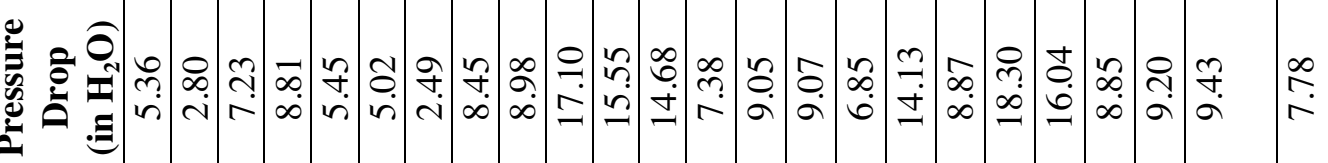

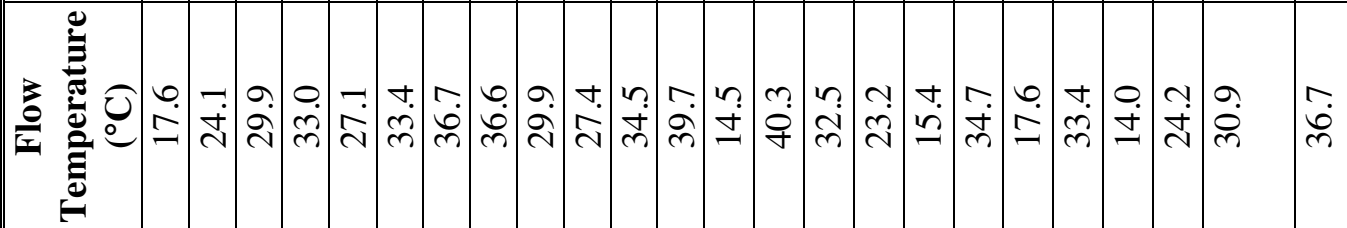

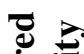

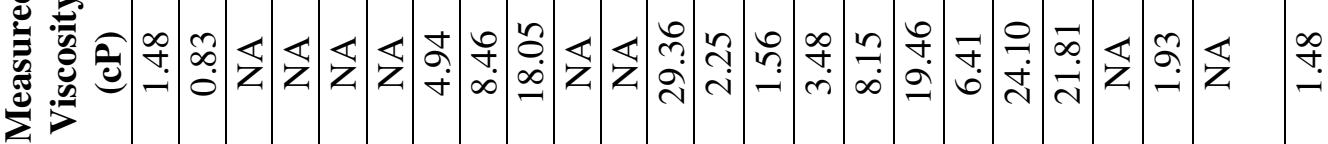

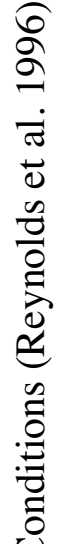

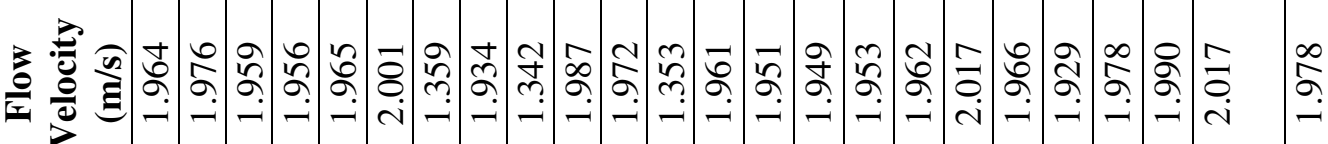

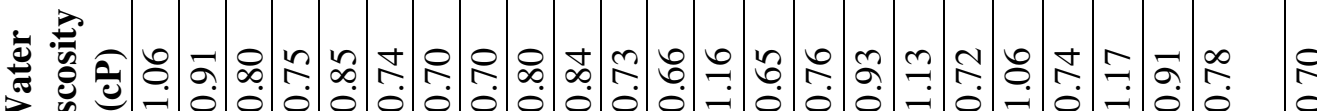

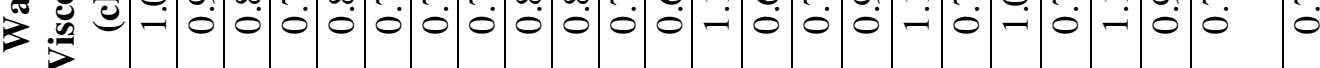

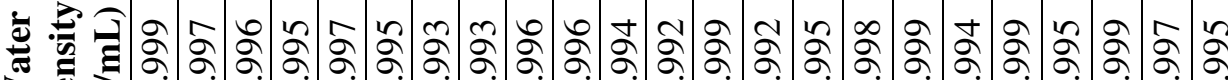

选

苍

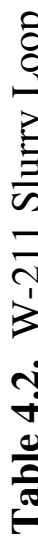

을

㱐

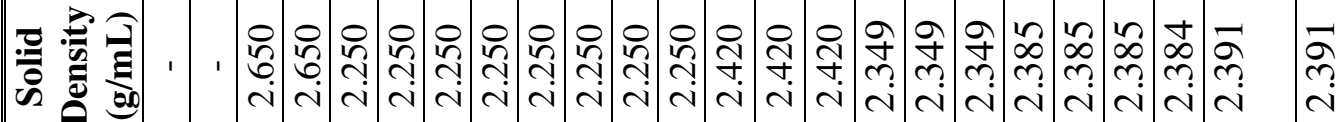

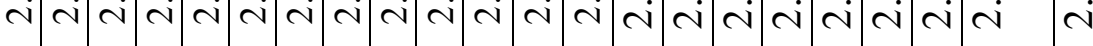
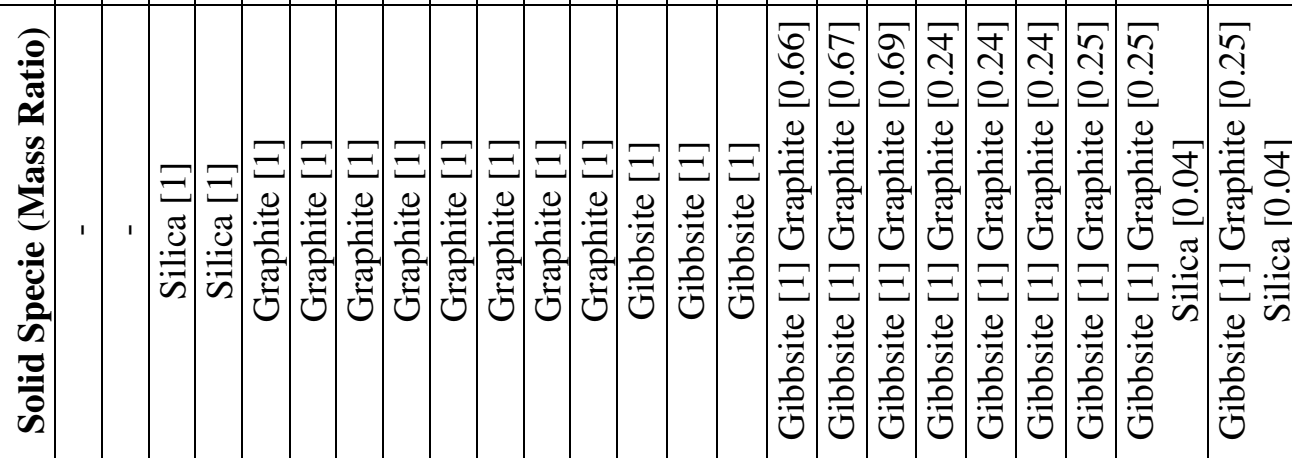

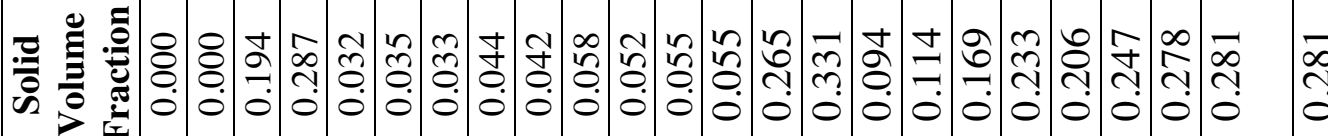

$\stackrel{\infty}{\sim}$

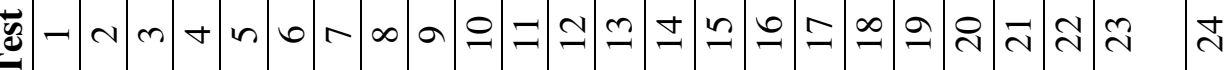


decreasing temperature. With a base fluid of water and insoluble solids, the slurry viscosity is expected to be much more sensitive to the solid volume fraction than to the temperature. Examination of the graphite and gibbsite/graphite slurry viscosities reveals that the slurry viscosity is inconsistent with this expected behavior and that the observable trends within the data are not consistent. The relative viscosity change of graphite slurry with solid volume fraction at a similar temperature is not consistent for similar changes in solid volume fraction. For the gibbsite/graphite slurry mixture, the trend of increasing viscosity with increased solid volume fraction holds for one set of data at similar temperatures, but this trend is reversed for two other similar temperature data sets. Further observations are presented in detail in Section 4.2.2.

Therefore, as we discuss further in Section 4.2.2, when viewing the pressure drop results of the Wasp model compared with those measured, it is necessary to keep in mind the potential for uncertainties in the flow characteristics and pressure drop measurements themselves.

\subsubsection{Wasp model validation to $\mathrm{W}-211$ test loop results}

Results from the Wasp model (presented in Section 3) were compared with the W-211 test loop pressure drop results, and the sensitivity of the results to varied inputs is considered. The pipeline roughness in each case is 0.0018 inch. Model input parameters are taken directly from Table 4.2 unless otherwise noted. The actual ascribed average pressure drop error (see Figure 4.6, for example) represents the 0.25 -inch water accuracy from the pressure transducer together with the range from the associated tests.

The sensitivity of the Wasp model results to particle size distribution was investigated. Particle size ranged from $0.96 \mu \mathrm{m}$ to $16 \mu \mathrm{m}$. The results from using average and actual particle size distributions for those cases (Tests 7 and 8, 12 through 20, and 22) in which both particle size distributions and viscosity data are available are presented in Figure 4.5. No appreciable difference is noted in the model between the results using average solid size and actual particle size distributions. Therefore, further analyses were conducted solely using the average particle size.

Comparisons of the Wasp model and measured pressure drop results for Tests 7 and 8, 12 through 20, and 22 are shown in Figures 4.6 and 4.7. Note in Figure 4.6 that the pressure drop for pure water (Tests 1 and 2) predicted by the Wasp model compares well with the energy equation results discussed in Section 4.2.1. Aside from Test 2 (with water), the largest discrepancies occur in Tests 12,16,17,18, and 19, corresponding roughly to the largest measured pressure drops and slurry viscosities (Table 4.2). As suggested in Section 4.2.1, however, close examination of the measured results reveals inconsistencies that may indicate measurement errors. For all the cases, $99.9 \%$ of the total solids were distributed vertically uniformly in the flow (i.e., carried in the vehicle) (see Section 3.3.1).

As discussed in Section 3, the slurry viscosity is a function of the solid volume fraction. Additionally, the slurry viscosity may be affected by temperature. However, with the insoluble solids used in the W-211 tests, temperature effects should be minimal. A 3-D plot of the measured slurry viscosity for those cases with the mixture of gibbsite and graphite (Tests 16 


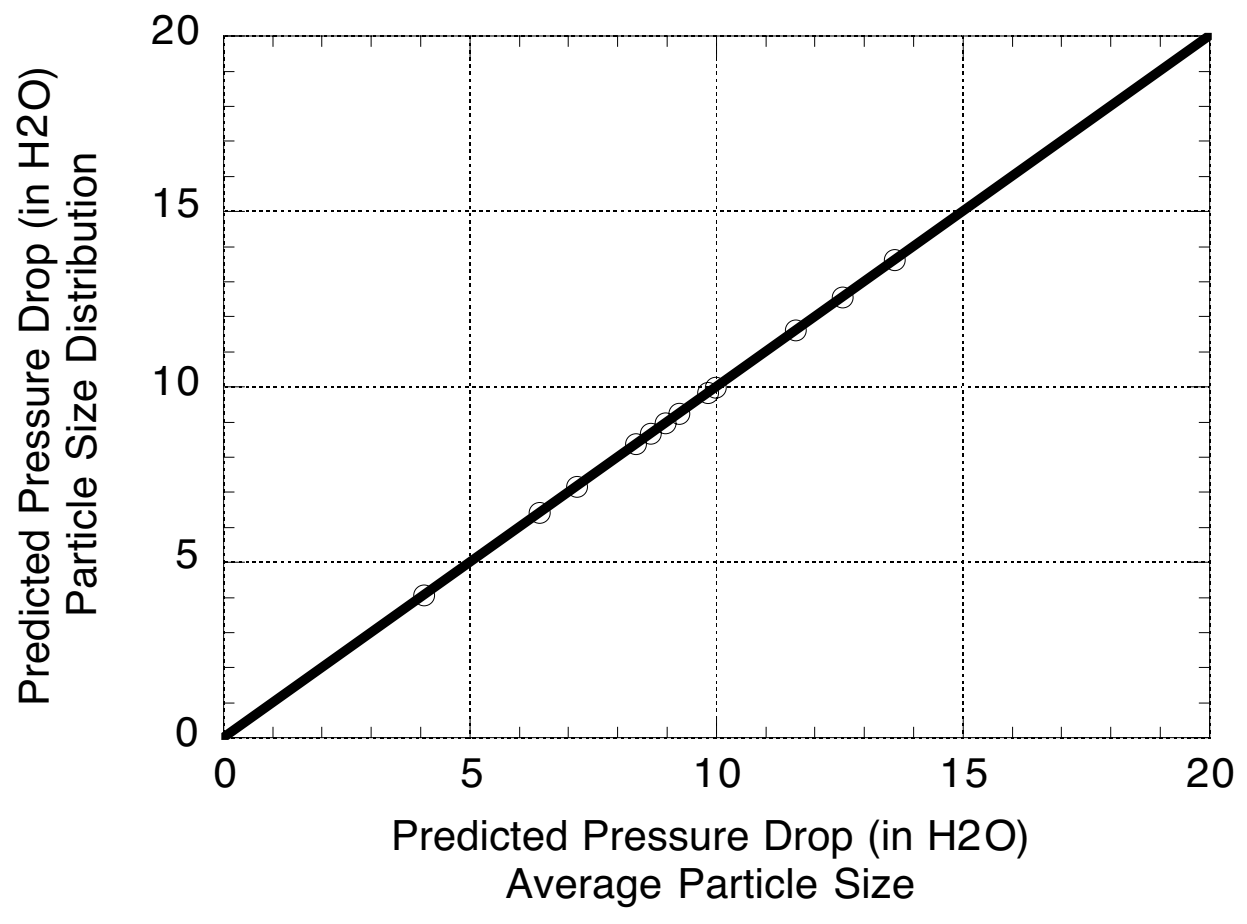

Figure 4.5. Comparison of Wasp Model Results for W-211 Test Loop (actual particle size distributions and average particle sizes)

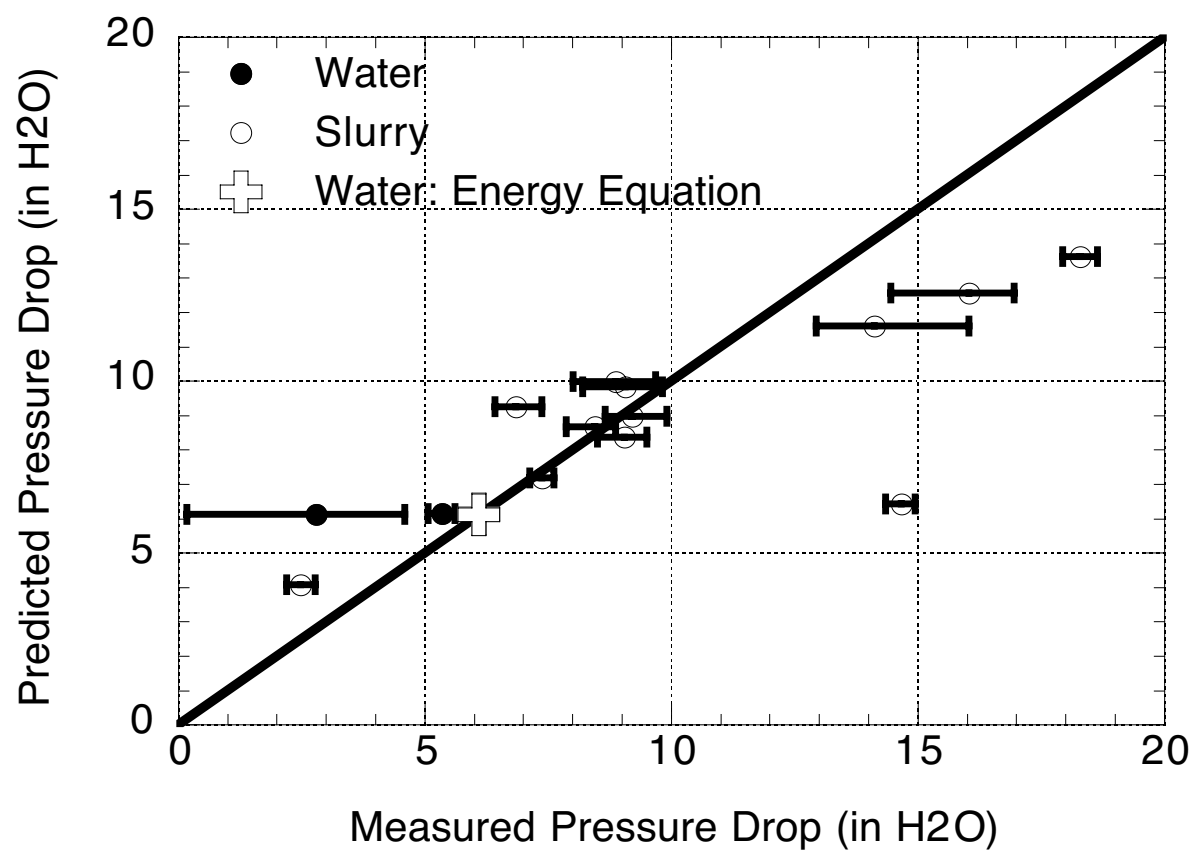

Figure 4.6. Comparison of Measured and Wasp Model Results for W-211 Test Loop (solid symbols are pure water cases; cross symbol is energy equation result from Moody diagram) 


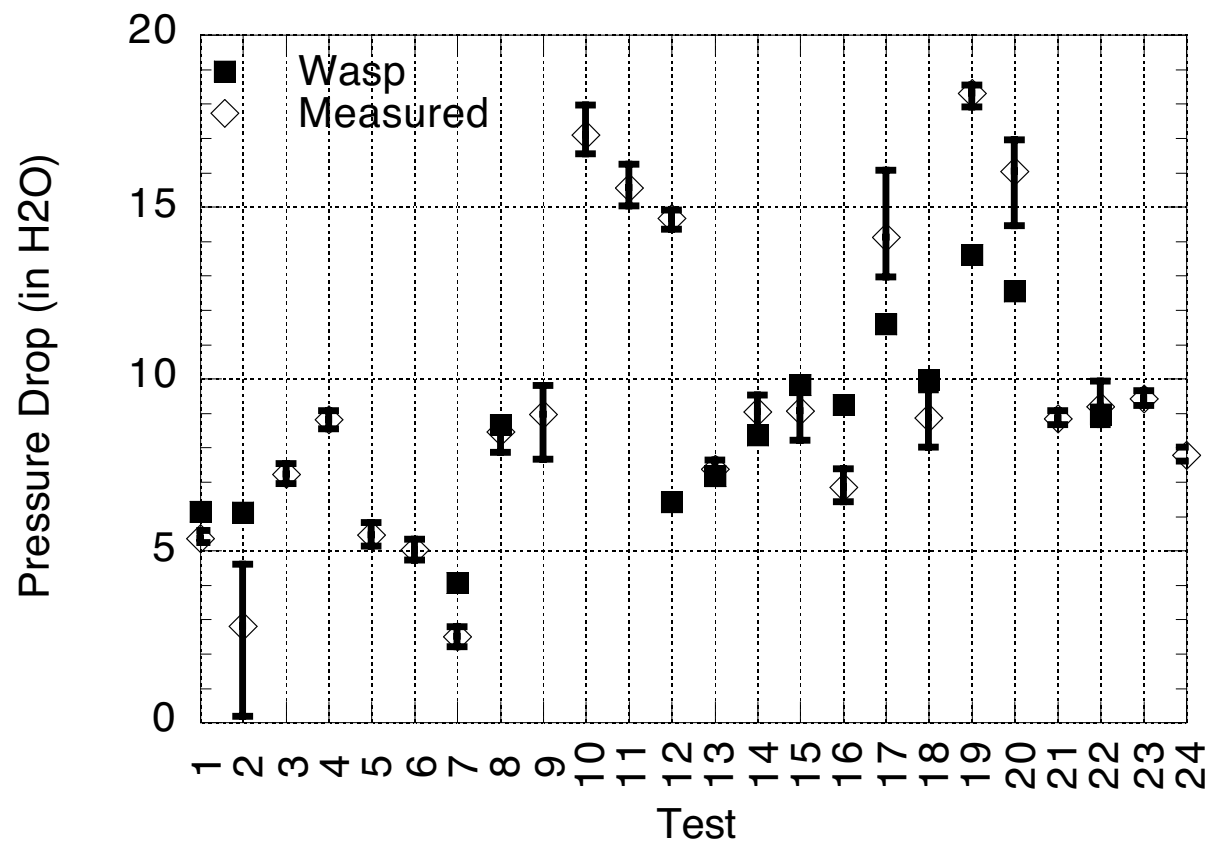

Figure 4.7. Measured and Wasp Model Results for W-211 Test Loop

through 20 and 22) as a function of the solid volume fraction and temperature is shown in Figure 4.8. The data points are numbered in order of increasing solid volume fraction, the test number is listed, and the error between the measured and calculated pressure drop that will be subsequently presented (Figure 4.12) is included. It is clear that there is no correlation between solid volume fraction and the slurry viscosity. Additionally, even if the extreme viscosity differences were attributable to temperature, there is clearly no correlation with temperature and, in fact, contradictory results are achieved (Tests 19 and 20, for example).

The pressure drop depends on the liquid density and viscosity; the solid density, particle size, and volume fraction; the slurry viscosity; the flow velocity; and the characteristics of the flow path (see Section 3). As may be seen in Table 4.2, the only parameters that have significant variation in Tests 16 through 20 and 22 (true for the bulk of the tests as well) are the solid volume fraction and slurry viscosity. The measured pressure drop as a function of the solid volume fraction and slurry viscosity is shown in Figure 4.9. Qualitatively, it appears that the pressure drop increases with increasing solid volume fraction and slurry viscosity, as expected. However, Figure 4.9 provides another view of the relation between slurry viscosity and solid volume fraction, and clearly, as in Figure 4.8, there are conflicting results. Further, when Tests 1 and 2, 7 and 8,12 through 20, and 22 are all plotted, the pressure drop relation is not as clear (Figure 4.10). These observations, together with the results for the pure water case, suggest that errors beyond those shown (e.g., Figure 4.7) may be present in the measured pressure drops. 


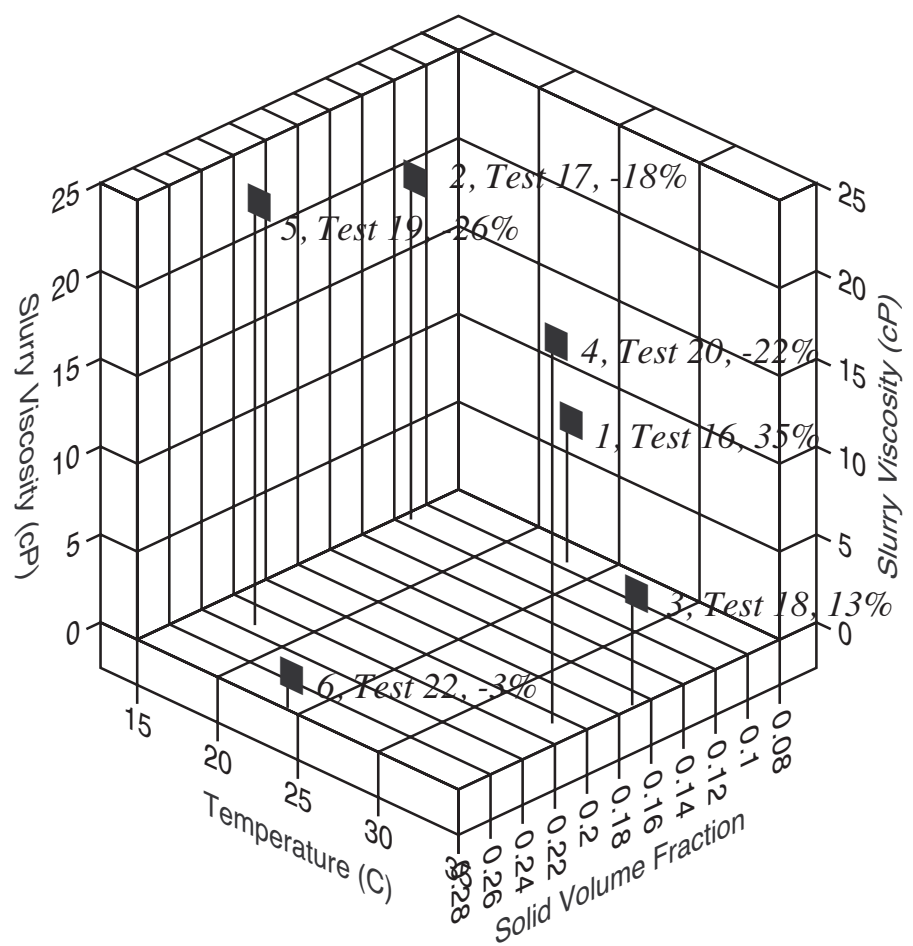

Figure 4.8. Measured Slurry Viscosity as a Function of the Solid Volume Fraction and Temperature (count in order of ascending solid volume fraction, error between measured and calculated results [see Figure 4.12])

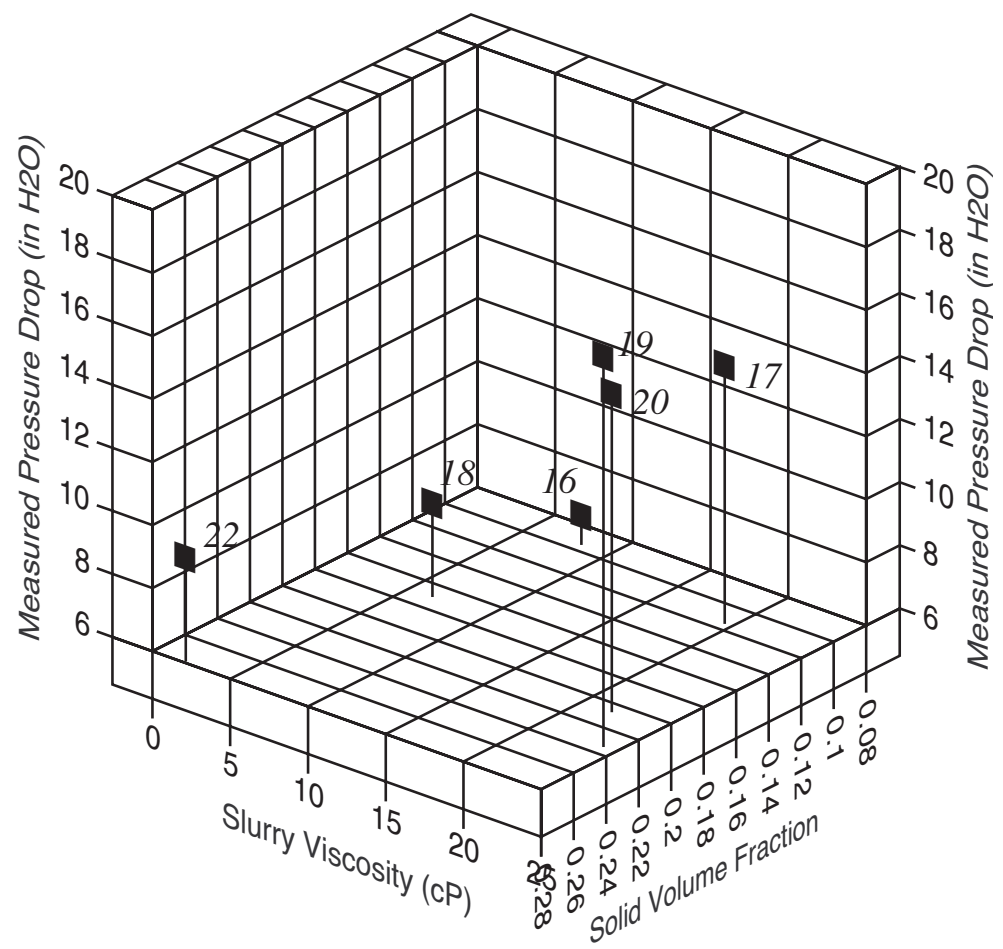

Figure 4.9. Measured Pressure Drop as a Function of the Solid Volume Fraction and Slurry Viscosity 
Traditionally, when the viscosity of a slurry is unknown, the Einstein-type relation, which relates the viscosity of a slurry to its solid volume fraction and the base liquid viscosity, is used. The Wasp model results with the Thomas relation (Equation 3.6) of the modified Einstein viscosity (Wasp et al. 1977) are shown in Figure 4.11.

The Wasp model errors against the measured pressure drop with both the measured (Figure 4.7) and calculated (Figure 4.11) slurry viscosity are compared in Figure 4.12. The accuracy of the Wasp model results is improved with knowledge of the slurry viscosity. To illustrate this, the distribution of the error between the Wasp model with the measured viscosity and the measured pressure drop are shown in Figure 4.13, and the distribution of the error between the Wasp model with the Thomas relation and the measured pressure drop are shown in Figure 4.14. In each case, the Wasp model results tended to under-predict when compared with the measured pressure drop, indicating that some safety factor over the Wasp model prediction is advisable. The median error for those tests with a measured viscosity is $2.8 \%$ low and $10.0 \%$ low for those same tests using the Thomas relation for the viscosity. The standard deviations of the error with the measured viscosity and the Thomas relation are almost identical at $30.4 \%$ and $30.1 \%$ respectively.

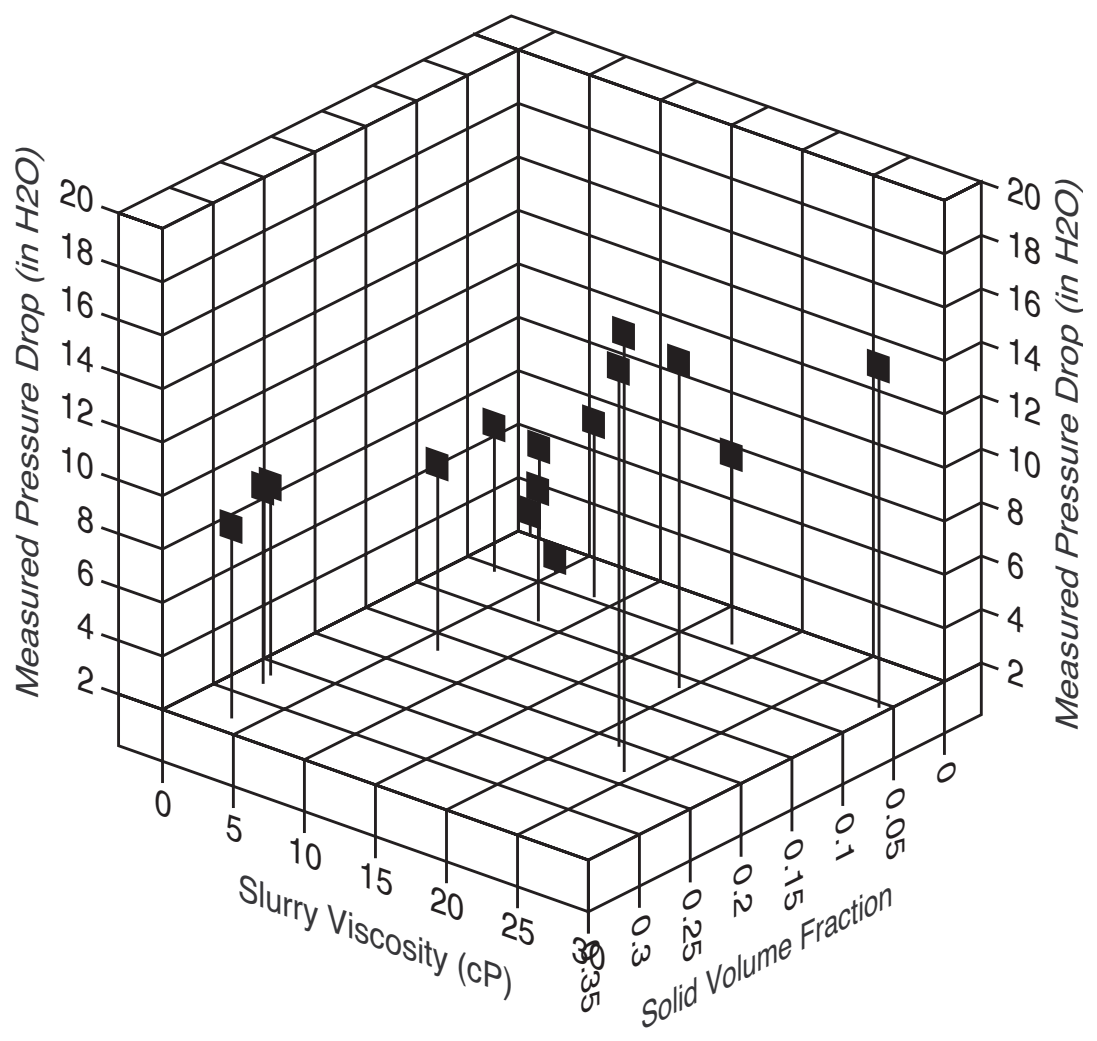

Figure 4.10. Measured Pressure Drop as a Function of the Solid Volume Fraction and Slurry Viscosity: Tests 1, 2, 7, 8, 12 through 20 , and 22 


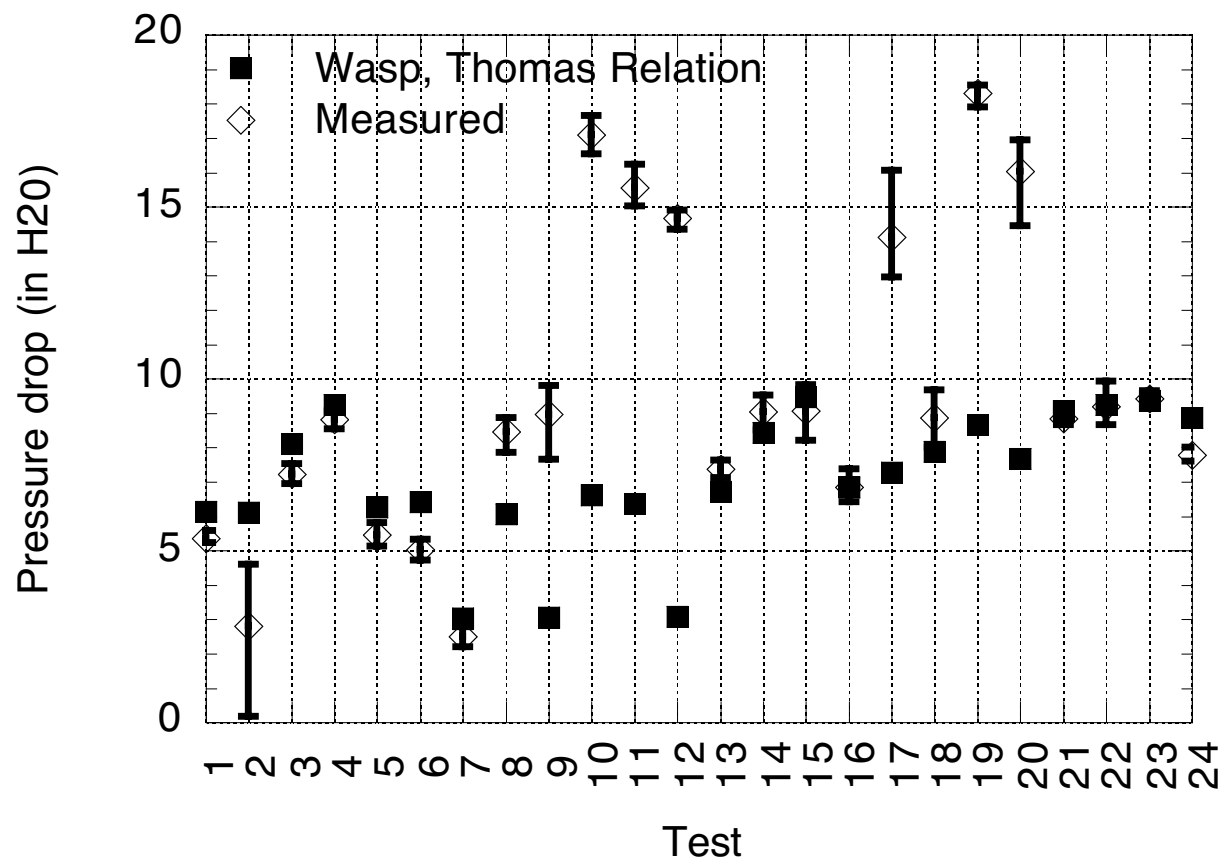

Figure 4.11. Measured and Wasp Model Results for W-211 Test Loop (Thomas relation)

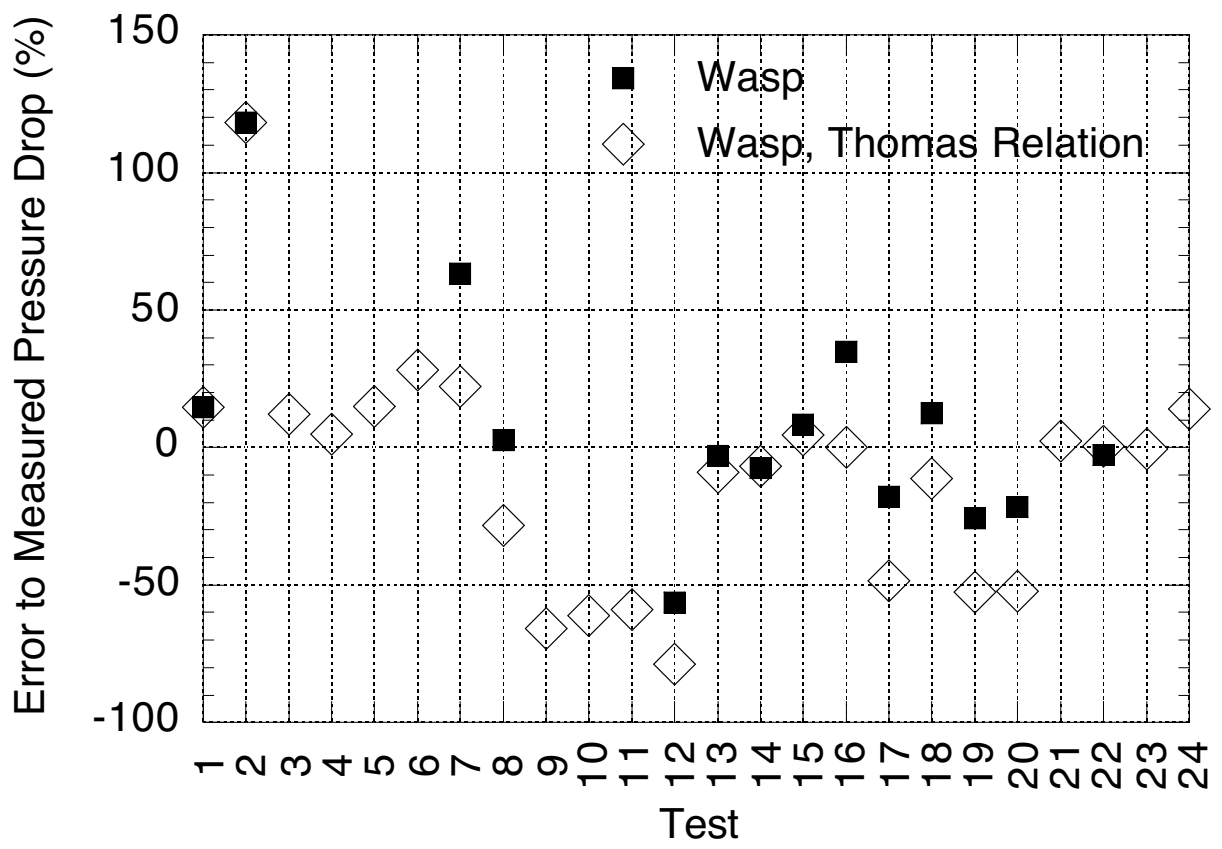

Figure 4.12. Error Between the Measured and Wasp Model Results 


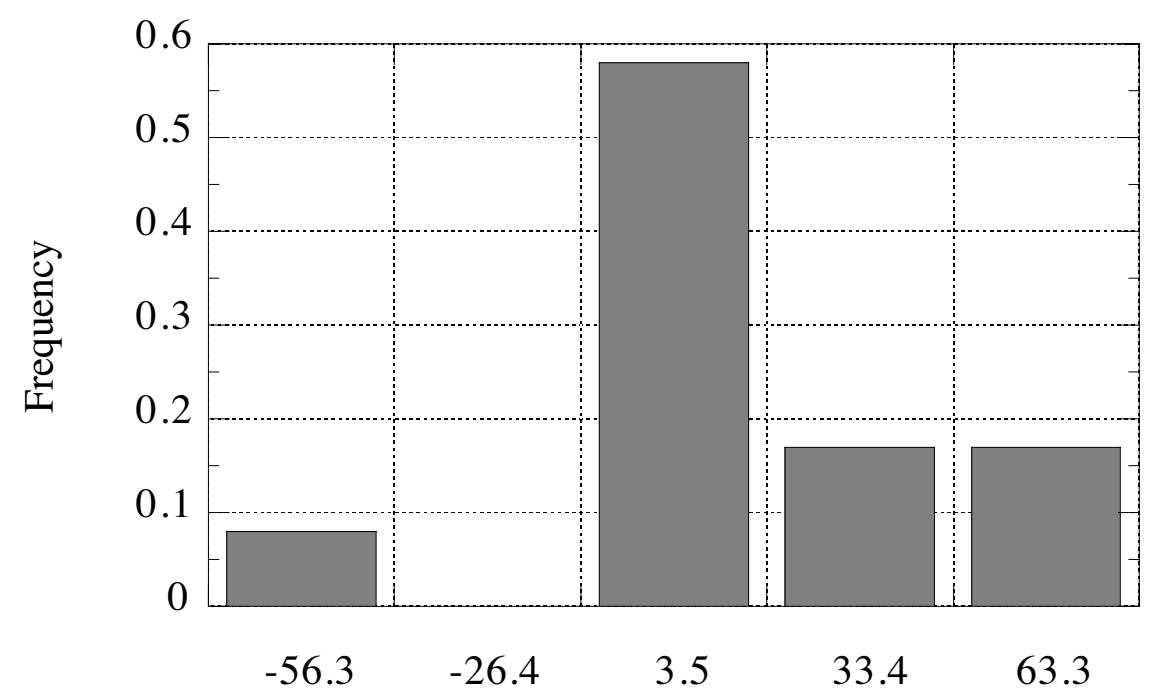

Wasp Model Error to Measured Pressure Drop (\%)

Figure 4.13. Wasp Model Error with Measured Viscosity Compared with Measured Pressure Drop

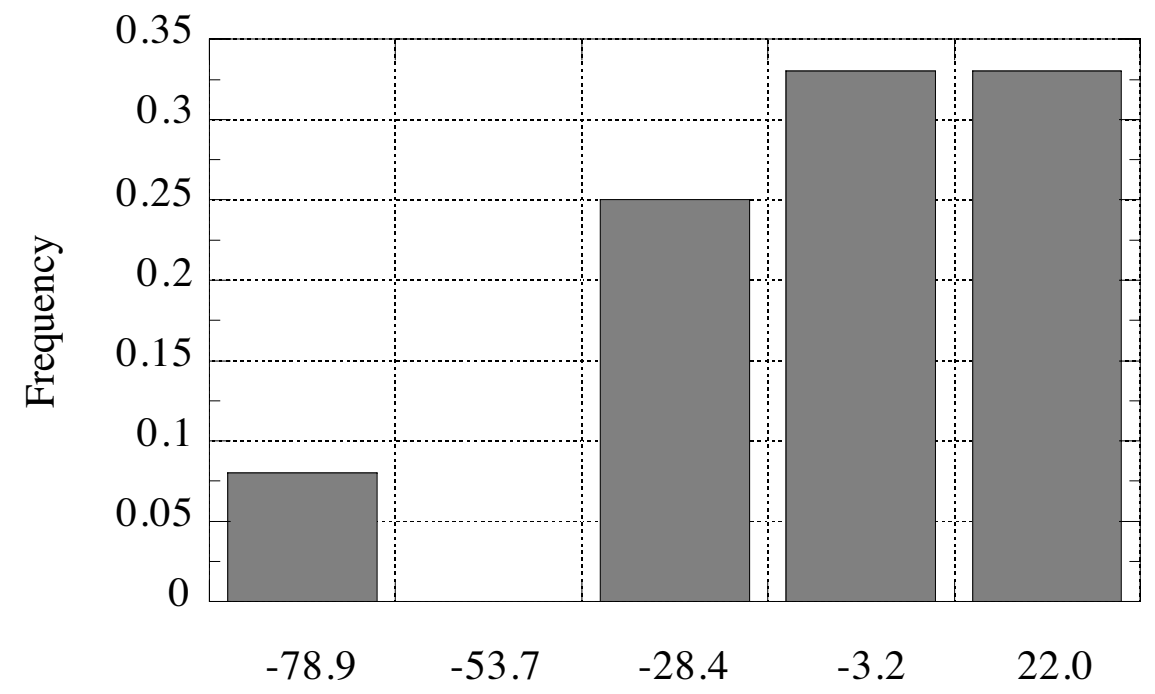

Wasp Model Error to Measured Pressure Drop (\%)

Figure 4.14. Wasp Model Error with Thomas Formulation Compared with Measured Pressure Drop 
These past and current Wasp model validation tests indicate that the Wasp model appears to be applicable to the ranges of fine particles tested, even though the model was developed with much coarser coal particles. This may be due to the fact that most of the fine particles of the W211 tests were predicted to be in the "vehicle" portion of the slurry, which the Wasp model specifically addresses. As is presented in Section 5.4, the majority of the solids for the SY-101 transfer were determined to be in the "vehicle." These studies also indicate that the measured slurry viscosity (or case-specific formulas obtained from the measured viscosity data) should be used whenever data are available. 


\subsection{SY-101 Waste Cross-Site Transfer}

The primary objective of this study was to evaluate the feasibility of transferring waste currently stored in Tank SY-101 in the 200 West Area to a storage tank in the 200 East Area through a 6.2-mile, 3-inch-diameter stainless steel pipeline intended for transfer of the supernatant liquid. With pipeline pressure restrictions, we determined 1) whether the current waste can be transferred without additional dilution with water, 2) if it is transferable, under what SY-101 waste conditions and what slurry velocity the waste can be transferred, 3) if it is not transferable, how much dilution is needed to make it transferable, and 4) what slurry velocity could be used to transfer diluted SY-101 waste. We used the Wasp slurry transport model, which was described in Section 3, and its validation test results, presented in Section 4, to determine the critical velocity and expected pressure drop for the given waste and transport conditions. In addition to the Wasp model, we also used the Oroskar and Turain (1980) and Zandi and Govatas (1967) models for critical velocity calculations to confirm the Wasp model predictions of critical velocity calculations.

In this section we describe the cross-site transfer pipeline, discuss recent liquid transfers from Tank SY-102 in the 200 West Area to the AP Tank Farm in the 200 East Area through the crosssite transfer pipeline (expected to be used for SY-101 cross-site transfer), present a scoping evaluation of the cross-site transfer, and evaluate the actual SY-101 cross-site transfer.

\subsection{Cross-Site Transfer Line}

A replacement cross-site transfer system to transport liquid waste from the 200 West to the 200 East Area was installed in the late 1990s under Project W-058. This supernate transfer line is a pipe-in-pipe system connecting the 241-SY Tank Farm in the 200 West Area with the 244-A Lift Station (Brantley 1994). For the purposes of this analysis, this pipeline was evaluated from the valve pit at Tank SY-101 to Tank 241-AP-104 (AP-104). A schematic of the modeled pipeline is presented in Figure 5.1, and equivalent component separation lengths and elevations are given in Table 5.1 (Grant 1997; Domnoske-Rauch 1998; Pacquet 1998; Julyk et al. 2000). ${ }^{\text {(a) }}$ All pipeline fittings are expressed in terms of equivalent length. The primary piping is 304L stainless steel. A surface roughness length of 0.0018 inch $(50 \mu \mathrm{m})$ was used in this analysis.

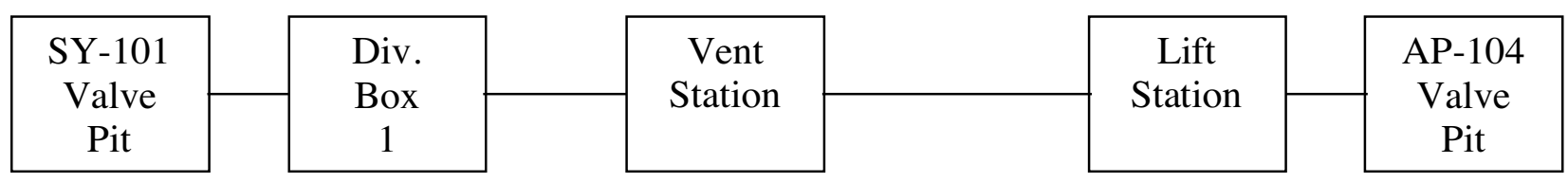

Figure 5.1. Schematic of Cross-Site Transfer Line

(a) Internal Memo, MJ Sutey to SD Reisnweber, September 7, 1995. Subject: ECTS Percent Solids Capabilities. 
Table 5.1. Cross-Site Transfer Line Parameters

\begin{tabular}{||l|c|c||}
\hline \multicolumn{1}{|c|}{ Component } & $\begin{array}{c}\text { Equivalent Length (m) } \\
\text { (from previous component) }\end{array}$ & Elevation (m) \\
\hline SY-101 Valve Pit & - & 0 \\
\hline Diversion Box 1 & 1145 & 3.1 \\
\hline Vent Station & 3520 & 25.6 \\
\hline Lift Station & 5706 & 2.8 \\
\hline AP-104 Valve Pit & 1165 & 1.6 \\
\hline
\end{tabular}

The piping (including jumpers) was designed to withstand a minimum of $400 \mathrm{psi}$, except for some segments in the 200 East Area with pressure ratings between 200 to $400 \mathrm{psi}$. However, the supernatant cross-site transfer line has a software restriction to stop the SY-101 transfer pump when the pressure at the vent station reaches 180 psi. Therefore, any downstream pressure rating above $180 \mathrm{psi}$ is automatically satisfied. Thus, we did not explicitly include any pressure rating above 180 psi in the 200 East Area. In addition, the current SY-101 transfer pump can generate up to 220 psi for the potential SY-101 slurry transfer. Therefore, required conditions for the pipeline and transfer pump are to satisfy

- a pressure drop of 400 psi or less over the entire pipeline

- a pressure drop of 180 psi or less from the vent station to the AP-104 valve pit

- a required transfer pump pressure head of 220 psi or less for the slurry transfer.

The SY-101 transfer pump is the limiting restriction, as is discussed in subsection 5.4.3.2.

\subsection{Liquid Waste Transfer Through the Cross-Site Transfer Line}

SY-102 serves as a receiver tank for process water and saltwell-pumped liquid from the 200 West Area tanks. SY-102 also received diluted SY-101 slurry during the mitigation campaigns of late 1999 and early 2000. Wastes from SY-102 are subsequently pumped cross-site through the W-058 supernate transfer line. Pressure drop data taken during these cross-site transfers from SY-102 were compared with results determined using the Wasp model described in Section 3.

Three cross-site transfers from SY-102 were considered. They include the transfers of January 12 through 19, 2000, February 10 through 18, 2000, and March 22 through 28, 2000. Each transfer consisted of a mixture of diluted SY-101 slurry and saltwell liquid. Pressure drop measurements are available from diversion box 1 to the vent station (see Figure 5.1). To evaluate the pressure drop of this section of the pipeline with the Wasp model, the characteristics of the transferred waste must be known.

With no in situ measurements available, waste properties were estimated based on waste compatibility criteria and SY-101 waste parameters. Prior to the introduction of diluted SY-101 waste into SY-102 on December 18 and 19, 1999, the waste level in SY-102 was 291 inches. 
The density of this material was estimated as $1.25 \mathrm{~g} / \mathrm{mL}$. (a) The waste compatibility criteria stipulate that the liquid density in SY-102 is to be kept at or below $1.35 \mathrm{~g} / \mathrm{mL}$ (Fowler 1999). The 89,000 gallons of diluted SY-101 waste was introduced into the tank at a density of $1.32 \mathrm{~g} / \mathrm{mL}$. Before the cross-site transfer began on January 12, 2000, an additional 32 inches of saltwell liquid had been added. Assuming that this material was under the same restrictions as that previously introduced into the tank, its density can also be considered to be $1.25 \mathrm{~g} / \mathrm{mL}$. Thus the liquid in SY-102 on January 12, 2000 would have had a density of approximately $1.26 \mathrm{~g} / \mathrm{mL}$. The effect of dissolution of the SY-101 solids into the in-line dilution water, solids settling, and preclusion of solids from the cross-site transfer line by the flex and float transfer pump in SY-102 are neglected in this final density value, given the uncertainty for the bulk of the material in the tank. The viscosity of the liquid is estimated to be about $4.4 \mathrm{cP}$ based on SY-101 liquid viscosity data (see subsection 5.4.2.1). This is similar to the viscosity of other Hanford tank liquids at similar densities. Similar calculations were conducted for each transfer. The waste parameters and the measured and calculated pressure drops are presented in Table 5.2. The measured values are averaged over the transfer during the maximum average flow rate, and the pressure head due to the elevation change has been removed from the measured pressure drops for model comparison purposes.

At first glance, it appears that the Wasp model overpredicts the pressure drop by approximately $60 \%$ (recall from Section 3 that the Wasp model with no solids is simply an energy balance on the flow). However, evaluation of the flow for pure water $(1 \mathrm{~g} / \mathrm{mL}, 1 \mathrm{cP})$ results in a pressure drop of approximately $61 \mathrm{psi}$. Calculation of the pressure drop from the energy equation via the Moody diagram for water and the estimated waste flow yields 61 and 98 psi, respectively, matching the Wasp model predictions. These results imply that there may be errors in the measured flow rate and/or pressure drop, and neither support nor contradict the validity of the Wasp model.

Table 5.2. Cross-Site Transfer Data

\begin{tabular}{||c|c|c|c|c|c|c||}
\hline \hline Date & $\begin{array}{c}\text { Measured } \\
\text { Pressure } \\
\text { Drop (psi) }\end{array}$ & $\begin{array}{c}\text { Measured } \\
\text { Flow Rate } \\
\text { (gpm) }\end{array}$ & $\begin{array}{c}\text { Flow } \\
\text { Velocity } \\
\text { (ft/sec) }\end{array}$ & $\begin{array}{c}\text { Density } \\
(\mathbf{g} / \mathbf{m L})\end{array}$ & $\begin{array}{c}\text { Wasp } \\
\text { Viscosity } \\
\text { (cP) }\end{array}$ & $\begin{array}{c}\text { Pressure } \\
\text { Drop (psi) }\end{array}$ \\
\hline $1 / 12-1 / 19$ & 60 & 66 & 3 & 1.26 & 4.4 & 96 \\
\hline $2 / 10-2 / 18$ & 63 & 66 & 3 & 1.29 & 4.7 & 99 \\
\hline $3 / 22-3 / 28$ & 63 & 66 & 3 & 1.30 & 4.8 & 100 \\
\hline
\end{tabular}

\subsection{Scoping Evaluation of Acceptable Waste Conditions for Cross- Site Transfer}

We conducted the scoping analysis to examine the potential range of conditions to be considered for the SY-101 waste cross-site transfer assessment. Cross-site waste transfer must satisfy the following restrictions:

(a) Numatec Hanford Corporation Internal Memo 82100-99-015, JC Person to NW Kirch, April 22, 1999. Subject: Dilution Studies of Tank 241-SY-101 Waste. Preliminary Results. 
Restriction 1: The slurry velocity must be greater than the critical velocity to suspend all solids during the transfer (see Equation 3.1).

Restriction 2: The slurry flow must be turbulent (i.e., the slurry Reynolds Number must be above approximately 2300 (see Equation 3.2).

Restriction 3: The pipeline pressure must not exceed 400 psi in any part of the pipeline (i.e., the waste must be transferred from SY-101 to the receiving tank in 200 East Area with less than $400 \mathrm{psi}$ ), as stated in Section 5.1.

Restriction 4: The pipeline pressure at the vent station (see Figure 5.1) must be less than 180 psi (i.e., the waste must be transferable from the vent station to a receiving tank (assumed to be in the AP Tank Farm in 200 East Area with less than 180 psi), as stated in Section 5.1.

Restriction 5: The required transfer pump head must not exceed $220 \mathrm{psi}$, as stated in Section 5.1.

Restrictions 1 and 2 can be met with a sufficiently high velocity. Restrictions 3 and 4 are pipeline restrictions and will be met with a velocity low enough not to exceed the pressure drop limitations of the pipeline system. Restriction 5 is imposed by the transfer pump already installed in SY-101 and will be met with a low velocity. Thus, the last three restrictions impose requirements that conflict with the first two. Also note that restriction 5 is more limiting than 3 and 4, as discussed in Section 5.4.3. Of course, these pipeline and transfer pump restrictions could be alleviated by strengthening (or upgrading the pressure certification of) the supernatant cross-site pipeline system and using a more powerful transfer pump, or by using the slurry crosssite pipeline with a booster pump.

We conducted a scoping (preliminary) evaluation to determine what waste conditions satisfy these five restrictions. The pipeline velocity of $1.83 \mathrm{~m} / \mathrm{s}(6 \mathrm{ft} / \mathrm{s})$ (corresponding to $132 \mathrm{gpm}$ in a 3 -in. pipeline) has generally been assumed to be the acceptable slurry velocity. However, when water is transferred through the cross-site transfer line at this velocity, the pressure drop between the vent station to the AP Tank Farm will be 400 psi, even accounting for the 24-m elevation drop (see Table 5.1). Moreover, the total pressure requirement to transfer water through the entire cross-site pipeline at this velocity is $735 \mathrm{psi}$ (accounting for a 1.5-m elevation gain to the AP Tank Farm), significantly exceeding the 400-psi and 220-psi limitations. Therefore, restrictions 3, 4, and 5 will not be satisfied at this velocity. Water alone, much less SY-101 waste at higher density and viscosity, cannot be transferred at $6 \mathrm{ft} / \mathrm{sec}$, as indicated in Table 5.3. Restrictions 1 and 2 are not applicable to the liquid-alone transfer. To satisfy both Restrictions 3 and 4 for water, the pipe flow velocity should not exceed $1.25 \mathrm{~m} / \mathrm{s}(4.1 \mathrm{ft} / \mathrm{s})$ (see Table 5.3$)$. Restriction 5 is still exceeded at this velocity, however.

If SY-101 liquid without solids is to be transferred, the $1.25 \mathrm{~m} / \mathrm{s}(4.1 \mathrm{ft} / \mathrm{sec})$ velocity requires a 288-psi pressure at the vent station, and total pressure drop would be 564 psi, exceeding all three pressure drop limitations. For SY-101 liquid, the pipe velocity should be $1.0 \mathrm{~m} / \mathrm{s}$ $(3.3 \mathrm{ft} / \mathrm{sec})$ to satisfy the $180 \mathrm{psi}$ restriction at the vent station and the $400 \mathrm{psi}$ overall pressure drop restriction (restrictions 3 and 4). To satisfy restriction 5 with SY-101 liquid, the pipe flow velocity should not exceed $0.74 \mathrm{~m} / \mathrm{s}(2.4 \mathrm{ft} / \mathrm{sec})$. 
Table 5.3. Ability to Transfer Water and SY-101 Liquid Waste to the AP Tank Farm Through Cross-Site Pipeline

\begin{tabular}{|l|c|c|c|c||}
\hline $\begin{array}{c}\text { Substance to be } \\
\text { Transferred }\end{array}$ & $\begin{array}{c}\text { Transfer } \\
\text { Velocity } \\
(\mathbf{m} / \mathbf{s})\end{array}$ & $\begin{array}{c}\text { Total Required } \\
\text { Pressure } \\
\text { (psi) }\end{array}$ & $\begin{array}{c}\text { Required } \\
\text { Pressure at } \\
\text { Vent Station } \\
\text { (psi) }\end{array}$ & $\begin{array}{c}\text { Cross-Site } \\
\text { Pipeline } \\
\text { Transferability }\end{array}$ \\
\hline Water & 1.83 & 735 & 400 & No \\
\hline Water & 1.25 & 360 & 179 & $\begin{array}{c}\text { Yes, except } \\
\text { restriction 5 }\end{array}$ \\
\hline SY-101 Liquid & 1.25 & 564 & 288 & No \\
\hline SY-101 Liquid & 1.0 & 377 & 177 & $\begin{array}{c}\text { Yes, except } \\
\text { restriction 5 }\end{array}$ \\
\hline SY-101 Liquid & 0.74 & 220 & 83 & Yes \\
\hline
\end{tabular}

When the slurry contains solids, we must consider restrictions 1 and 2 in addition to 3, 4, and 5. To obtain some insight, we conducted a scoping analysis using two (coarse and fine) possible distributions of SY-101 solid sizes (see Tables 5.8 and 5.9 in subsection 5.4.2.2). These size distributions are presented in detail in Section 5.4.2.

Given the results presented in Table 5.3, high concentrations of the SY-101 nonconvective waste (sludge) for either set of solid size distributions will not satisfy restrictions 1 through 5 . Thus we evaluated various waste conditions that do satisfy all five restrictions. Four examples are shown in Table 5.4. Case 1 uses a coarse particle size distribution and assumes a solids concentration of $17 \mathrm{vol} \%$ (solids concentration of the SY-101 sludge; see subsection 5.4.2.3), while Case 2 assumes the solids concentration to be 8.5 vol\% (half of Case 1). Cases 3 and 4 correspond to Cases 1 and 2, respectively, but use a fine solid particle size distribution. The critical velocity (Equation 3.1) and acceptable slurry velocity for these four cases are $0.42-0.68 \mathrm{~m} / \mathrm{s}(1.4-2.2 \mathrm{ft} / \mathrm{sec})$ and $0.72-0.82 \mathrm{~m} / \mathrm{s}(2.4-2.7 \mathrm{ft} / \mathrm{sec})$, respectively (see Table 5.4).

Table 5.4. Some Examples of Acceptable Waste and Transport Conditions

\begin{tabular}{|l|c|c|c|c|c|}
\hline \multicolumn{1}{|c|}{ Case } & $\begin{array}{c}\text { Assigned Solid } \\
\text { Concentrations } \\
\text { (vol\%) }\end{array}$ & $\begin{array}{c}\text { Critical } \\
\text { Velocity } \\
\text { (m/s) }\end{array}$ & $\begin{array}{c}\text { Acceptable } \\
\text { Velocity } \\
\text { (m/s) }\end{array}$ & $\begin{array}{c}\text { Acceptable } \\
\text { Slurry } \\
\text { Viscosity } \\
\text { (cP) }\end{array}$ & $\begin{array}{c}\text { Pipe Flow } \\
\text { Reynolds } \\
\text { Number }\end{array}$ \\
\hline $\begin{array}{l}\text { Case 1 } \\
\text { (coarse } \\
\text { solids) }\end{array}$ & 17 & 0.68 & 0.82 & 12 & 7,860 \\
\hline $\begin{array}{l}\text { Case 2 } \\
\text { (coarse } \\
\text { solids) }\end{array}$ & 8.5 & 0.60 & 0.72 & 31 & 2,600 \\
\hline $\begin{array}{l}\text { Case 3 } \\
\text { (fine solids) }\end{array}$ & 17 & 0.45 & 0.72 & 26 & 3,000 \\
\hline $\begin{array}{l}\text { Case 4 } \\
\text { (fine solids) }\end{array}$ & 8.5 & 0.42 & 0.72 & 30 & 2,630 \\
\hline
\end{tabular}


After reviewing the potential range of slurry velocities in Tables 5.3 and 5.4, which vary from 0.42 to $1.25 \mathrm{~m} / \mathrm{s}(1.4$ to $4.1 \mathrm{ft} / \mathrm{sec})$, we selected three, $0.46,0.76$, and $1.22 \mathrm{~m} / \mathrm{s}(1.5,2.5$, and $4 \mathrm{ft} / \mathrm{sec}$ ) for the SY-101 waste transfer in this study. The results are discussed in Section 5.4.

\subsection{1-SY-101 Waste Transfer}

We evaluated the feasibility of transferring SY-101 waste through the cross-site pipeline using the Wasp (1963) slurry transport model. We calculated the critical velocity and expected pressure drop to determine whether current SY-101 waste can be transferred through the existing 6.2-mile long, 3-inch-diameter supernate pipeline without additional dilution with water, and, if it cannot, how much dilution is needed subject to the five restrictions discussed in Section 5.3.

\subsubsection{Stochastic evaluation approach}

A Monte-Carlo simulation approach was used to investigate pipeline transport of the SY-101 waste. This approach can be used to determine the uncertainty of modeling results when adequate sampling is unavailable to provide accurate input parameters (see Section 5.4.2).

Input distributions and their appropriate parameters are identified and determined based on physical and engineering knowledge (see Section 5.4.2) to create scenarios that could possibly occur given every known possible combination of events. Each value used for the inputs is randomly sampled from an infinite population featuring the specified distribution and appropriate parameters. The typical distributions used for these inputs were uniform and normal distributions.

For each case, 5,000 simulation runs were made using the Wasp model presented in Section 3. Sampling a large number of cases allows all important physical effects included in the model to influence the predicted results. The result is a set of 5,000 model outputs that constitutes a probability distribution of the predicted results.

\subsubsection{Specific waste properties for Tank 241-SY-101}

The accuracy of the pressure drop results attained from the Wasp slurry transport model depends not only upon the accuracy of the model itself but also upon the accurate characterization of the waste flow. The parameters of interest for the SY-101 waste include the density and viscosity of the supernatant liquid, the density and volume fraction particle size distribution of the dry solids, and the volume fraction of dry solids and viscosity of the waste being transferred.

Identification of the physical and rheological parameters of the waste in SY-101 was made based on the post-mitigation April and June 2000 grab sample data. Additional data that supplemented these sampling events were extrapolated to the current tank conditions from the available SY-101 pre-mitigation data. 


\subsubsection{SY-101 supernatant liquid}

The supernatant liquid in SY-101 is about 260 inches thick (see subsection 5.4.2.3). Based on the June 2000 grab samples, the liquid density is $1.35 \pm 0.02 \mathrm{~g} / \mathrm{mL}$ (Johnson et al. 2000). The viscosity of the supernatant liquid in its current state has not been measured. Therefore, premitigation data were considered and extrapolated to the current waste conditions. These data included liquid core samples taken during Window C in May 1991 (Reynolds 1992), as well as dilution study results from core samples taken from November 1998 to February 1999. (a) The supernatant liquid viscosity, together with the mass fraction of water in the liquid (wHL, representing dilution) and the temperature at which the measurements were taken are presented in Tables 5.5 and 5.6. The data indicate that the liquid is a Newtonian fluid (refer to the cited references for the apparent liquid viscosity as a function of strain rate). Data scatter was tempered by removing the temperature and dilution effects.

Table 5.5. SY-101 Supernatant Liquid Viscosity at Dilution by Temperature

\begin{tabular}{|c|c|c|c|}
\hline wHL & Temp $\left({ }^{\circ} \mathbf{C}\right)$ & Measured Viscosity (cP) & Data Source \\
\hline \multirow{4}{*}{0.361} & 32 & 58 & Reynolds 1992 \\
\hline & 50 & 29 & Reynolds 1992 \\
\hline & 65 & 5 & Reynolds 1992 \\
\hline & 80 & 3 & Reynolds 1992 \\
\hline \multirow{2}{*}{0.417} & 30 & 20.5 & * \\
\hline & 47 & 10.8 & * \\
\hline \multirow{2}{*}{0.440} & 26 & 25.5 & * \\
\hline & 47 & 10.5 & * \\
\hline \multirow{2}{*}{0.478} & 27 & 4.7 & * \\
\hline & 47 & 3.2 & $*$ \\
\hline \multirow{2}{*}{0.617} & 24 & 6 & * \\
\hline & 47 & 3.7 & $*$ \\
\hline
\end{tabular}

Table 5.6. SY-101 Supernatant Liquid Viscosity at Temperature by Dilution

\begin{tabular}{|c|c|c|c|}
\hline Temp $\left({ }^{\circ} \mathbf{C}\right)$ & wHL & Measured Viscosity (cP) & Data Source \\
\hline \hline \multirow{3}{*}{47} & 0.417 & 10.8 & $*$ \\
\cline { 2 - 4 } & 0.440 & 10.5 & $*$ \\
\cline { 2 - 4 } & 0.478 & 3.2 & $*$ \\
\cline { 2 - 4 } & 0.617 & 3.7 & $*$ \\
\hline \multirow{2}{*}{$\begin{array}{l}\text { N Numatec Hanford Corporation internal memo 82100-99-017. “Results of Viscosity Measure- } \\
\text { ments of Tank 241-SY-101 Samples." Process Engineering to JC Person, May 3, 1999. }\end{array}$} \\
\hline
\end{tabular}

(a) Numatec Hanford Corporation Internal Memo 82100-99-017, Process Engineering to JC Person, May 3, 1999. Subject: Results of Viscosity Measurements of Tank 241-SY-101 Samples. 
To determine the effect of temperature at a given dilution, the viscosities in Table 5.5 were normalized at each dilution by the corresponding maximum viscosity. In lieu of a known relation, linear fits were made to the data (note that water viscosity with temperature over similar temperature ranges may be satisfactorily fit linearly), and the slopes of normalized viscosity were compared. No definitive difference in the temperature effect with varied dilution was identifiable (Figure 5.2). Therefore, a single fit was made to all data sets (Figure 5.2). The fit was of the form

$$
\mu_{1}=\mu_{0}(1+\mathrm{m} \cdot \Delta \mathrm{T})
$$

where $\mu_{1}$ is the new viscosity, $\mu_{0}$ is the initial viscosity, $m$ is the relative change with temperature, and $\Delta \mathrm{T}$ is the difference between the new and the initial temperatures. The slope $\mathrm{m}$ is adjusted via a least squares analysis and determined to be approximately $-0.019(1 / \mathrm{T})$.

The effect of dilution at a given temperature was evaluated in a similar fashion (Figure 5.3), with a fit of the form

$$
\mu_{1}=\mu_{0}(1+n \cdot \Delta w H L)
$$

optimized to the normalized viscosity data in Table 5.6. An additional data point of pure water was included (the viscosity of water at $47^{\circ} \mathrm{C}$ is approximately $0.58 \mathrm{cP}$ ). The slope " $\mathrm{n}$ " (the relative change with change in the mass fraction of water in the liquid:dilution) was determined to be approximately -1.616 .

The current waste temperature is approximately $28^{\circ} \mathrm{C}$ (subsection 5.4.2.3), and the mass fraction of water in the liquid is taken to be 0.588 (June 2000 core sample laboratory analytical results for species concentrations in the liquid. ${ }^{\text {(a) }}$ This mass fraction of water compares well with that computed from the liquid density based on concentrated solution data from the Hanford Site (see Figure 2.1.2 in Rassat et al. 2000). The viscosity data in Tables 5.5 and 5.6 extrapolated to these conditions are given in Table 5.7. Because of the scatter, a distribution of the apparent liquid viscosity was created (Figure 5.4). The bimodal shape was used because the viscosity data corresponding to the peaks were taken at conditions that most closely represent the current waste condition.

(a) Personal communication with JM Conner (CHG) on July 13, 2000. 


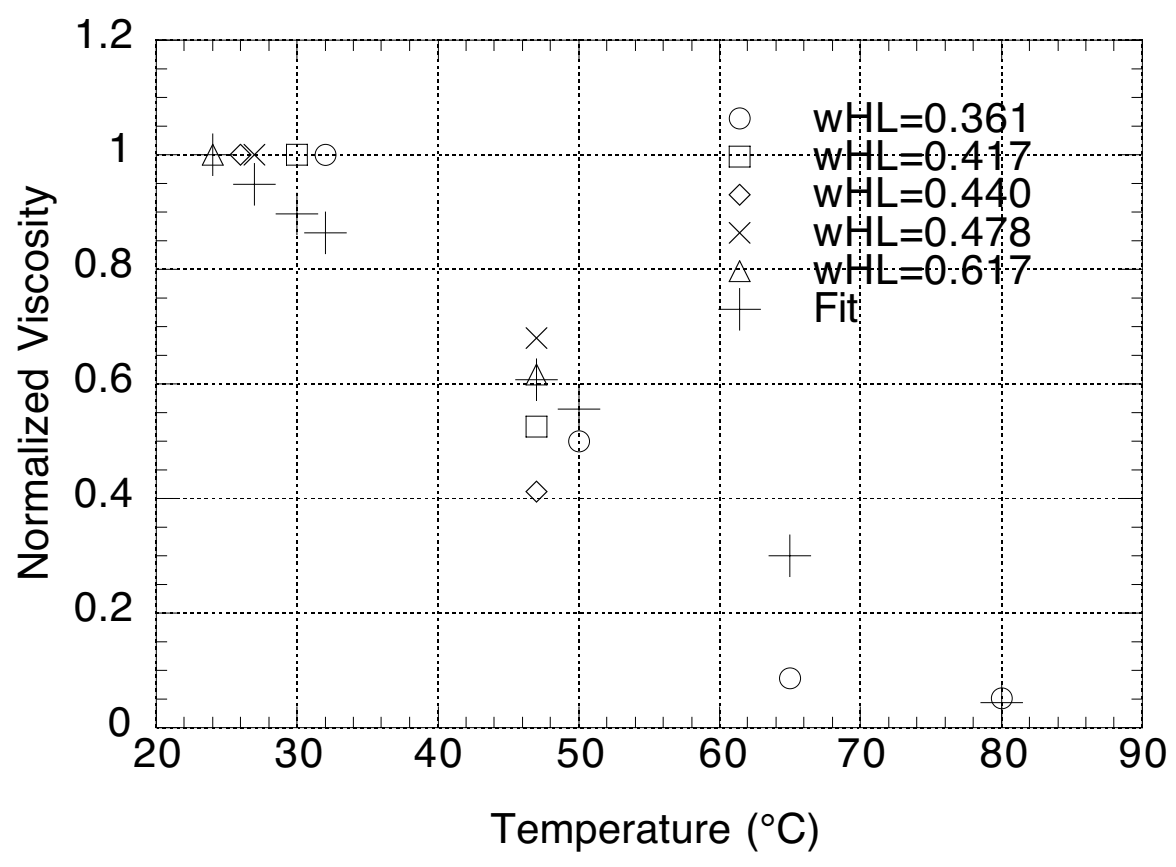

Figure 5.2. Normalized Viscosity as a Function of Temperature at Dilution

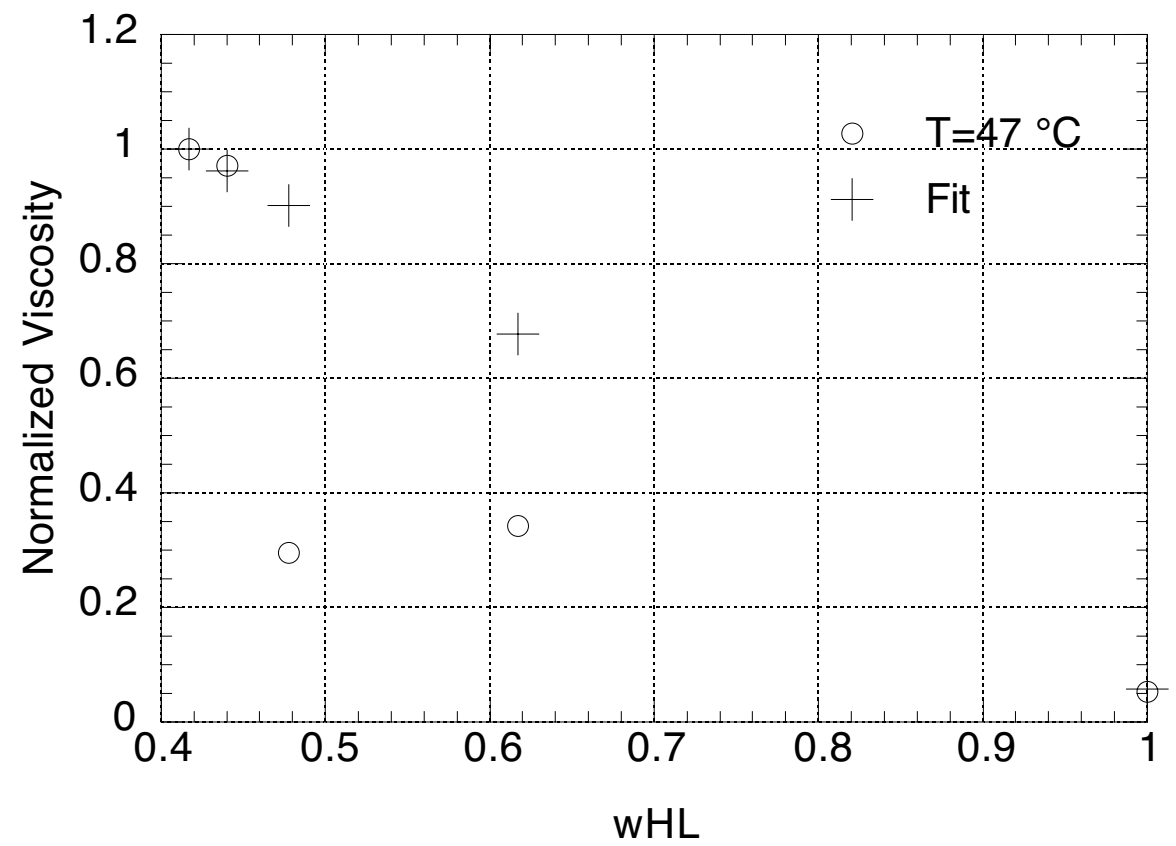

Figure 5.3. Normalized Viscosity as a Function of Dilution at Temperature 
Table 5.7. SY-101 Liquid Viscosity Values Extrapolated to Current Tank Conditions $\left(\right.$ temp $\left.=28^{\circ} \mathrm{C}, \mathrm{wHL}=0.588\right)$

\begin{tabular}{||c|c|c|c||}
\hline wHL & $\begin{array}{c}\text { Temp } \\
\left({ }^{\circ} \mathbf{C}\right)\end{array}$ & $\begin{array}{c}\text { Measured } \\
\text { Viscosity } \\
(\mathbf{c P})\end{array}$ & $\begin{array}{c}\text { Extrapolated Viscosity } \\
\text { for Current Condition } \\
(\mathbf{c P})\end{array}$ \\
\hline 0.361 & 32 & 58.0 & 39.5 \\
\hline 0.361 & 50 & 29.0 & 26.0 \\
\hline 0.361 & 65 & 5.0 & 5.4 \\
\hline 0.361 & 80 & 3.0 & 3.8 \\
\hline 0.417 & 30 & 20.5 & 15.4 \\
\hline 0.417 & 47 & 10.8 & 10.6 \\
\hline 0.440 & 26 & 25.5 & 18.7 \\
\hline 0.440 & 47 & 10.5 & 10.9 \\
\hline 0.478 & 27 & 4.7 & 3.8 \\
\hline 0.478 & 47 & 3.2 & 3.6 \\
\hline 0.617 & 24 & 6.0 & 5.8 \\
\hline 0.617 & 47 & 3.7 & 5.3 \\
\hline
\end{tabular}

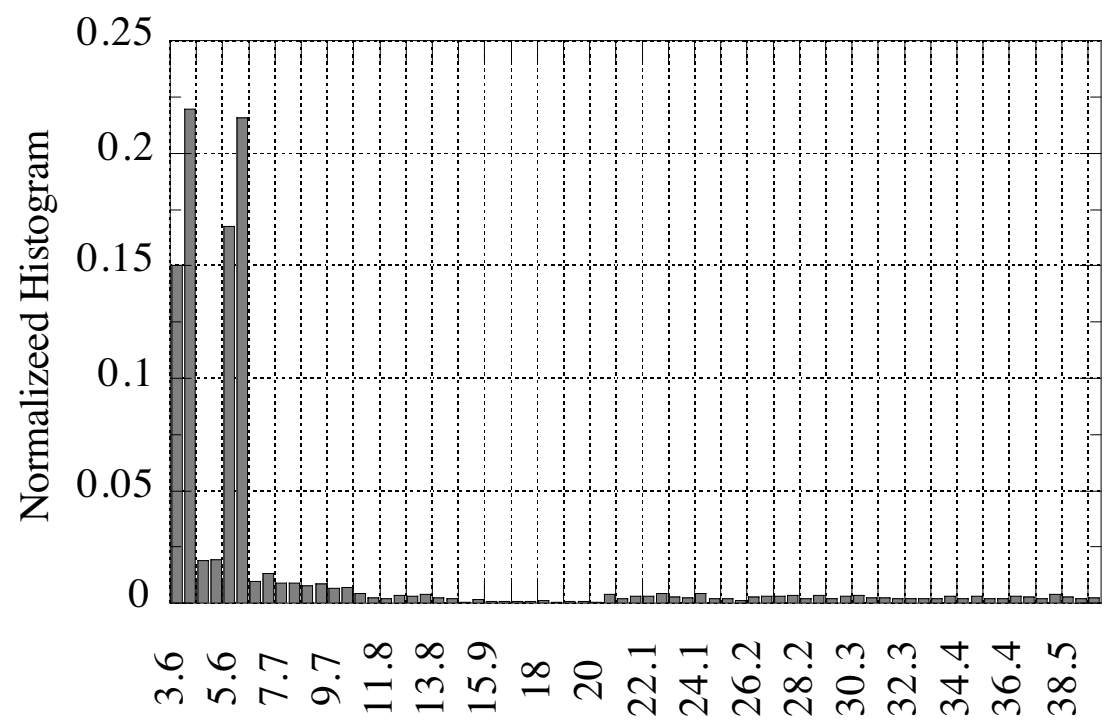

Liquid Viscosity (cP)

Figure 5.4. SY-101 Liquid Viscosity Distribution

\subsubsection{SY-101 dry solids}

The settled solids layer in SY-101 is less than 100 inches deep, as determined from the waste temperature profiles and neutron and gamma scans (see subsection 5.4.2.3). The density and particle size of the dry solids in this layer are discussed in detail below. Both pre- and postmitigation data are considered. 
As presented in Johnson et al. (2000), the centrifuged solids from the April 2000 grab samples were analyzed by polarized light microscopy (PLM) and scanning electron microscopy with energy-dispersive $\mathrm{x}$-ray spectroscopy (SEM/EDS). ${ }^{(a)}$ At least five solid phases were found by the combination of PLM and EDS and are described below in order of relative abundance together with the observed particle size.

- Sodium oxalate, $\mathrm{Na}_{2} \mathrm{C}_{2} \mathrm{O}_{4}(\sim 40 \%$ by volume), was identified by both PLM and SEM/EDS. Crystals were tiny anisotropic needles, roughly 1 x 5 microns, that tended to form agglomerates 100 microns or more in diameter.

- Aluminum hydroxide, $\mathrm{Al}(\mathrm{OH})_{3}(\sim 30 \%$ by volume), was identified by SEM/EDS and observed but not identified by PLM. Crystals were tiny (1 to 5 micron), and approximately cubic in shape but are actually anisotropic.

- Sodium phosphate, $\mathrm{Na}_{3} \mathrm{PO}_{4} \cdot 12 \mathrm{H}_{2} \mathrm{O}$ ( $20 \%$ by volume), was identified by PLM and $\mathrm{SEM} / \mathrm{EDS}$. The crystals were large rods or needles up to several hundred microns in length.

- Sodium fluoride phosphate, $\mathrm{Na}_{7} \mathrm{~F}\left(\mathrm{PO}_{4}\right)_{2} \cdot 19 \mathrm{H}_{2} \mathrm{O}$ (0 to $10 \%$ by volume), was identified only by PLM and only in the two deepest samples. This phase appeared as large, 100-micron, angular isotropic crystals.

- Calcium carbonate or calcium oxalate, $\mathrm{CaCO}_{3}$ or $\mathrm{CaC}_{2} \mathrm{O}_{4}(\sim 1 \%$ by volume), was identified by EDS x-ray spectra only.

- Chromium ( $\sim 1 \%$ by volume) of undetermined species (possibly chromium oxide) was observed with EDS x-ray spectra associated with $\mathrm{Al}(\mathrm{OH})_{3}$ but not with sodium oxalate or sodium phosphate.

The sodium oxalate agglomerations and the long sodium phosphate needles, along with the tiny aluminum hydroxide crystals, tend to form a weak, widely separated network. PLM and SEM/EDS were performed on the June 2000 samples to determine whether further dissolution or precipitation had occurred. Results were consistent with those for the April samples. ${ }^{(b)}$

Comparing the solid phases found by the combination of PLM and EDS with those identified from the analytical results of the April 2000 grab samples shows reasonably good agreement except for phosphate (see Figure 5.5). The bulk dry solid density computed from the individual specie density handbook values is approximately $2.2 \mathrm{~g} / \mathrm{mL}$ from the PLM and EDS analysis and 2.3 from the analytical results on the April 2000 samples.

(a) Fluor Hanford Inc. Interoffice Memo 8D500-DLH-00-045, DL Herting to RA Esch, August 21, 2000. Subject: Microscopy Analysis of SY-101 Grab Samples.

(b) Fluor Hanford Inc. Interoffice Memo 8D500-DLH-00-052, DL Herting to RA Esch, September 28, 2000. Subject: Microscopy Analysis of SY-101 Grab 2 Samples. 


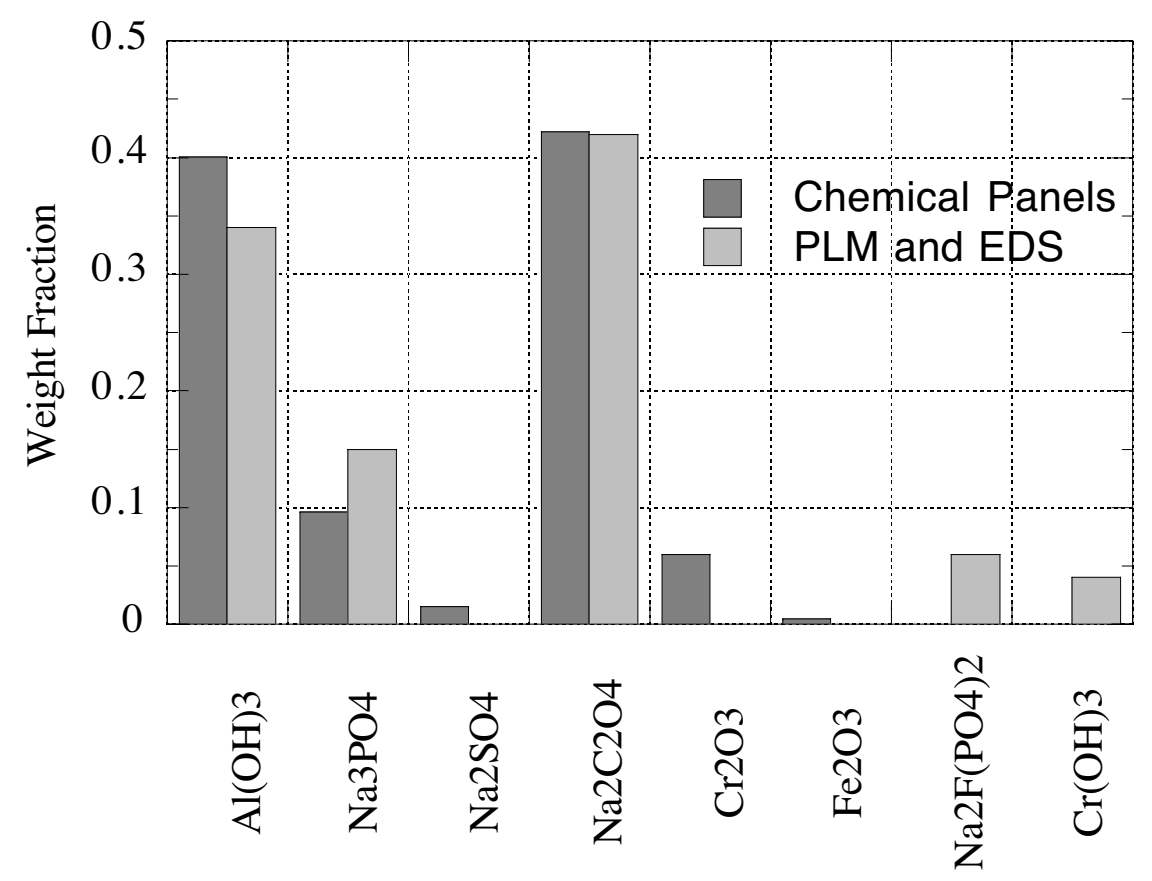

Figure 5.5. Identified Post-Mitigation SY-101 Solid Phases

Chemical analyses were conducted on the solids from a whole tank composite of the 1991 core samples. ${ }^{(a)}$ The bulk dry solids density can be computed from the individual solid-phase density handbook values to be approximately $2.3 \mathrm{~g} / \mathrm{mL}$. It was determined in the analysis of the dilution studies on the 1999 pre-mitigation core samples presented in Rassat et al. (2000) that the dry solid density was $2.2 \mathrm{~g} / \mathrm{mL}$. The dissolution model resulting from this analysis was used successfully to predict the post-mitigation waste configuration (Johnson et al. 2000).

Higher dry solid densities may be determined from the analytical results of the samples using the measured water content in both the centrifuged solids and the liquid, as discussed below for both pre- and post-mitigation samples. However, it is evident that these values are unreasonable given the identified solid phases (see above). This apparent overprediction is not exclusive to measurements taken in SY-101. The logic behind this conclusion is presented below.

To begin, assume that the interstitial liquid in the centrifuged solids is exactly the same as the centrifuged liquid. The mass fraction of dry solids in a sample can then be determined from

$$
\mathrm{wS}=1-\frac{\mathrm{wHCS}}{\mathrm{wHL}}
$$

where wHCS is the mass fraction of water in the centrifuged solids. The bulk density of the centrifuged solid sample can be expressed in terms of the mass fraction of dry solids as

(a) Westinghouse Hanford Corporation Internal Memo 8E110-PCL94-053, Process Chemistry Laboratories to GD Johnson, July 11, 1994. Subject: Chemical Composition of Tank 101-SY Solids. 


$$
\rho_{0}=\frac{1}{\frac{w S}{\rho_{S}}+\frac{1-w S}{\rho_{L}}}
$$

where $\rho_{\mathrm{S}}$ and $\rho_{\mathrm{L}}$ are the dry solid and liquid densities, respectively. The dry solid density can therefore be determined from

$$
\rho_{S}=\frac{\rho_{0}\left(1-\frac{w H C S}{w H L}\right)}{1-\frac{\rho_{0}}{\rho_{L}}\left(\frac{w H C S}{w H L}\right)}
$$

When Equation 5.4.5 was applied to selected Hanford tanks (four tanks with extensive waste analysis), the pattern of overprediction based on the identified dry solids (via chemical analysis, chemical modeling, or observation) was observed (Figure 5.6). The SY-101 data are taken from the 1998, 1999, and 2000 core and grab samples. Also presented are the results of the dissolution analysis on the 1998 and 1999 core sample dilution data (Rassat et al. 2000). The data for AN-105, AN-104, and AW-101 are taken from Herting (1997, 1998, 1999, respectively). Based on the identified solid phases for these tanks (Herting 1997, 1998, 1999), the solid densities are approximately $2.4 \mathrm{~g} / \mathrm{mL}$ for AN-105, $2.3 \mathrm{~g} / \mathrm{mL}$ for AN-104, and $2.1 \mathrm{~g} / \mathrm{mL}$ for AW-101. The calculated values based on the water measurements in the waste are represented by the large, bold symbols matched to the specific tank in the legend of Figure 5.6. In order of appearance in the legend (Figure 5.6), these values are $3.85 \mathrm{~g} / \mathrm{mL}$ (SY-101 98-99), $2.20 \mathrm{~g} / \mathrm{mL}$

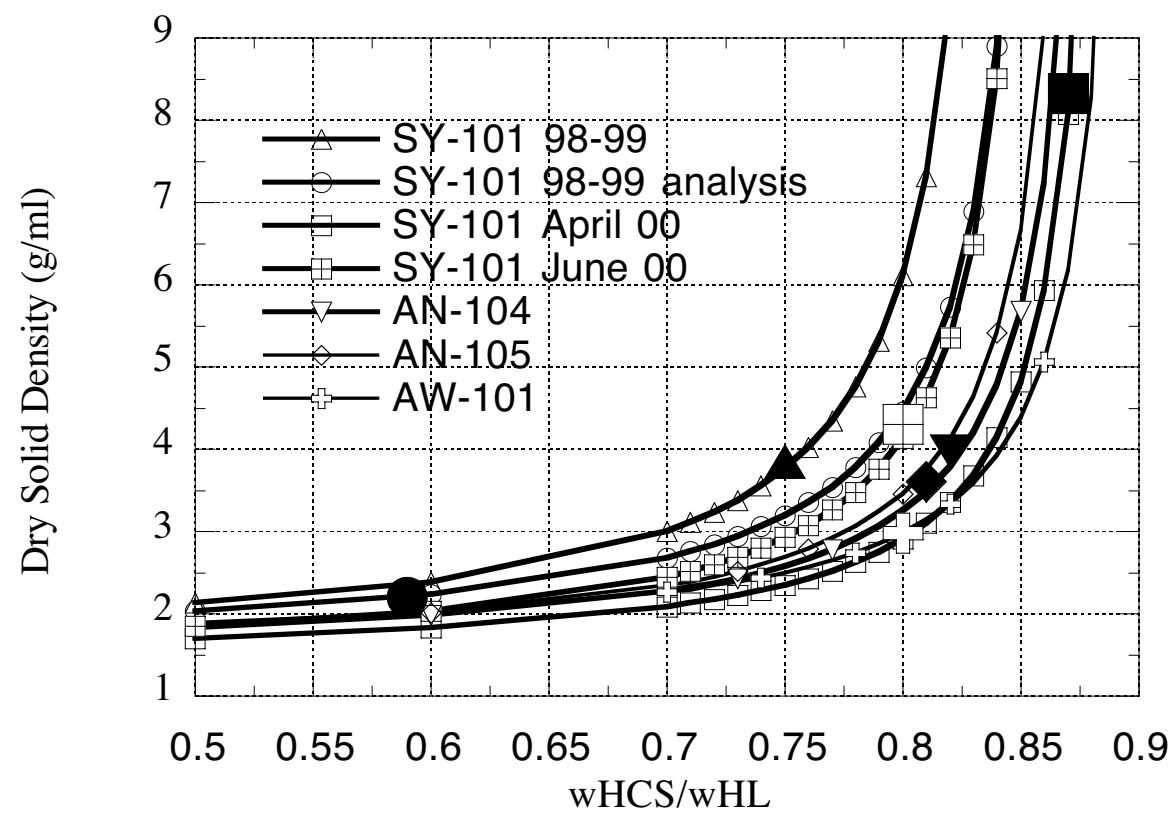

Figure 5.6. Dry Solid Density as a Function of wHCS/wHL for Selected Hanford Tanks (large, bold symbols matched to the specific tank in the legend represent the calculated values) 
(SY-101 98-99 analysis), $8.33 \mathrm{~g} / \mathrm{mL}$ (SY-101 April 2000), $4.31 \mathrm{~g} / \mathrm{mL}$ (SY-101 June 2000), $3.97 \mathrm{~g} / \mathrm{mL}$ (AN-104), $3.61 \mathrm{~g} / \mathrm{mL}$ (AN-105), and $2.98 \mathrm{~g} / \mathrm{mL}$ (AW-101). Note that the calculated values are on the elbow of the function describing the dry solid density and that small changes in the ratio of the water content in the centrifuged solids to that in the liquid are enough to lower the densities closer to those determined from the identified solid phases. Given the relative uncertainties in the terms of Equation (5.4.5), the apparently high densities are attributed to uncertainty in the water content.

Most of the data indicate, therefore, that the dry solid density in post-mitigation SY-101 is $2.2 \mathrm{~g} / \mathrm{mL}$ with a range of $\pm 0.15 \mathrm{~g} / \mathrm{mL}$. The range is determined empirically from uncertainties in the solid phase identification and associated water of hydration, relative quantities of the solid phases, and expected potential for error in the chemical analyses.

Two dry solid particle size distributions are evaluated in this analysis. The first and most representative of current tank conditions is taken from the PLM and SEM/EDS on the 2000 samples. This distribution by volume is presented in Table 5.8. The particle size distribution from the Window E samples of December 1991 (Reynolds 1993) was also considered (see Table 5.9). While it is not entirely unreasonable that the particle size will remain relatively constant with dilution so this distribution may be used for the post-mitigation state of SY-101 [AN-105 waste at different dilutions had similar particle size distributions (Herting 1997)], the

Table 5.8. Dry Solid Particle Size Distribution from the PLM and SEM/EDS Performed on the April/June 2000 SY-101 Samples

\begin{tabular}{||c|c|}
\hline Particle Size $(\boldsymbol{\mu m})$ & Volume Fraction \\
\hline 2.2 & 0.30 \\
\hline 100 & 0.68 \\
\hline 200 & 0.02 \\
\hline
\end{tabular}

Table 5.9. Dry Solid Particle Size Distribution from Window E SY-101 Samples

\begin{tabular}{|c|c|}
\hline Particle Size $(\boldsymbol{\mu m})$ & Volume Fraction \\
\hline 0.75 & 0.071 \\
\hline 1.5 & 0.187 \\
\hline 2.5 & 0.134 \\
\hline 3.5 & 0.131 \\
\hline 4.5 & 0.101 \\
\hline 5.5 & 0.066 \\
\hline 6.5 & 0.046 \\
\hline 7.5 & 0.011 \\
\hline 9.0 & 0.014 \\
\hline 11.5 & 0.041 \\
\hline 31.0 & 0.187 \\
\hline 33.5 & 0.011 \\
\hline
\end{tabular}


extensive processing that the Window E samples underwent is expected to have affected the particle size distribution analysis. This particle size distribution is therefore used because of the effect of particle size on the Wasp model calculation of the pressure drop (Section 3). It is also considered because of the relatively short time that the SY-101 waste has been undisturbed (the last mixer pump run was in April 2000) and the mixing/disturbing effect of the transfer pump upon any solids introduced into the transfer line.

\subsubsection{Dry solid content and viscosity of SY-101 slurry}

The volume fraction of dry solids and the viscosity of the settled solid layer in SY-101 are considered in this section. From these data, the expected parameters of the transferred waste are extrapolated and inferred. The volume fraction of dry solids in the settled solid (nonconvective) layer can be determined from the dry solid density, the density of the layer, and the liquid density as

$$
\mathrm{Cv}=\frac{\rho_{B}-\rho_{L}}{\rho_{S}-\rho_{L}}
$$

where $\rho_{\mathrm{B}}$ is the bulk de-gassed density of the settled solids layer. The average density of this layer was measured at $1.48 \mathrm{~g} / \mathrm{mL}$ from the June 2000 grab samples. The height of the settled solids at the sampling time was approximately 112 inches. By October 2000, the settled solid layer height had decreased to 100 inches, from which a bulk density of $1.50 \mathrm{~g} / \mathrm{mL}$ (corresponding to a solid volume fraction of 0.17 ) can be determined (Johnson et al. 2000).

The current height of the settled solid layer may be determined using a neutron/gamma probe and the temperature profiles in the waste. The neutron/gamma probe detection response is an indicator of water content, which provides a means to identify waste layer boundaries. The probe was deployed into the tank through two different risers (17B and 17C), most recently on June 14, 2001. It is apparent from both the neutron (Figure 5.7) and gamma (Figure 5.8) scans that the settled solid layer is still at or below 100 inches at each riser (the lower water content below 100 inches indicates the presence of solids). The waste surface level of approximately 350 inches compares well with the current Enraf ${ }^{\circledR}$ measurement of 352 inches.

The waste temperature profiles from risers $17 \mathrm{~B}$ and $17 \mathrm{C}$ clearly show the decrease in the settled solid layer height with time (Figures 5.9 and 5.10). Each trace represents a single thermocouple at the specified elevation. The bold black line indicates the 100-inch thermocouple temperature. The upper "cluster" of temperatures represents the settled solids layer; the lower cluster represents the supernatant liquid layer. Spikes and jumps in the data are attributed to instrumentation errors. However, as corroborated by other data (neutron/gamma scans), the apparent trends are real. Note the departure, from left to right on the plots, of subsequently lower thermocouples from the temperature range of the settled solids layer into the temperature range of the supernatant liquid. This represents the decrease in the settled solids layer height as the subsequent thermocouples are uncovered and reach the supernatant liquid temperature. The 100-inch thermocouple registered the supernatant liquid temperature in October 2000. The 76-inch thermocouple began to depart from the settled solids layer temperature in July 2000 but apparently has not been fully uncovered. 


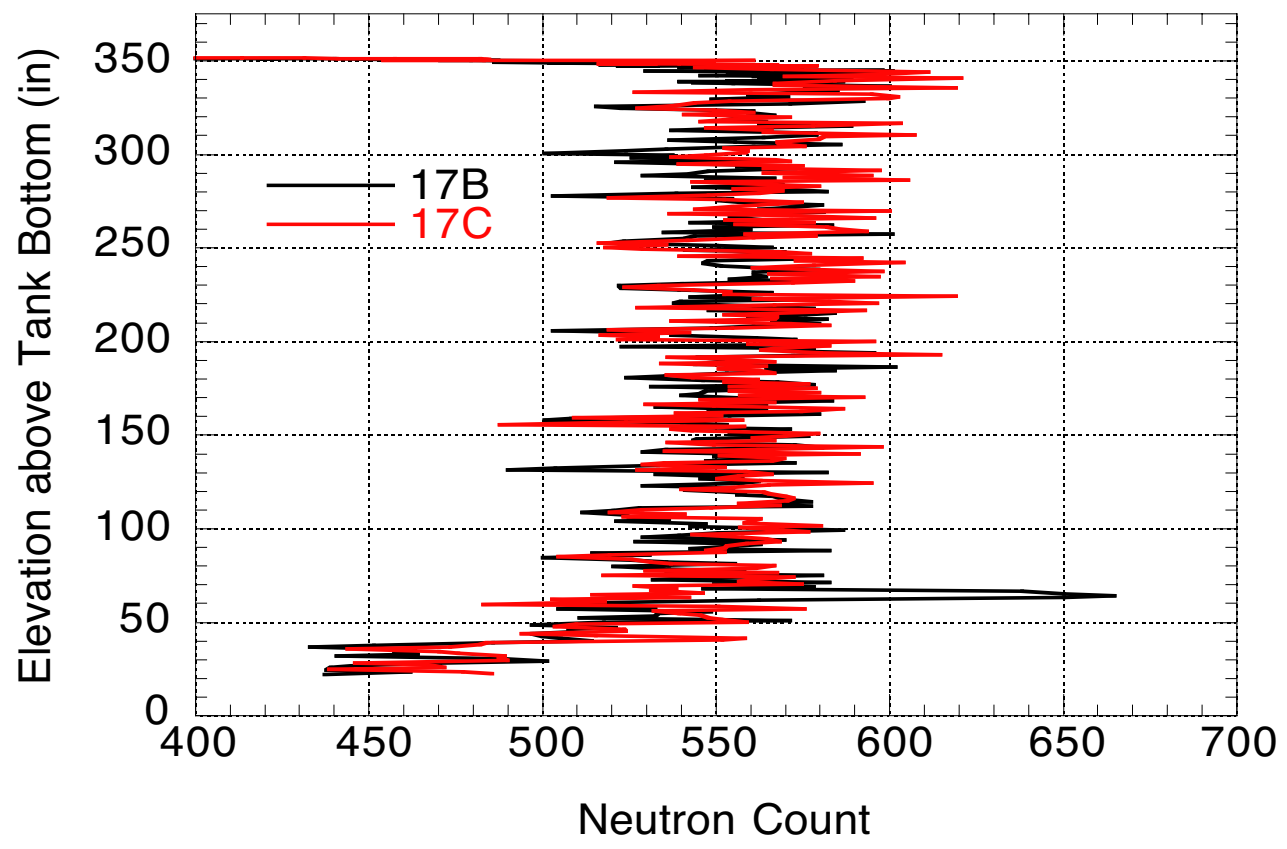

Figure 5.7. Neutron Count Profile

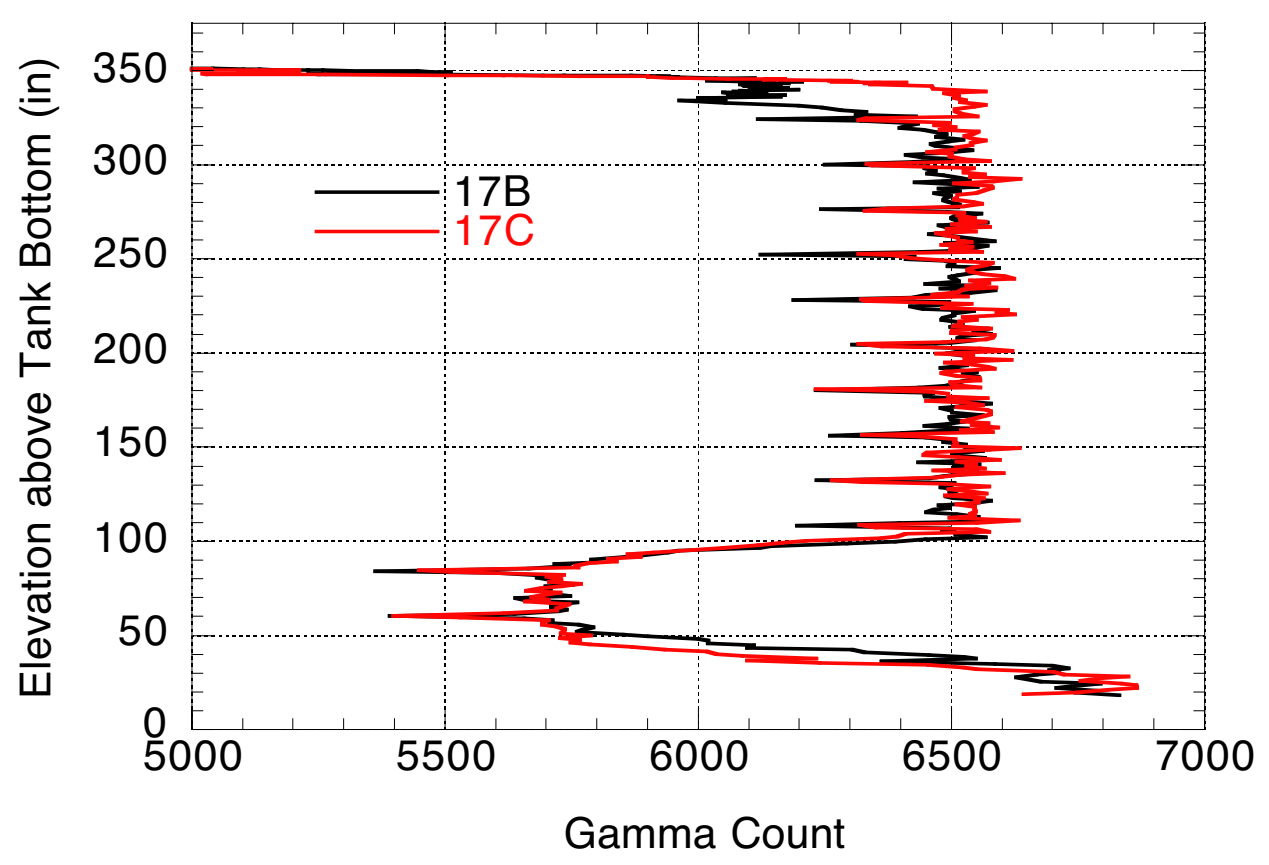

Figure 5.8. Gamma Count Profile 

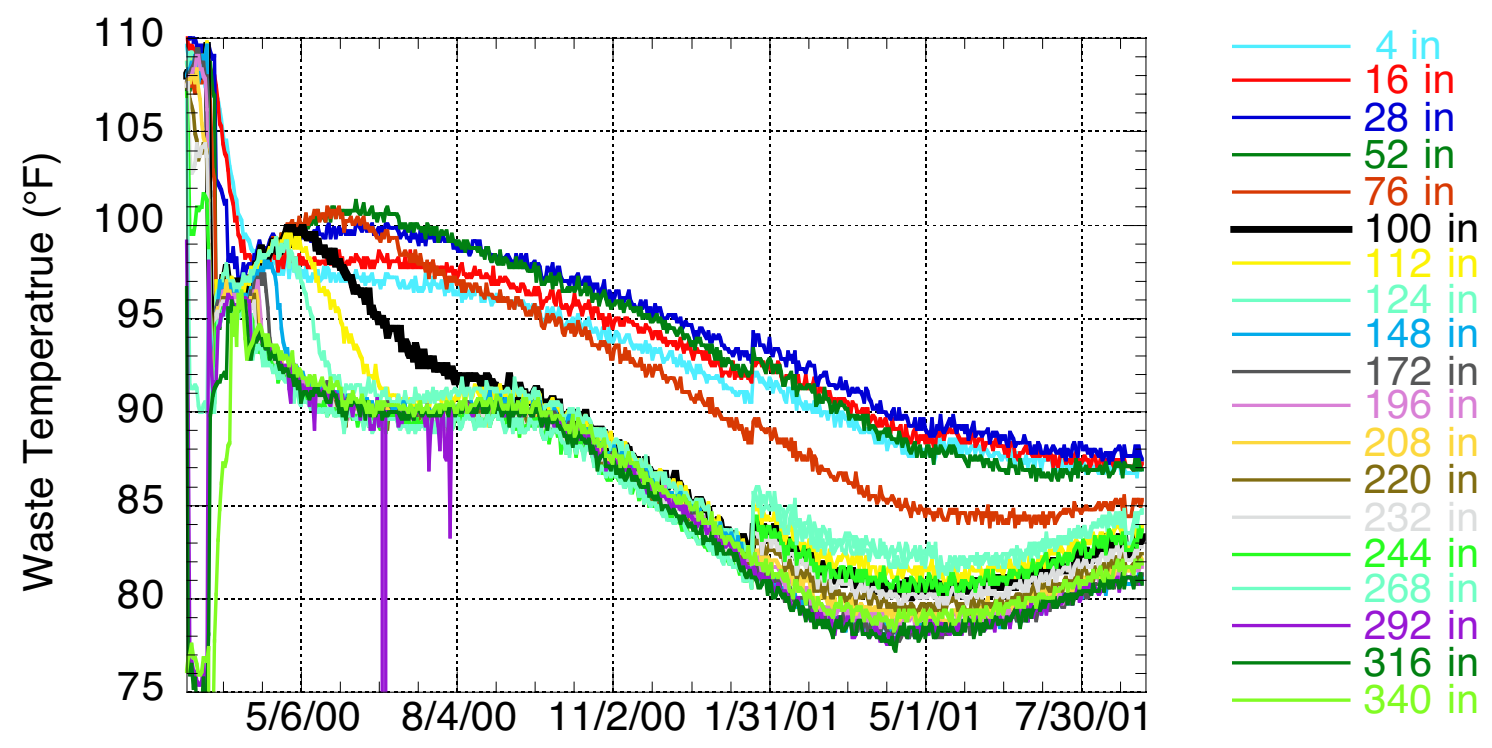

Figure 5.9. Temperature Profile History in Riser 17B
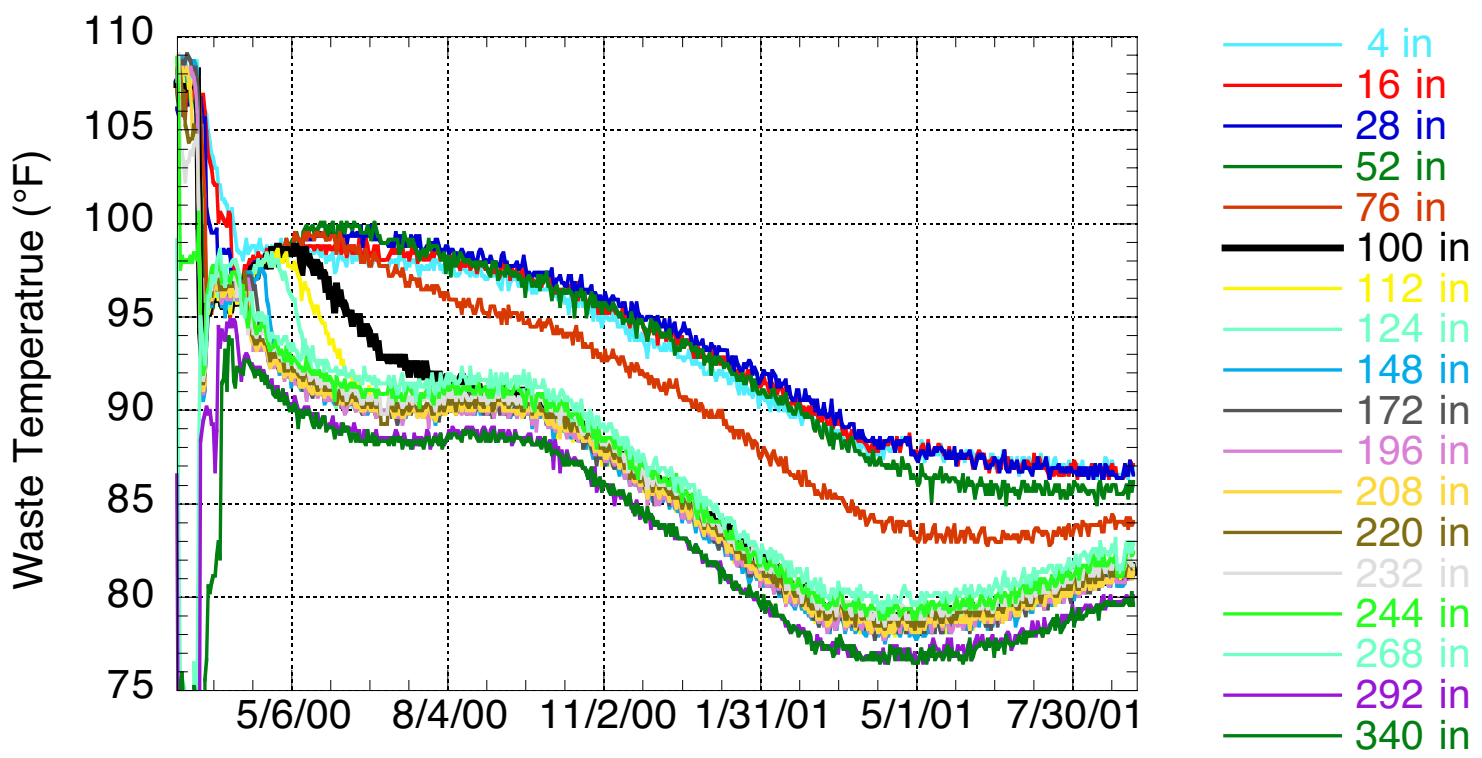

Figure 5.10. Temperature Profile History in Riser 17C 
The settled solids layer depth is therefore at or below 100 inches and above 76 inches, while the inlet height of the transfer pump in SY-101 is at $102 \pm 1.5$ inches above the tank bottom. ${ }^{(a)}$ Because the exact height of the settled solids layer is unknown (Figures 5.7 through 5.10), four different solid volume fractions are considered as possible transfer conditions. If the separation between the inlet of the transfer pump is so large that no solids are introduced into the transfer line, supernatant liquid $(\mathrm{Cv}=0.0)$ will be transferred. Depending on this separation, various mixtures of supernatant liquid and settled solids may be introduced into the transfer line. Two cases were chosen to represent this effect: $\mathrm{Cv}=(1 / 3) \mathrm{Cvmax}$, and $\mathrm{Cv}=(2 / 3) \mathrm{Cvmax}$. Finally, a dry solid volume fraction of 0.17 (Cvmax) is considered to represent the case where the transfer pump inlet is at or below the settled solid layer depth.

The addition of solid particles to a liquid makes the viscosity of the mixture (slurry) greater than that of the liquid itself. The slurry viscosity is a function of the base liquid viscosity, the solid fraction, and the temperature. Typically, a slurry is non-Newtonian in behavior, and the viscosity is therefore also a function of the strain rate.

No rheological measurements have been taken on post-mitigation SY-101 waste (repeated efforts made to acquire such measurements for the current analysis were not successful). Therefore, the available viscosity data for slurry samples from pre-mitigation SY-101 were investigated. These data include the Window E core samples (Reynolds 1993), deployment of the ball rheometer in SY-101 in 1995 (Stewart et al. 1995), and the 1998-1999 core samples. ${ }^{(b)}$ The viscosity data were evaluated and extrapolated to the expected transfer conditions. Operational data from the SY-101 mixer pump before, during, and after the mitigation activities were also considered, as were data from the 1999-2000 transfers of waste from SY-101 to SY-102. However, the latter two methods do not produce results that are meaningful or applicable to this investigation (due partially to potential instrumentation error and/or different flow conditions).

Three transfer velocities were selected, as discussed in Section 5.3. The strain rate in the pipeline associated with these velocities may be estimated from

$$
\gamma=\frac{8 \mathrm{~V}}{\mathrm{D}}
$$

where $\mathrm{V}$ is the transfer velocity and $\mathrm{D}$ is the pipeline diameter (Wasp et al. 1977).

The measured viscosity of SY-101 slurry at various strain rates (associated with the three transfer velocities via Equation 5.4.7), solid fractions, and temperatures is given in Table 5.10. The ball rheometer was deployed in the tank in 1995, and the viscosity measurements are taken from the then well-mixed mixed slurry layer. The repetitions at temperature are maximum, median, and minimum measurements. The viscosity measurements for the 1998-1999 core samples were conducted on a core from the same slurry layer. It was noted that the sample had solidified after being removed from the tank and had to be stirred to be transferred into the

(a) Personal communication with GA Leshikar (CHG) on May 14, 2001.

(b) Numatec Hanford Corporation Internal Memo 82100-99-017, Process Engineering to JC Person, May 3, 1999. Subject: Results of Viscosity Measurements of Tank 241-SY-101 Samples. 
Table 5.10. Measured SY-101 Slurry Viscosity

\begin{tabular}{|c|c|c|c|c|c|}
\hline $\begin{array}{c}\text { Solid } \\
\text { Volume } \\
\text { Fraction }\end{array}$ & $\begin{array}{c}\text { Temp. } \\
\text { (C) }\end{array}$ & $\begin{array}{c}\text { Measured } \\
\text { Viscosity }(\mathrm{cP}) \\
{[\gamma=128(1 / \mathrm{s})]}\end{array}$ & $\begin{array}{c}\text { Measured } \\
\text { Viscosity }(\mathbf{c P}) \\
{[\gamma=80(1 / \mathbf{s})]}\end{array}$ & $\begin{array}{c}\text { Measured } \\
\text { Viscosity }(\mathrm{cP}) \\
{[\gamma=48(\mathbf{1} / \mathbf{s})]}\end{array}$ & Data Source \\
\hline 0.155 & 46.5 & 175 & 230 & 311 & Stewart et al. 1995 \\
\hline 0.155 & 46.5 & 69 & 85 & 106 & Stewart et al. 1995 \\
\hline 0.155 & 46.5 & 26 & 30 & 35 & Stewart et al. 1995 \\
\hline 0.155 & 24 & 255 & 429 & 705 & $*$ \\
\hline 0.155 & 24 & 105 & 109 & 115 & $*$ \\
\hline 0.155 & 25 & 100 & 112 & 119 & $*$ \\
\hline 0.155 & 25 & 82 & 86 & 90 & $*$ \\
\hline 0.155 & 47 & 37 & 44 & 51 & $*$ \\
\hline 0.155 & 47 & 35 & 39 & 43 & $*$ \\
\hline 0.155 & 26 & 260 & 345 & 450 & * \\
\hline 0.155 & 26 & 141 & 145 & 152 & $*$ \\
\hline 0.155 & 27 & 139 & 146 & 164 & $*$ \\
\hline 0.155 & 27 & 115 & 118 & 121 & $*$ \\
\hline 0.155 & 47 & 48 & 61 & 75 & $*$ \\
\hline 0.155 & 47 & 45 & 53 & 62 & $*$ \\
\hline 0.296 & 50 & 400 & 720 & 1080 & Reynolds 1993 \\
\hline 0.296 & 65 & 460 & 740 & 950 & Reynolds 1993 \\
\hline
\end{tabular}

viscometer. Upon introduction into the viscometer, four consecutive viscosity measurements were performed. In each case, the strain rate was ramped up and then back down, so two passes are associated with each measurement. The Window E core sample analyzed was taken from the settled solids layer in 1991. Only the return pass of the viscometer was considered, so the waste was in a disturbed state similar to the aforementioned measurements. This is also deemed to be more representative of a transfer scenario because the transfer pump will mix/disturb the waste upon introduction into the transfer line.

The temperature effect was removed from the SY-101 slurry viscosity data by analyzing the data at constant volume fractions and strain rates over a range of temperatures. As with the liquid viscosity (subsection 5.4.1.1), the viscosities were normalized at each strain rate by the corresponding maximum viscosity. Data from Tingey et al. (1994) were also considered. Again, a linear fit was used to each data set, and the slope of each normalized viscosity was compared. No definitive difference was identifiable in the temperature effect with varied strain rate (Figure 5.11). A linear fit was therefore made concurrently to all data sets (Figure 5.11). The fit was of the form

$$
\mu_{1}=\mu_{0}(1+\mathrm{p} \cdot \Delta \mathrm{T})
$$




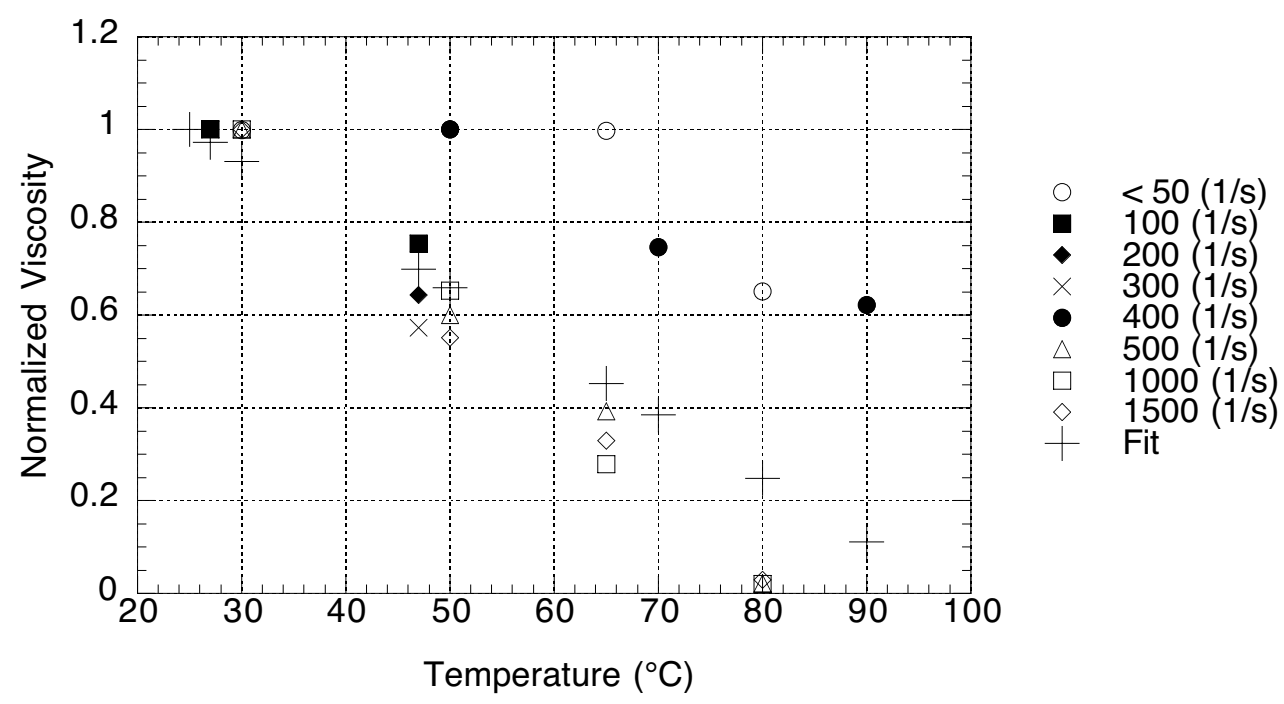

Figure 5.11. Normalized SY-101 Slurry Viscosity as a Function of Temperature

where $\mu_{1}$ is the new viscosity, $\mu_{0}$ is the initial viscosity, $\mathrm{p}$ is the relative change with temperature, and $\Delta \mathrm{T}$ is the difference between the new and the initial temperatures. The slope "p" is adjusted via a least-squares analysis and is determined to be approximately $-0.021(1 / \mathrm{T})$.

No correction for the effect of dilution (from pre- to post-mitigation) was made to the SY-101 slurry viscosity. Dilution will reduce the solid volume fraction of the slurry (even neglecting the effects of dissolution) and thereby reduce the slurry viscosity. As discussed in subsection 5.4.2.1, dilution also reduces the liquid viscosity. However, this reduction, at the slurry solid volume fractions under consideration, is considered to be minimal compared with the effect of the solids content. Therefore, it was judged reasonable, given the range of the slurry viscosity measurements (Table 5.10) and under the effect of the dilution campaign in SY-101, that for a constant solid volume fraction the viscosity of the pre-mitigation slurry is similar to that of the post-mitigation slurry. Further, as is discussed, the waste viscosity used in applying the Wasp model results from a fit on the transferred solid volume fraction (and strain rate) that includes the dilution-reduced liquid viscosity with no solid volume fraction.

The current waste temperature is approximately $28^{\circ} \mathrm{C}$, and the temperature-corrected slurry viscosity distributions for the given strain rate and lower solid volume fraction $(0.155)$ are shown in Figures 5.12 through 5.14. Uniform distributions are used to describe the slurry viscosity at the solid volume fraction of 0.296 . The upper and lower bounds for these distributions are 583 to $813 \mathrm{cP}$ for $\gamma=1281 / \mathrm{s}, 1049$ to $1309 \mathrm{cP}$ for $\gamma=801 / \mathrm{s}$, and 1574 to $1680 \mathrm{cP}$ for $\gamma=48 \mathrm{1} / \mathrm{s}$.

From these slurry viscosity distributions and that which describes the liquid viscosity (see Figure 5.4), a function was created which describes the slurry viscosity at the current waste temperature dependent on the solid volume fraction and strain rate. Typically, the viscosity of a slurry as a function of the solid volume fraction is described exponentially (Wasp et al. 1977). 


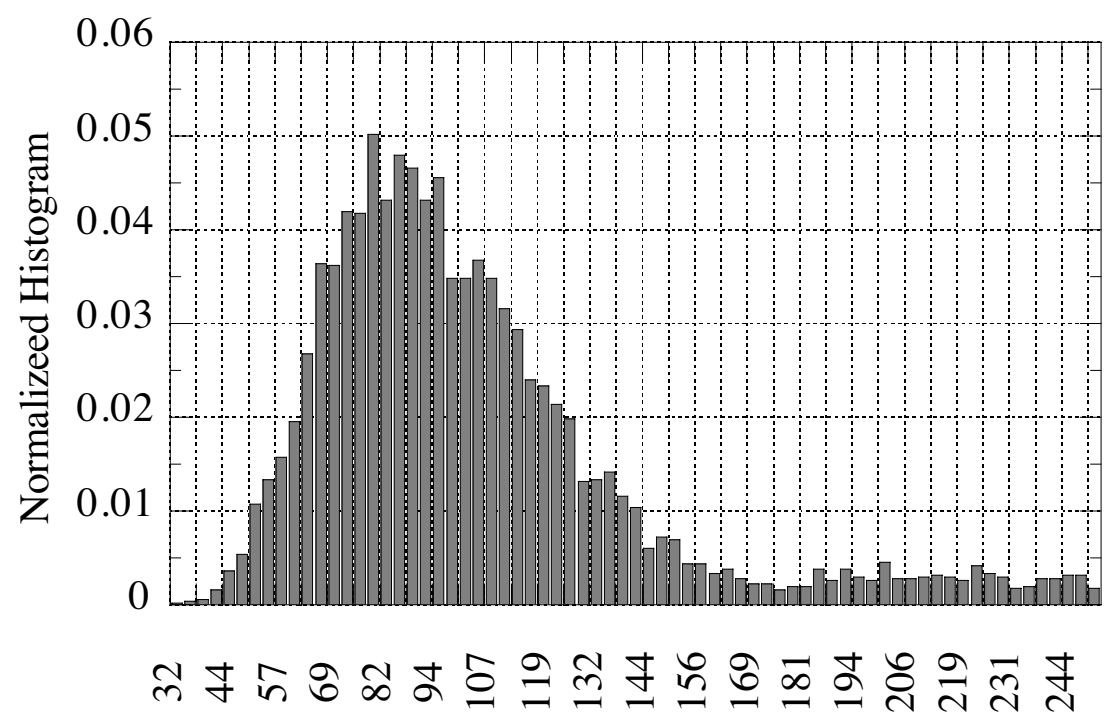

Slurry Viscosity (cP)

Figure 5.12. SY-101 Slurry Viscosity Distribution $(\gamma=1281 / \mathrm{s}, \mathrm{Cv}=0.155)$

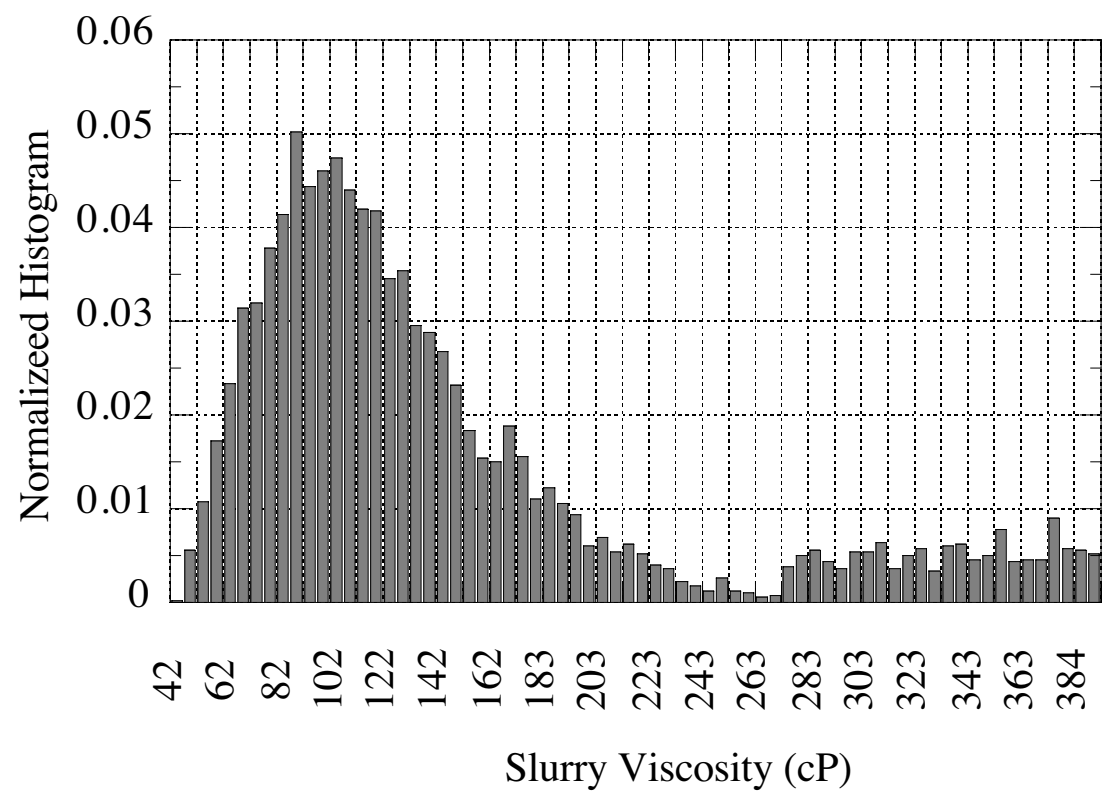

Figure 5.13. SY-101 Slurry Viscosity Distribution $(\gamma=801 / \mathrm{s}, \mathrm{Cv}=0.155)$ 


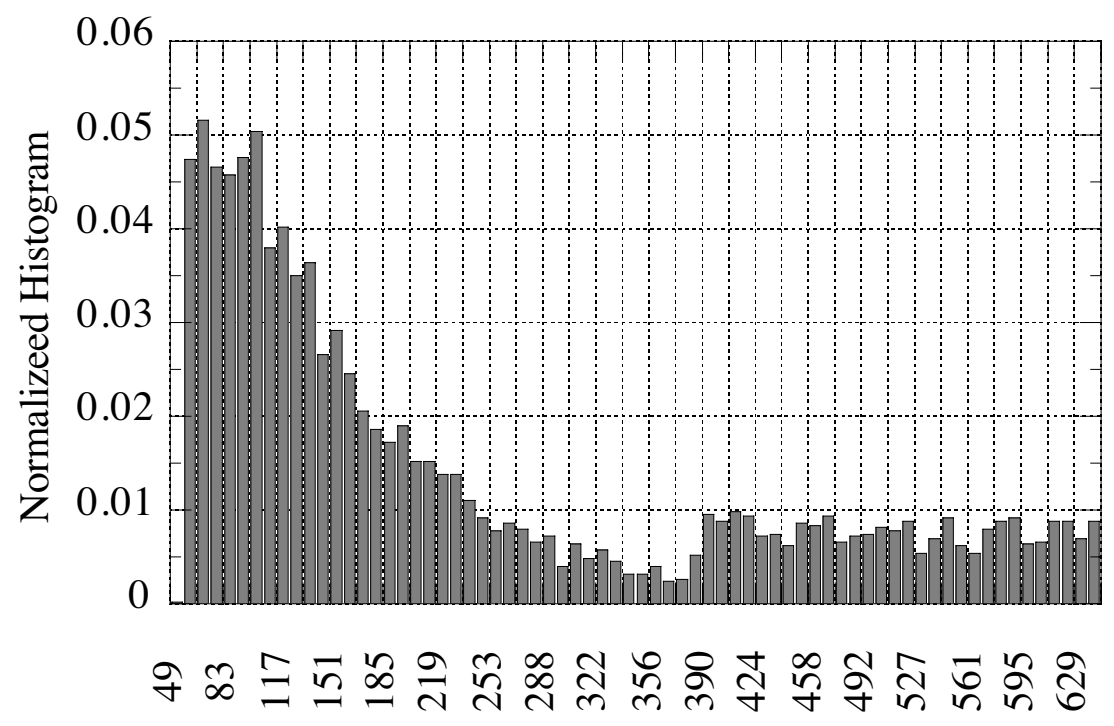

Slurry Viscosity (cP)

Figure 5.14. SY-101 Slurry Viscosity Distribution $(\gamma=48 \mathrm{~L} / \mathrm{s}, \mathrm{Cv}=0.155)$

Therefore, a fit to the data of the form

$$
\mu_{\mathrm{SL}}=\mu_{\mathrm{L}} \mathrm{e}^{\mathrm{ACv}}
$$

was used where $\mathrm{A}$ is a constant and $\mathrm{Cv}$ is the dry solid volume fraction.

For each simulation, a viscosity is selected from the distributions at each solid volume fraction $(0.0,0.155$, and 0.296$)$ for the appropriate strain rate as determined by the transfer velocity. Equation 5.4.9 is then optimized to these three data points using a least squares analysis. The slurry viscosity for the specified transfer conditions may then be evaluated. Figure 5.15 is an example of this methodology. For illustration purposes, the fit has been made to the medians of the viscosity distributions, at $\gamma=80 \mathrm{~L} / \mathrm{s}$. In practice, the fit is made to the selected viscosity for a given solid volume fraction in each simulation run for the appropriate strain rate. 


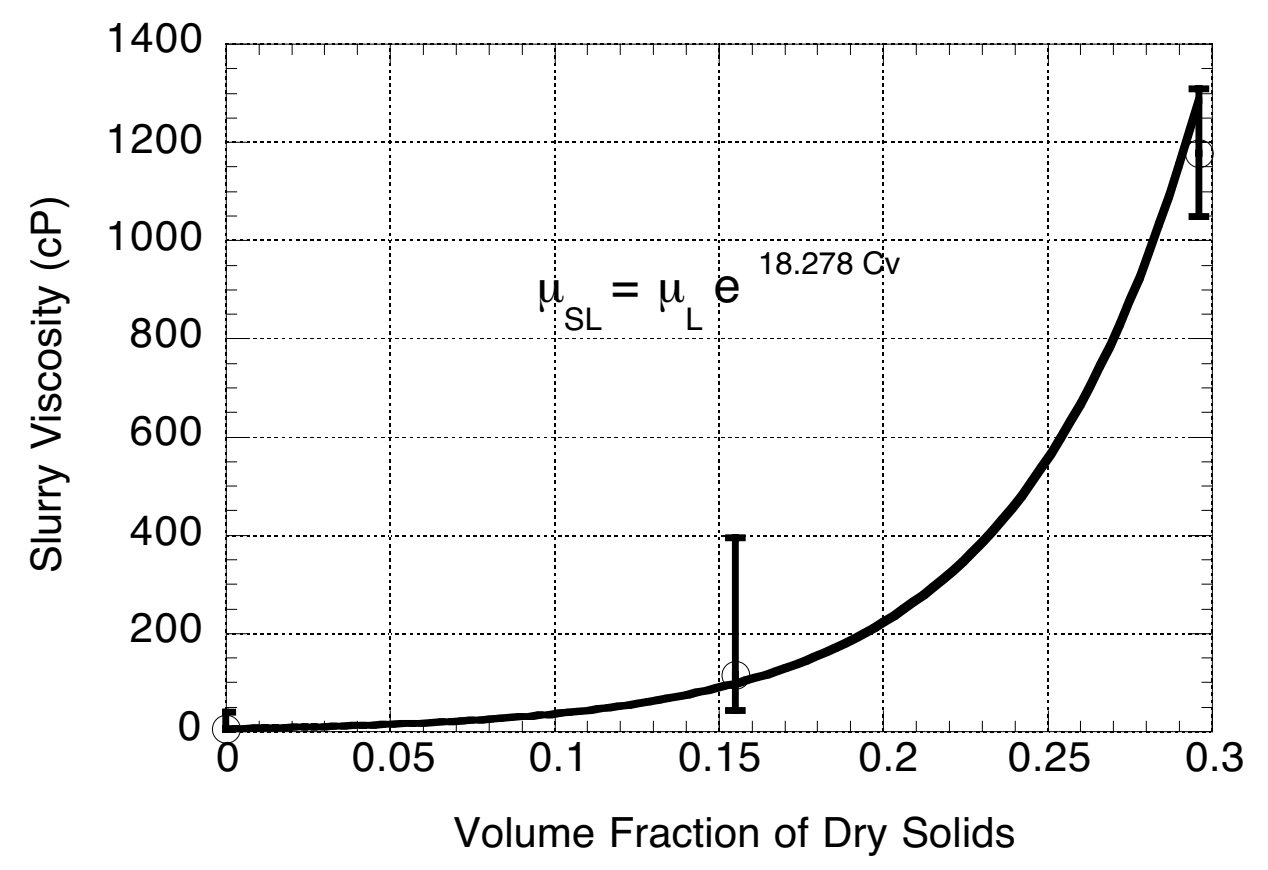

Figure 5.15. Example of the Determination of the Slurry Viscosity at Transfer Conditions $\left(\gamma=80 \mathrm{~s}^{-1}\right)$

\subsubsection{Pipeline modeling results and evaluations}

We used the Wasp slurry transport model (Wasp 1963) to calculate the critical velocity and expected pressure drop to determine stochastically whether current SY-101 waste can be transferred through the existing 6.2-mile-long, 3-inch-diameter pipeline without additional dilution with water and, if it cannot, how much dilution is needed.

\subsubsection{Assessment setup}

As discussed in Section 5.4.2, there are two different possibilities for the current SY-101 solid size distributions, as shown in Tables 5.8 and 5.9. Moreover, although the transfer pump inlet in SY-101 is fixed at approximately 102 inches above the tank bottom, the nonconvective layer (sludge) thickness is changing with time, and the exact thickness is unknown (see subsection 5.4.2.3 and Figures 5.7 through 5.10). Thus, depending on the actual nonconvective layer thickness at the time of transfer, the pump inlet may or may not withdraw the nonconvective layer. We therefore selected four possible solid concentrations: the pump withdraws the SY-101 waste from 1) only the supernatant liquid, 2) one-third from nonconvective layer (sludge) waste and two-thirds from the supernatant liquid, 3) two-thirds from the nonconvective layer (sludge) waste and one-third from the supernatant liquid, and 4) only the nonconvective layer. We also selected slurry velocities of $0.46,0.76$, and $1.2 \mathrm{~m} / \mathrm{s}$ $(1.5,2.5$ and $4.0 \mathrm{ft} / \mathrm{sec})$ based on the scoping evaluation discussed in Section 5.3. As a result, 24 individual cases were evaluated that combined two different SY-101 solid size distributions, three different slurry velocities, and four different solid concentrations, as shown in Table 5.11. 
Table 5.11. SY101 Cross-Site Transfer Evaluation Cases

\begin{tabular}{|c|c|c|c|c|c|c|c|c|c|}
\hline \multirow[t]{2}{*}{$\begin{array}{c}\text { Test } \\
\text { cases }\end{array}$} & \multicolumn{2}{|c|}{$\begin{array}{c}\text { Particle } \\
\text { sizes }\end{array}$} & \multicolumn{3}{|c|}{$\begin{array}{c}\text { Slurry velocity } \\
(\mathrm{m} / \mathrm{s})\end{array}$} & \multicolumn{4}{|c|}{$\begin{array}{c}\begin{array}{c}\text { Solids concentration } \\
(\mathrm{vol} \%)\end{array}\end{array}$} \\
\hline & Coarse & Fine & 1.2 & 0.76 & 0.46 & 0 & 5.67 & 11.3 & 17 \\
\hline 1 & $\mathrm{X}$ & & $\mathrm{X}$ & & & $\mathrm{X}$ & & & \\
\hline 2 & $\mathrm{X}$ & & $x$ & & & & $\mathrm{X}$ & & \\
\hline 3 & $\mathrm{X}$ & & $\mathrm{X}$ & & & & & $\mathrm{X}$ & \\
\hline 4 & $\mathrm{X}$ & & $\mathrm{X}$ & & & & & & $\mathrm{X}$ \\
\hline 5 & $\mathrm{X}$ & & & $\mathrm{x}$ & & $\mathrm{X}$ & & & \\
\hline 6 & $\mathrm{X}$ & & & $\mathrm{X}$ & & & $\mathrm{X}$ & & \\
\hline 7 & $\mathrm{X}$ & & & $\mathrm{X}$ & & & & $\mathrm{X}$ & \\
\hline 8 & $\mathrm{X}$ & & & $\mathrm{X}$ & & & & & $\mathrm{x}$ \\
\hline 9 & $\mathrm{X}$ & & & & $\mathrm{X}$ & $\mathrm{X}$ & & & \\
\hline 10 & $\mathrm{X}$ & & & & $\mathrm{X}$ & & $\mathrm{X}$ & & \\
\hline 11 & $\mathrm{X}$ & & & & $\mathrm{X}$ & & & $\mathrm{X}$ & \\
\hline 12 & $\mathrm{X}$ & & & & $\mathrm{X}$ & & & & $\mathrm{X}$ \\
\hline 13 & & $\mathrm{X}$ & $\mathrm{x}$ & & & $\mathrm{X}$ & & & \\
\hline 14 & & $\mathrm{X}$ & $\mathrm{X}$ & & & & $\mathrm{X}$ & & \\
\hline 15 & & $\mathrm{X}$ & $\mathrm{X}$ & & & & & $\mathrm{X}$ & \\
\hline 16 & & $\mathrm{X}$ & $\mathrm{x}$ & & & & & & $\mathrm{x}$ \\
\hline 17 & & $\mathrm{X}$ & & $\mathrm{X}$ & & $\mathrm{X}$ & & & \\
\hline 18 & & $\mathrm{X}$ & & $\mathrm{X}$ & & & $\mathrm{X}$ & & \\
\hline 19 & & $\mathrm{X}$ & & $\mathrm{X}$ & & & & $\mathrm{X}$ & \\
\hline 20 & & $\mathrm{X}$ & & $\mathrm{X}$ & & & & & $\mathrm{X}$ \\
\hline 21 & & $\mathrm{X}$ & & & $\mathrm{X}$ & $\mathrm{X}$ & & & \\
\hline 22 & & $\mathrm{X}$ & & & $\mathrm{X}$ & & $\mathrm{X}$ & & \\
\hline 23 & & $\mathrm{X}$ & & & $\mathrm{X}$ & & & $\mathrm{X}$ & \\
\hline 24 & & $\mathrm{X}$ & & & $\mathrm{x}$ & & & & $\mathrm{X}$ \\
\hline
\end{tabular}

As stated previously, the following five restrictions must be satisfied for the cross-site transfer to be acceptable:

Restriction 1: The slurry velocity must be greater than the critical velocity.

Restriction 2: The slurry flow must be turbulent.

Restriction 3: The pipeline pressure must not exceed 400 psi in any part of the pipeline.

Restriction 4: The pipeline pressure at the vent station (Figure 5.1) must be less than 180 psi.

Restriction 5: The required transfer pump pressure must not exceed 220 psi.

For each of these 24 cases, we conducted the Monte Carlo simulation analysis by running the Wasp Model 5,000 times to obtain statistically valid results based on the parameter input distributions discussed in Section 5.4.2. 


\subsubsection{SY-101 waste transfer without dilution}

We first assessed these cases without any additional dilution by water. If this assessment indicated that it is not possible to transfer the specific cases, we performed the assessment again with dilution. Summaries of the simulation results with the coarse particle size cases (Cases 1 through 12) are shown in Tables 5.12 through 5.14. Results for Cases 13 through 24, having the fine particle size, are shown in Tables 5.15 through 5.17. Required pressure drops for the total system and the vent station shown in these tables are the pressures that are required to move the waste from Tank SY-101 and from the vent station, respectively, to the receiver tank of AP-104 in 200 East Area. The presented results are the upper bound of 95\% confidence interval (UB 95 CI), lower bound of the $95 \%$ confidence interval (LB $95 \mathrm{CI}$ ), and median values. For all cases, the UB 95 CI indicates that, with $97.5 \%$ probability, expected values are below those indicated. Similarly, the LB 95 CI indicates that with $97.5 \%$ of probability expected values are above those indicated at that level. The median values have $50 \%$ probability that expected values are below (or above) those shown at that level. We selected cases to be acceptable if they satisfy all five restrictions at the UB $95 \mathrm{CI}$. These tables also provide which restrictions are not satisfied when the SY-101 waste was judged not transferable.

As expected, Cases 1 through 4 do not satisfy pipe and pump pressure restrictions 3, 4 and 5 . Case 4 does not satisfy the turbulence criterion (restriction 2) either. Thus, none of the SY-101 waste can be transferred at $1.2 \mathrm{~m} / \mathrm{s}(4.0 \mathrm{ft} / \mathrm{sec})$, as indicated in Table 5.12. However, when there are no solids in the pipe flow (Case 1), restrictions 1 and 2 would not be applicable. Thus, there is no need to transfer the liquid waste at this relatively high velocity. The liquid pipe flow must satisfy only the pipeline and transfer pump pressure limitations (restrictions 3, 4 and 5). In practice, therefore, it is feasible to transfer the SY-101 liquid waste at a velocity low enough to

Table 5.12. Monte Carlo Simulation Results for Test Cases 1 through 4

\begin{tabular}{|c|c|c|c|c|c|c|c|c|c|}
\hline \multirow[t]{2}{*}{ Case } & \multirow{2}{*}{$\begin{array}{c}\text { Confidence } \\
\text { interval } \\
(\%)\end{array}$} & \multicolumn{2}{|c|}{ Transferable? } & \multirow{2}{*}{$\begin{array}{c}\text { Slurry } \\
\text { flow rate } \\
\text { (gpm) }\end{array}$} & \multicolumn{2}{|c|}{$\begin{array}{c}\text { Required } \\
\text { pressure drop } \\
\text { (psi) } \\
\end{array}$} & \multirow{2}{*}{$\begin{array}{c}\text { Slurry } \\
\text { velocity } \\
(\mathbf{m} / \mathbf{s})\end{array}$} & \multirow{2}{*}{$\begin{array}{c}\text { Critical } \\
\text { velocity } \\
(\mathbf{m} / \mathbf{s})\end{array}$} & \multirow{2}{*}{$\begin{array}{c}\text { Pipe } \\
\text { Reynolds } \\
\text { No. }\end{array}$} \\
\hline & & Yes/No & \begin{tabular}{|c|} 
Failed \\
restrictions
\end{tabular} & & $\begin{array}{c}\text { Total } \\
\text { system }\end{array}$ & $\begin{array}{c}\text { Vent } \\
\text { station }\end{array}$ & & & \\
\hline \multirow[t]{3}{*}{1} & UB 95 CI & \multirow{3}{*}{ No } & \multirow{3}{*}{$3,4,5$} & \multirow{3}{*}{87} & 922 & 501 & \multirow{3}{*}{1.2} & $\mathrm{~N} / \mathrm{A}$ & 35,200 \\
\hline & Median & & & & 581 & 298 & & $\mathrm{~N} / \mathrm{A}$ & 23,800 \\
\hline & LB 95 CI & & & & 537 & 272 & & N/A & 3,620 \\
\hline \multirow[t]{3}{*}{2} & UB 95 CI & \multirow{3}{*}{ No } & \multirow{3}{*}{$3,4,5$} & \multirow{3}{*}{87} & 1,052 & 577 & \multirow{3}{*}{1.2} & 0.59 & 14,300 \\
\hline & Median & & & & 726 & 383 & & 0.56 & 10,100 \\
\hline & LB 95 CI & & & & 669 & 349 & & 0.52 & 2,610 \\
\hline \multirow[t]{3}{*}{3} & UB 95 CI & \multirow{3}{*}{ No } & \multirow{3}{*}{$3,4,5$} & \multirow{3}{*}{87} & 1,074 & 589 & \multirow{3}{*}{1.2} & 0.67 & 5,470 \\
\hline & Median & & & & 944 & 511 & & 0.63 & 4,220 \\
\hline & LB 95 CI & & & & 878 & 472 & & 0.59 & 2,720 \\
\hline \multirow[t]{3}{*}{4} & UB 95 CI & \multirow{3}{*}{ No } & \multirow{3}{*}{$2,3,4,5$} & \multirow{3}{*}{87} & 1,736 & 981 & \multirow{3}{*}{1.2} & 0.72 & 2,045 \\
\hline & Median & & & & 1,301 & 722 & & 0.68 & 1,640 \\
\hline & LB 95 CI & & & & 1,211 & 669 & & 0.64 & 720 \\
\hline
\end{tabular}


satisfy these pipeline and pump pressure limitations as long as potential temperature-reduction effects on the waste phase and properties are not considered. This is also true for Cases 5, 9, 13, 17 , and 21 .

With a slurry velocity of $0.76 \mathrm{~m} / \mathrm{s}(2.5 \mathrm{ft} / \mathrm{sec}), \mathrm{SY}-101$ waste for Cases 5 through 8 would not be transferable, regardless of solid concentrations, due to pipe, pump pressure, and turbulence restrictions (for Case 8), as shown in Table 5.13.

Table 5.13. Monte Carlo Simulation Results for Test Cases 5 through 8

\begin{tabular}{|c|c|c|c|c|c|c|c|c|c|}
\hline \multirow[t]{2}{*}{ Case } & \multirow{2}{*}{$\begin{array}{c}\text { Confidence } \\
\text { interval } \\
(\%)\end{array}$} & \multicolumn{2}{|c|}{ Transferable? } & \multirow{2}{*}{$\begin{array}{c}\text { Slurry } \\
\text { flow rate } \\
(\mathrm{gpm})\end{array}$} & \multicolumn{2}{|c|}{$\begin{array}{c}\text { Required } \\
\text { pressure drop } \\
\text { (psi) } \\
\end{array}$} & \multirow{2}{*}{$\begin{array}{c}\text { Slurry } \\
\text { velocity } \\
(\mathbf{m} / \mathbf{s})\end{array}$} & \multirow{2}{*}{$\begin{array}{c}\text { Critical } \\
\text { velocity } \\
(\mathbf{m} / \mathbf{s})\end{array}$} & \multirow{2}{*}{$\begin{array}{c}\text { Pipe } \\
\text { Reynolds } \\
\text { No. }\end{array}$} \\
\hline & & Yes/No & $\begin{array}{c}\text { Failed } \\
\text { restrictions }\end{array}$ & & $\begin{array}{c}\text { Total } \\
\text { system }\end{array}$ & $\begin{array}{c}\text { Vent } \\
\text { station }\end{array}$ & & & \\
\hline \multirow{3}{*}{5} & UB 95 CI & \multirow{3}{*}{ No } & \multirow{3}{*}{4,5} & \multirow{3}{*}{55} & 395 & 187 & \multirow{3}{*}{0.76} & $\mathrm{~N} / \mathrm{A}$ & 22,000 \\
\hline & Median & & & & 252 & 102 & & $\mathrm{~N} / \mathrm{A}$ & 14,900 \\
\hline & LB 95 CI & & & & 231 & 90 & & N/A & 2,700 \\
\hline \multirow{3}{*}{6} & UB 95 CI & \multirow{3}{*}{ No } & \multirow{3}{*}{4,5} & \multirow{3}{*}{55} & 390 & 183 & \multirow{3}{*}{0.76} & 0.59 & 8,240 \\
\hline & Median & & & & 328 & 146 & & 0.56 & 5,840 \\
\hline & LB 95 CI & & & & 330 & 129 & & 0.52 & 3,130 \\
\hline \multirow{3}{*}{7} & UB 95 CI & \multirow{3}{*}{ No } & \multirow{3}{*}{$3,4,5$} & \multirow{3}{*}{55} & 440 & 211 & \multirow{3}{*}{0.76} & 0.67 & 2,820 \\
\hline & Median & & & & 425 & 202 & & 0.63 & 2,650 \\
\hline & LB 95 CI & & & & 417 & 197 & & 0.59 & 2,370 \\
\hline \multirow{3}{*}{8} & UB 95 CI & \multirow{3}{*}{ No } & \multirow{3}{*}{$2,3,4,5$} & \multirow{3}{*}{55} & 897 & 481 & \multirow{3}{*}{0.76} & 0.72 & 925 \\
\hline & Median & & & & 668 & 345 & & 0.68 & 754 \\
\hline & LB 95 CI & & & & 620 & 316 & & 0.64 & 356 \\
\hline
\end{tabular}

With a slurry velocity of $0.45 \mathrm{~m} / \mathrm{s}(1.5 \mathrm{ft} / \mathrm{sec})$, only Case 9 (liquid waste) satisfies all five restrictions, as shown in Table 5.14. For Cases 10, 11 and 12, the slurry velocities are below the critical velocity, and Cases 11 and 12 also violate the turbulence requirement and transfer pump restriction. Case 12, with the highest solid concentration at $17 \mathrm{vol} \%$, also failed the pipeline pressure restrictions.

Cases 13 through 16, with finer solid particle sizes and a slurry velocity of $1.2 \mathrm{~m} / \mathrm{s}(4 \mathrm{ft} / \mathrm{sec})$, fail to satisfy the pipeline and pump pressure restrictions, as shown in Table 5.15. Similarly, none of Cases 17 through 20 with a slurry velocity of $0.76 \mathrm{~m} / \mathrm{s}(2.5 \mathrm{ft} / \mathrm{sec})$ satisfy the vent station and pump pressure restrictions (see Table 5.16), so the waste cannot be transferred under these conditions. With the lowest slurry velocity, $0.45 \mathrm{~m} / \mathrm{s}(1.5 \mathrm{ft} / \mathrm{sec})$, Cases 21 and 22 satisfy all five restrictions (see Table 5.17); so waste can be transferred at $0.46 \mathrm{~m} / \mathrm{s}(1.5 \mathrm{ft} / \mathrm{sec}$ ) if solid concentrations are less than 5.67 vol\% (1/3 sludge).

Comparing the coarse particle cases (Cases 1 through 12) with the fine particle cases (Cases 13 through 24) reveals that particle size hardly affects the SY-101 waste transferability except in Case 22. As summarized in Table 5.18, only Cases 9, 20 and 21 are judged to be transferable. 
Table 5.14. Monte Carlo Simulation Results for Test Cases 9 through 12

\begin{tabular}{|c|c|c|c|c|c|c|c|c|c|}
\hline \multirow[t]{2}{*}{ Case } & \multirow{2}{*}{$\begin{array}{c}\text { Confidence } \\
\text { interval } \\
(\%)\end{array}$} & \multicolumn{2}{|c|}{ Transferable? } & \multirow{2}{*}{$\begin{array}{c}\text { Slurry } \\
\text { flow rate } \\
\text { (gpm) }\end{array}$} & \multicolumn{2}{|c|}{$\begin{array}{c}\text { Required } \\
\text { pressure drop } \\
\text { (psi) }\end{array}$} & \multirow{2}{*}{$\begin{array}{c}\text { Slurry } \\
\text { velocity } \\
(\mathbf{m} / \mathbf{s})\end{array}$} & \multirow{2}{*}{$\begin{array}{c}\text { Critical } \\
\text { velocity } \\
(\mathrm{m} / \mathrm{s})\end{array}$} & \multirow{2}{*}{$\begin{array}{c}\text { Pipe } \\
\text { Reynolds } \\
\text { No. }\end{array}$} \\
\hline & & Yes/No & $\begin{array}{c}\text { Failed } \\
\text { restrictions }\end{array}$ & & $\begin{array}{c}\text { Total } \\
\text { system }\end{array}$ & $\begin{array}{c}\text { Vent } \\
\text { station }\end{array}$ & & & \\
\hline \multirow{3}{*}{9} & UB 95 CI & \multirow{3}{*}{ Yes } & & \multirow{3}{*}{33} & 132 & 30 & \multirow{3}{*}{0.46} & N/A & 13,200 \\
\hline & Median & & & & 104 & 14 & & $\mathrm{~N} / \mathrm{A}$ & 8,960 \\
\hline & LB 95 CI & & & & 95 & 9 & & $\mathrm{~N} / \mathrm{A}$ & 3,710 \\
\hline \multirow{3}{*}{10} & UB 95 CI & \multirow{3}{*}{ No } & \multirow{3}{*}{1} & \multirow{3}{*}{33} & 151 & 40 & \multirow{3}{*}{0.46} & 0.59 & 4,810 \\
\hline & Median & & & & 140 & 34 & & 0.56 & 3,390 \\
\hline & LB 95 CI & & & & 128 & 27 & & 0.52 & 2,590 \\
\hline \multirow{3}{*}{11} & UB 95 CI & \multirow{3}{*}{ No } & \multirow{3}{*}{$1,2,5$} & \multirow{3}{*}{33} & 306 & 131 & \multirow{3}{*}{0.46} & 0.67 & 1,480 \\
\hline & Median & & & & 204 & 70 & & 0.63 & 1,130 \\
\hline & LB 95 CI & & & & 187 & 60 & & 0.59 & 380 \\
\hline \multirow{3}{*}{12} & UB 95 CI & \multirow{3}{*}{ No } & \multirow{3}{*}{$1,2,3,4,5$} & \multirow{3}{*}{33} & 441 & 210 & \multirow{3}{*}{0.46} & 0.72 & 447 \\
\hline & Median & & & & 319 & 137 & & 0.68 & 372 \\
\hline & LB 95 CI & & & & 296 & 123 & & 0.64 & 177 \\
\hline
\end{tabular}

Table 5.15. Monte Carlo Simulation Results for Test Cases 13 Through 16

\begin{tabular}{|c|c|c|c|c|c|c|c|c|c|}
\hline \multirow[t]{2}{*}{ Case } & \multirow{2}{*}{$\begin{array}{c}\text { Confidence } \\
\text { interval } \\
(\%)\end{array}$} & \multicolumn{2}{|c|}{ Transferable? } & \multirow{2}{*}{$\begin{array}{c}\text { Slurry } \\
\text { flow rate } \\
\text { (gpm) }\end{array}$} & \multicolumn{2}{|c|}{$\begin{array}{c}\text { Required } \\
\text { pressure drop } \\
\text { (psi) }\end{array}$} & \multirow{2}{*}{$\begin{array}{c}\text { Slurry } \\
\text { velocity } \\
(\mathbf{m} / \mathbf{s})\end{array}$} & \multirow{2}{*}{$\begin{array}{c}\text { Critical } \\
\text { velocity } \\
(\mathbf{m} / \mathbf{s})\end{array}$} & \multirow{2}{*}{$\begin{array}{c}\text { Pipe } \\
\text { Reynolds } \\
\text { No. }\end{array}$} \\
\hline & & Yes/No & $\begin{array}{c}\text { Failed } \\
\text { restrictions }\end{array}$ & & $\begin{array}{c}\text { Total } \\
\text { system }\end{array}$ & $\begin{array}{c}\text { Vent } \\
\text { station }\end{array}$ & & & \\
\hline \multirow{3}{*}{13} & UB 95 CI & \multirow{3}{*}{ No } & \multirow{3}{*}{$3,4,5$} & \multirow{3}{*}{87} & 922 & 501 & \multirow{3}{*}{1.2} & N/A & 35,200 \\
\hline & Median & & & & 581 & 298 & & N/A & 23,800 \\
\hline & LB 95 CI & & & & 537 & 272 & & N/A & 3,620 \\
\hline \multirow{3}{*}{14} & UB 95 CI & \multirow{3}{*}{ No } & \multirow{3}{*}{$3,4,5$} & \multirow{3}{*}{87} & 1,052 & 577 & \multirow{3}{*}{1.2} & 0.59 & 13,700 \\
\hline & Median & & & & 732 & 386 & & 0.56 & 9,800 \\
\hline & LB 95 CI & & & & 676 & 353 & & 0.52 & 2,620 \\
\hline \multirow{3}{*}{15} & UB 95 CI & \multirow{3}{*}{ No } & \multirow{3}{*}{$3,4,5$} & \multirow{3}{*}{87} & 1,077 & 590 & \multirow{3}{*}{1.2} & 0.67 & 5,320 \\
\hline & Median & & & & 950 & 514 & & 0.63 & 4,140 \\
\hline & LB 95 CI & & & & 886 & 476 & & 0.59 & 2,710 \\
\hline \multirow{3}{*}{16} & UB 95 CI & \multirow{3}{*}{ No } & \multirow{3}{*}{$2,3,4,5$} & \multirow{3}{*}{87} & 1,739 & 982 & \multirow{3}{*}{1.2} & 0.72 & 2,019 \\
\hline & Median & & & & 1,306 & 724 & & 0.68 & 1,625 \\
\hline & LB 95 CI & & & & 1,217 & 672 & & 0.64 & 718 \\
\hline
\end{tabular}


Table 5.16. Monte Carlo Simulation Results for Test Cases 17 through 20

\begin{tabular}{|c|c|c|c|c|c|c|c|c|c|}
\hline \multirow[t]{2}{*}{ Case } & \multirow{2}{*}{$\begin{array}{c}\text { Confidence } \\
\text { interval } \\
(\%)\end{array}$} & \multicolumn{2}{|c|}{ Transferable? } & \multirow{2}{*}{$\begin{array}{c}\text { Slurry } \\
\text { flow } \\
\text { rate } \\
\text { (gpm) }\end{array}$} & \multicolumn{2}{|c|}{$\begin{array}{c}\text { Required } \\
\text { pressure drop } \\
\text { (psi) }\end{array}$} & \multirow{2}{*}{$\begin{array}{l}\text { Slurry } \\
\text { velocity } \\
(\mathbf{m} / \mathbf{s})\end{array}$} & \multirow{2}{*}{$\begin{array}{l}\text { Critical } \\
\text { velocity } \\
(\mathbf{m} / \mathbf{s})\end{array}$} & \multirow{2}{*}{$\begin{array}{c}\text { Pipe } \\
\text { Reynolds } \\
\text { No. }\end{array}$} \\
\hline & & Yes/No & $\begin{array}{c}\text { Failed } \\
\text { restrictions }\end{array}$ & & $\begin{array}{c}\text { Total } \\
\text { system }\end{array}$ & $\begin{array}{c}\text { Vent } \\
\text { station }\end{array}$ & & & \\
\hline \multirow{3}{*}{17} & UB 95 CI & \multirow{3}{*}{ No } & \multirow{3}{*}{4,5} & \multirow{3}{*}{55} & 395 & 187 & \multirow{3}{*}{0.76} & N/A & 22,000 \\
\hline & Median & & & & 252 & 102 & & N/A & 14,900 \\
\hline & LB 95 CI & & & & 231 & 90 & & N/A & 2,700 \\
\hline \multirow{3}{*}{18} & UB $95 \mathrm{CI}$ & \multirow{3}{*}{ No } & \multirow{3}{*}{4,5} & \multirow{3}{*}{55} & 393 & 184 & \multirow{3}{*}{0.76} & 0.59 & 7,690 \\
\hline & Median & & & & 332 & 148 & & 0.56 & 5,590 \\
\hline & LB 95 CI & & & & 305 & 132 & & 0.52 & 3,080 \\
\hline \multirow{3}{*}{19} & UB $95 \mathrm{CI}$ & \multirow{3}{*}{ No } & \multirow{3}{*}{$3,4,5$} & \multirow{3}{*}{55} & 439 & 210 & \multirow{3}{*}{0.76} & 0.67 & 2,710 \\
\hline & Median & & & & 430 & 205 & & 0.63 & 2,550 \\
\hline & LB 95 CI & & & & 421 & 200 & & 0.59 & 2,390 \\
\hline \multirow{3}{*}{20} & UB $95 \mathrm{CI}$ & \multirow{3}{*}{ No } & \multirow{3}{*}{$2,3,4,5$} & \multirow{3}{*}{55} & 898 & 482 & \multirow{3}{*}{0.76} & 0.72 & 912 \\
\hline & Median & & & & 671 & 347 & & 0.68 & 746 \\
\hline & LB 95 CI & & & & 623 & 318 & & 0.64 & 355 \\
\hline
\end{tabular}

Table 5.17. Monte Carlo Simulation Results for Test Cases 21 through 24

\begin{tabular}{|c|c|c|c|c|c|c|c|c|c|}
\hline \multirow[t]{2}{*}{ Case } & \multirow{2}{*}{$\begin{array}{c}\text { Confidence } \\
\text { interval } \\
(\%)\end{array}$} & \multicolumn{2}{|c|}{ Transferable? } & \multirow{2}{*}{$\begin{array}{c}\text { Slurry } \\
\text { flow rate } \\
\text { (gpm) }\end{array}$} & \multicolumn{2}{|c|}{$\begin{array}{c}\text { Required } \\
\text { pressure drop } \\
\text { (psi) }\end{array}$} & \multirow{2}{*}{$\begin{array}{c}\text { Slurry } \\
\text { velocity } \\
(\mathbf{m} / \mathbf{s})\end{array}$} & \multirow{2}{*}{$\begin{array}{c}\text { Critical } \\
\text { velocity } \\
(\mathbf{m} / \mathbf{s})\end{array}$} & \multirow{2}{*}{$\begin{array}{c}\text { Pipe } \\
\text { Reynolds } \\
\text { No. }\end{array}$} \\
\hline & & Yes/No & \begin{tabular}{|c} 
Failed \\
restrictions
\end{tabular} & & $\begin{array}{c}\text { Total } \\
\text { system }\end{array}$ & $\begin{array}{c}\text { Vent } \\
\text { station }\end{array}$ & & & \\
\hline \multirow{3}{*}{21} & UB 95 CI & \multirow{3}{*}{ Yes } & & \multirow{3}{*}{33} & 132 & 30 & \multirow{3}{*}{0.46} & N/A & 13,200 \\
\hline & Median & & & & 104 & 14 & & N/A & 8,960 \\
\hline & LB 95 CI & & & & 95 & 9 & & N/A & 3,710 \\
\hline \multirow{3}{*}{22} & UB 95 CI & \multirow{3}{*}{ Yes } & & \multirow{3}{*}{33} & 151 & 41 & \multirow{3}{*}{0.46} & 0.42 & 4,300 \\
\hline & Median & & & & 142 & 35 & & 0.39 & 3,160 \\
\hline & LB 95 CI & & & & 130 & 28 & & 0.37 & 2,550 \\
\hline \multirow{3}{*}{23} & UB 95 CI & \multirow{3}{*}{ No } & \multirow{3}{*}{$1,2,5$} & \multirow{3}{*}{33} & 307 & 132 & \multirow{3}{*}{0.46} & 0.67 & 1,400 \\
\hline & Median & & & & 206 & 71 & & 0.63 & 1,090 \\
\hline & LB 95 CI & & & & 189 & 62 & & 0.59 & 370 \\
\hline \multirow{3}{*}{24} & UB 95 CI & \multirow{3}{*}{ No } & \multirow{3}{*}{$1,2,3,4,5$} & \multirow{3}{*}{33} & 442 & 210 & \multirow{3}{*}{0.46} & 0.72 & 439 \\
\hline & Median & & & & 321 & 138 & & 0.68 & 367 \\
\hline & LB $95 \mathrm{CI}$ & & & & 298 & 124 & & 0.64 & 176 \\
\hline
\end{tabular}


Table 5.18. Cross-Site Transferability of SY-101 Waste Without Additional Dilution

\begin{tabular}{|c|c|}
\hline Cases & Is SY-101 waste transferable? \\
\hline 1 & No \\
\hline 2 & No \\
\hline 3 & No \\
\hline 4 & No \\
\hline 5 & No \\
\hline 6 & No \\
\hline 7 & No \\
\hline 8 & No \\
\hline 9 & Yes \\
\hline 10 & No \\
\hline 11 & No \\
\hline 12 & No \\
\hline 13 & No \\
\hline 14 & No \\
\hline 15 & No \\
\hline 16 & No \\
\hline 17 & No \\
\hline 18 & No \\
\hline 19 & No \\
\hline 20 & No \\
\hline 21 & Yes \\
\hline 22 & Yes \\
\hline 23 & No \\
\hline 24 & No \\
\hline
\end{tabular}

Thus, without additional dilution, only liquid waste (without any solids) can be transferred at or lower than $0.46 \mathrm{~m} / \mathrm{s}(1.5 \mathrm{ft} / \mathrm{sec})$ (see Cases 9 and 21). For a waste containing solids, only slurry with 5.67 vol\% solids concentration (two-thirds supernatant liquid and one-third nonconvective layer sludge) for the fine particle case (Case 22) can be transferred. For this case, more than $99.7 \%$ of the total solid would be transferred in the (homogeneous) vehicle (see Section 3.3.1). However, Case 10, which corresponds to Case 22 for coarser particles, failed. Thus, the SY-101 slurry, consisting of two-thirds supernatant liquid and one-third nonconvective layer sludge waste, should be considered nontransferable. SY-101 waste is therefore transferable only when there are no solids in the waste.

All 21 of the tested cases except Case 10 failed to satisfy pipeline (restrictions 3 and 4) and/or transfer pump (restriction 5) pressure restrictions at specified velocities. Case 10 (having the slowest slurry velocity, $0.46 \mathrm{~m} / \mathrm{s}$, and $5.67 \mathrm{vol} \%$ solid concentration) failed because the slurry velocity is less than the critical velocity (restriction 2). The most constraining condition came from restriction 5. We discuss how much dilution is needed to satisfy restriction 5 in subsection 5.4.3.3. We address restrictions 3 and 4 in subsection 5.4.3.4. Note that restrictions 3 and 4 are met automatically when restriction 5 is satisfied. 


\subsubsection{SY-101 waste transfer with dilution to satisfy transfer pump restrictions}

SY-101 waste can be transferred with no dilution under only the following three conditions (see Table 5.18):

- $\quad$ supernatant liquid alone at a velocity of $0.45 \mathrm{~m} / \mathrm{s}(1.5 \mathrm{ft} / \mathrm{sec})($ Case 9$)$

- supernatant liquid alone at a velocity of $0.45 \mathrm{~m} / \mathrm{s}(1.5 \mathrm{ft} / \mathrm{sec})($ Case 21$)$

- combination of two-thirds (by volume) supernatant liquid and one-third sludge at $0.45 \mathrm{~m} / \mathrm{s}(1.5 \mathrm{ft} / \mathrm{sec})($ Case 22$)$

which satisfy all of the following five restrictions:

Restriction 1: The slurry velocity must be greater than the critical velocity.

Restriction 2: The slurry flow must be turbulent.

Restriction 3: The pipeline pressure must not exceed 400 psi in any part of the pipeline

Restriction 4: The pipeline pressure at the vent station (Figure 5.1) must be less than 180 psi.

Restriction 5: The required transfer pump pressure must not exceed 220 psi.

SY-101 waste in the other 21 cases must be diluted with water to become transferable. We now discuss how much dilution is needed for those cases to meet restrictions 1, 2, and 5 (recall that restriction 5 is more limiting than restrictions 3 and 4). To determine the required dilution for each of these cases, we examined the upper bound, median, and the lower bound of the $95 \%$ confidence interval of the input distributions with no dilution. We applied the Wasp model to these three levels modified to diluted conditions to determine the required dilution amount and slurry velocity that satisfy the five restrictions.

Additional dilution of SY-101 waste with water would change the density and viscosity of the resulting liquid and slurry. These values were obtained with the same methods discussed in Section 5.4.2 using new weight fractions of water in the diluted SY-101 waste to reflect the added water. Although there would be possible waste phase changes (solid dissolution and/or precipitation) due to the water addition, we did not consider these chemical changes, partially because the SY-101 waste is already diluted with water to dissolve many dissolvable solids. Solids in SY-101 in its current condition are described in subsection 5.4.2.2 (see Figure 5.5).

The required water dilution volume (to one part by volume of SY-101 waste) and associated slurry conditions that satisfy all five restrictions are presented in Tables 5.19 through 5.21 for the coarse particle sizes. Corresponding results for fine particle sizes are shown in Tables 5.22 through 5.24. Under the waste and slurry conditions listed in these tables, SY-101 waste is transferable through the cross-site pipeline.

Tables 5.19 and 5.22 show the evaluation results of SY-101 waste dilution needed at the velocity of $1.2 \mathrm{~m} / \mathrm{s}$. For water alone to be transferred at $1.2 \mathrm{~m} / \mathrm{s}(4.0 \mathrm{ft} / \mathrm{sec})$, the resulting pressure drop for the cross-site transfer is 335 psi, exceeding the available transfer pump head (220 psi) (restriction 5). Thus, no dilution of SY-101 waste (with or without solids) can be 
Table 5.19. Required Water Dilution and Slurry Operational Conditions for Cases 1 through 4

\begin{tabular}{|c|c|c|c|c|c|c|c|c|}
\hline \multirow[t]{2}{*}{ Case } & \multirow{2}{*}{$\begin{array}{c}\text { Confidence } \\
\text { interval } \\
(\%)\end{array}$} & \multirow{2}{*}{$\begin{array}{c}\text { Required } \\
\text { water dilution } \\
\text { (volume ratio) }\end{array}$} & \multirow{2}{*}{$\begin{array}{c}\text { Slurry } \\
\text { flow rate } \\
\text { (gpm) }\end{array}$} & \multicolumn{2}{|c|}{$\begin{array}{c}\text { Required } \\
\text { pressure drop } \\
(\text { psi) }\end{array}$} & \multirow{2}{*}{$\begin{array}{c}\text { Slurry } \\
\text { velocity } \\
(\mathbf{m} / \mathbf{s})\end{array}$} & \multirow{2}{*}{$\begin{array}{c}\text { Critical } \\
\text { velocity } \\
(\mathrm{m} / \mathrm{s})\end{array}$} & \multirow{2}{*}{$\begin{array}{c}\text { Pipe } \\
\text { Reynolds } \\
\text { No. }\end{array}$} \\
\hline & & & & $\begin{array}{c}\text { Total } \\
\text { system }\end{array}$ & $\begin{array}{c}\text { Vent } \\
\text { station }\end{array}$ & & & \\
\hline 1 & \multirow{4}{*}{ UB $95 \mathrm{CI}$} & \multirow{4}{*}{$\begin{array}{l}100 \\
\text { to } \\
200\end{array}$} & \multirow{4}{*}{87} & \multirow{4}{*}{\multicolumn{2}{|c|}{$>220$ for water }} & \multirow{4}{*}{1.2} & $\mathrm{~N} / \mathrm{A}$ & \multirow{4}{*}{$>110,000$} \\
\hline 2 & & & & & & & 0.32 & \\
\hline 3 & & & & & & & 0.36 & \\
\hline 4 & & & & & & & 0.39 & \\
\hline
\end{tabular}

Table 5.20. Required Water Dilution and Slurry Operational Conditions for Cases 5 through 8

\begin{tabular}{|c|c|c|c|c|c|c|c|c|}
\hline \multirow[t]{2}{*}{ Case } & \multirow{2}{*}{$\begin{array}{c}\text { Confidence } \\
\text { interval } \\
(\%)\end{array}$} & \multirow{2}{*}{$\begin{array}{c}\text { Required } \\
\text { water dilution } \\
\text { (volume ratio) }\end{array}$} & \multirow{2}{*}{$\begin{array}{c}\text { Slurry } \\
\text { flow rate } \\
(\mathrm{gpm})\end{array}$} & \multicolumn{2}{|c|}{$\begin{array}{c}\text { Required } \\
\text { pressure drop } \\
\text { (psi) }\end{array}$} & \multirow{2}{*}{$\begin{array}{c}\text { Slurry } \\
\text { velocity } \\
(\mathbf{m} / \mathbf{s})\end{array}$} & \multirow{2}{*}{$\begin{array}{c}\text { Critical } \\
\text { velocity } \\
(\mathbf{m} / \mathbf{s})\end{array}$} & \multirow{2}{*}{$\begin{array}{c}\text { Pipe } \\
\text { Reynolds } \\
\text { No. }\end{array}$} \\
\hline & & & & $\begin{array}{c}\text { Total } \\
\text { system }\end{array}$ & $\begin{array}{c}\text { Vent } \\
\text { station }\end{array}$ & & & \\
\hline \multirow{3}{*}{5} & UB 95 CI & \multirow{3}{*}{5.0} & \multirow{3}{*}{55} & 220 & 93 & \multirow{3}{*}{0.76} & N/A & 9,500 \\
\hline & Median & & & 163 & 59 & & $\mathrm{~N} / \mathrm{A}$ & 39,300 \\
\hline & LB 95 CI & & & 157 & 56 & & N/A & 47,900 \\
\hline \multirow{3}{*}{6} & UB 95 CI & \multirow{3}{*}{6.0} & \multirow{3}{*}{55} & 220 & 93 & \multirow{3}{*}{0.76} & 0.54 & 9,500 \\
\hline & Median & & & 167 & 62 & & 0.52 & 37,800 \\
\hline & LB 95 CI & & & 162 & 59 & & 0.49 & 45,400 \\
\hline \multirow{3}{*}{7} & UB 95 CI & \multirow{3}{*}{6.9} & \multirow{3}{*}{55} & 220 & 94 & \multirow{3}{*}{0.76} & 0.61 & 9,500 \\
\hline & Median & & & 171 & 64 & & 0.58 & 36,300 \\
\hline & LB 95 CI & & & 167 & 62 & & 0.56 & 43,100 \\
\hline \multirow{3}{*}{8} & UB 95 CI & \multirow{3}{*}{8.1} & \multirow{3}{*}{55} & 220 & 93 & \multirow{3}{*}{0.76} & 0.65 & 9,700 \\
\hline & Median & & & 175 & 67 & & 0.62 & 35,300 \\
\hline & LB 95 CI & & & 171 & 64 & & 0.60 & 41,300 \\
\hline
\end{tabular}

Table 5.21. Required Water Dilution and Slurry Operational Conditions for Cases 10-12

\begin{tabular}{|c|c|c|c|c|c|c|c|c|}
\hline \multirow[t]{2}{*}{ Case } & \multirow{2}{*}{$\begin{array}{c}\text { Confidence } \\
\text { interval } \\
(\%)\end{array}$} & \multirow{2}{*}{$\begin{array}{c}\text { Required } \\
\text { water dilution } \\
\text { (volume ratio) }\end{array}$} & \multirow{2}{*}{$\begin{array}{c}\text { Slurry } \\
\text { flow rate } \\
\text { (gpm) }\end{array}$} & \multicolumn{2}{|c|}{$\begin{array}{c}\text { Required } \\
\text { pressure drop } \\
\text { (psi) }\end{array}$} & \multirow{2}{*}{$\begin{array}{c}\text { Slurry } \\
\text { velocity } \\
(\mathrm{m} / \mathrm{s})\end{array}$} & \multirow{2}{*}{$\begin{array}{c}\text { Critical } \\
\text { velocity } \\
(\mathbf{m} / \mathbf{s})\end{array}$} & \multirow{2}{*}{$\begin{array}{c}\text { Pipe } \\
\text { Reynolds } \\
\text { No. }\end{array}$} \\
\hline & & & & $\begin{array}{c}\text { Total } \\
\text { system }\end{array}$ & $\begin{array}{c}\text { Vent } \\
\text { station }\end{array}$ & & & \\
\hline \multirow{3}{*}{10} & UB 95 CI & \multirow{3}{*}{19} & \multirow{3}{*}{33} & 113 & 31 & \multirow{3}{*}{0.46} & 0.46 & 2,390 \\
\hline & Median & & & 71 & 6 & & 0.44 & 15,000 \\
\hline & LB 95 CI & & & 67 & 4 & & 0.42 & 21,200 \\
\hline \multirow{3}{*}{11} & UB 95 CI & \multirow{3}{*}{43} & \multirow{3}{*}{33} & 111 & 30 & \multirow{3}{*}{0.46} & 0.46 & 2,470 \\
\hline & Median & & & 70 & 6 & & 0.44 & 11,500 \\
\hline & LB 95 CI & & & 66 & 3 & & 0.42 & 21,800 \\
\hline \multirow{3}{*}{12} & UB 95 CI & \multirow{3}{*}{70} & \multirow{3}{*}{33} & 110 & 30 & \multirow{3}{*}{0.46} & 0.46 & 2,490 \\
\hline & Median & & & 70 & 6 & & 0.44 & 15,700 \\
\hline & LB 95 CI & & & 66 & 3 & & 0.42 & 22,000 \\
\hline
\end{tabular}


Table 5.22. Required Water Dilution and Slurry Operational Conditions for Cases 13-16

\begin{tabular}{|c|c|c|c|c|c|c|c|c|}
\hline \multirow[t]{2}{*}{ Case } & \multirow{2}{*}{$\begin{array}{c}\text { Confidence } \\
\text { interval } \\
(\%)\end{array}$} & \multirow{2}{*}{$\begin{array}{c}\text { Required } \\
\text { water dilution } \\
\text { (volume ratio) }\end{array}$} & \multirow{2}{*}{$\begin{array}{c}\text { Slurry } \\
\text { flow rate } \\
\text { (gpm) }\end{array}$} & \multicolumn{2}{|c|}{$\begin{array}{c}\text { Required } \\
\text { pressure drop } \\
\text { (psi) }\end{array}$} & \multirow{2}{*}{$\begin{array}{c}\text { Slurry } \\
\text { velocity } \\
(\mathbf{m} / \mathbf{s})\end{array}$} & \multirow{2}{*}{$\begin{array}{c}\text { Critical } \\
\text { velocity } \\
(\mathbf{m} / \mathbf{s})\end{array}$} & \multirow{2}{*}{$\begin{array}{c}\text { Pipe } \\
\text { Reynolds } \\
\text { No. }\end{array}$} \\
\hline & & & & $\begin{array}{c}\text { Total } \\
\text { system }\end{array}$ & $\begin{array}{c}\text { Vent } \\
\text { station }\end{array}$ & & & \\
\hline 13 & \multirow{4}{*}{ UB 95 CI } & \multirow{4}{*}{$\begin{array}{c}100 \\
\text { to } \\
200\end{array}$} & \multirow{4}{*}{87} & \multirow{4}{*}{\multicolumn{2}{|c|}{$>220$ for water }} & \multirow{4}{*}{1.2} & N/A & \multirow{4}{*}{$>110,000$} \\
\hline 14 & & & & & & & 0.23 & \\
\hline 15 & & & & & & & 0.25 & \\
\hline 16 & & & & & & & 0.27 & \\
\hline
\end{tabular}

Table 5.23. Required Water Dilution and Slurry Operational Conditions for Cases 17-20

\begin{tabular}{|c|c|c|c|c|c|c|c|c|}
\hline \multirow[t]{2}{*}{ Case } & \multirow{2}{*}{$\begin{array}{c}\text { Confidence } \\
\text { interval } \\
(\%)\end{array}$} & \multirow{2}{*}{$\begin{array}{c}\text { Required water } \\
\text { dilution } \\
\text { (volume ratio) }\end{array}$} & \multirow{2}{*}{$\begin{array}{c}\text { Slurry flow } \\
\text { rate } \\
\text { (gpm) }\end{array}$} & \multicolumn{2}{|c|}{$\begin{array}{c}\text { Required } \\
\text { pressure drop } \\
(p s i) \\
\end{array}$} & \multirow{2}{*}{$\begin{array}{l}\text { Slurry } \\
\text { velocity } \\
(\mathbf{m} / \mathbf{s})\end{array}$} & \multirow{2}{*}{$\begin{array}{c}\text { Critical } \\
\text { velocity } \\
(\mathbf{m} / \mathbf{s})\end{array}$} & \multirow{2}{*}{$\begin{array}{c}\text { Pipe } \\
\text { Reynolds } \\
\text { No. }\end{array}$} \\
\hline & & & & $\begin{array}{c}\text { Total } \\
\text { system } \\
\end{array}$ & $\begin{array}{c}\text { Vent } \\
\text { station } \\
\end{array}$ & & & \\
\hline \multirow{3}{*}{17} & UB 95 CI & \multirow{3}{*}{5.0} & \multirow{3}{*}{55} & 220 & 93 & \multirow{3}{*}{0.76} & N/A & 9,500 \\
\hline & Median & & & 163 & 59 & & N/A & 39,300 \\
\hline & LB 95 CI & & & 157 & 56 & & N/A & 47,900 \\
\hline \multirow{3}{*}{18} & UB $95 \mathrm{CI}$ & \multirow{3}{*}{5.5} & \multirow{3}{*}{55} & 219 & 93 & \multirow{3}{*}{0.76} & 0.38 & 9,600 \\
\hline & Median & & & 165 & 61 & & 0.36 & 35,600 \\
\hline & LB 95 CI & & & 160 & 58 & & 0.35 & 42,300 \\
\hline \multirow{3}{*}{19} & UB $95 \mathrm{CI}$ & \multirow{3}{*}{7.2} & \multirow{3}{*}{55} & 220 & 93 & \multirow{3}{*}{0.76} & 0.43 & 9,500 \\
\hline & Median & & & 169 & 63 & & 0.41 & 32,300 \\
\hline & LB 95 CI & & & 163 & 60 & & 0.39 & 37,900 \\
\hline \multirow{3}{*}{20} & UB $95 \mathrm{CI}$ & \multirow{3}{*}{8.5} & \multirow{3}{*}{55} & 220 & 93 & \multirow{3}{*}{0.76} & 0.45 & 9,600 \\
\hline & Median & & & 171 & 64 & & 0.44 & 30,100 \\
\hline & LB 95 CI & & & 166 & 61 & & 0.42 & 34,600 \\
\hline
\end{tabular}

Table 5.24. Required Water Dilution and Slurry Operational Conditions for Cases 23 and 24

\begin{tabular}{|c|c|c|c|c|c|c|c|c|}
\hline \multirow[t]{2}{*}{ Case } & \multirow{2}{*}{$\begin{array}{c}\text { Confidence } \\
\text { interval } \\
(\%)\end{array}$} & \multirow{2}{*}{$\begin{array}{c}\text { Required } \\
\text { water dilution } \\
\text { (volume ratio) }\end{array}$} & \multirow{2}{*}{$\begin{array}{l}\text { Slurry flow } \\
\text { rate } \\
\text { (gpm) }\end{array}$} & \multicolumn{2}{|c|}{$\begin{array}{c}\text { Required } \\
\text { pressure drop } \\
(\mathrm{psi})\end{array}$} & \multirow{2}{*}{$\begin{array}{c}\text { Slurry } \\
\text { velocity } \\
(\mathbf{m} / \mathbf{s})\end{array}$} & \multirow{2}{*}{$\begin{array}{c}\text { Critical } \\
\text { velocity } \\
(\mathbf{m} / \mathbf{s})\end{array}$} & \multirow{2}{*}{$\begin{array}{c}\text { Pipe } \\
\text { Reynolds } \\
\text { No. }\end{array}$} \\
\hline & & & & $\begin{array}{c}\text { Total } \\
\text { system }\end{array}$ & $\begin{array}{c}\text { Vent } \\
\text { station }\end{array}$ & & & \\
\hline \multirow{3}{*}{23} & UB $95 \mathrm{CI}$ & \multirow{3}{*}{22} & \multirow{3}{*}{33} & 115 & 32 & \multirow{3}{*}{0.46} & 0.36 & 2,300 \\
\hline & Median & & & 71 & 6 & & 0.35 & 13,900 \\
\hline & LB 95 CI & & & 66 & 3 & & 0.33 & 19,500 \\
\hline \multirow{3}{*}{24} & UB $95 \mathrm{CI}$ & \multirow{3}{*}{30} & \multirow{3}{*}{33} & 114 & 32 & \multirow{3}{*}{0.46} & 0.37 & 2,300 \\
\hline & Median & & & 71 & 6 & & 0.36 & 13,800 \\
\hline & LB 95 CI & & & 66 & 3 & & 0.34 & 19,300 \\
\hline
\end{tabular}


transferred at a velocity of $1.2 \mathrm{~m} / \mathrm{s}$. Dilution of SY-101 waste 100 to 200 times with water would make the waste essentially water, obviously resulting in a pressure drop similar to that of water.

With a slurry velocity of $0.76 \mathrm{~m} / \mathrm{s}(2.5 \mathrm{ft} / \mathrm{sec}), 5.0 \sim 8.5$ times dilution by volume will enable SY-101 waste (varying from liquid only to $100 \%$ sludge) to be transferred at UB 95 CI (see Tables 5.20 and 5.23). At these dilutions, the estimated critical velocity $(0.35 \sim 0.65 \mathrm{~m} / \mathrm{s})$ and critical Reynolds number $(\sim 2400)$ are somewhat below slurry velocity $(0.76 \mathrm{~m} / \mathrm{s})$ and resulting Reynolds numbers $(9,500 \sim 41,300)$. Thus, a slurry velocity of slightly less than $0.76 \mathrm{~m} / \mathrm{s}$ $(2.5 \mathrm{ft} / \mathrm{sec})$ may still satisfy these five restrictions. In these coarse particle cases (see Table 5.8 for the coarse size distribution), a significant portion (up to approximately 50\%) of the slurry flow is being transferred as Durand (heterogeneous) flow (see Section 3.3.1). This may cause bed load fluctuations, thus pressure fluctuations. For the fine particle cases (see Table 5.9 for the fine size distribution), over $99 \%$ of the slurry flow is transferred in the (homogeneous) vehicle (see Section 3.3.1). Therefore, pressure fluctuations are not expected to occur.

At slurry viscosity of $0.46(1.5 \mathrm{ft} / \mathrm{sec})$ would require much more dilution. It is interesting that the smaller dilution at first reduces slurry viscosity more rapidly than it reduces solids concentrations, which actually increases the critical velocity and makes the waste more difficult to transfer. However, as dilution increases, the favorable effect of the solids concentration reduction outweighs the unfavorable effects of slurry viscosity on the critical velocity, overcoming the five cross-site transfer restrictions. At this velocity $0.46 \mathrm{~m} / \mathrm{s}(1.5 \mathrm{ft} / \mathrm{sec}), \mathrm{SY}-101$ waste must be diluted 19 to 70 times by volume with water to reduce the slurry viscosity and density enough to ensure the slurry flows are turbulent (see Tables 5.21 and 5.24). These dilution requirements are much greater than the $6.0 \sim 8.5$ dilution required at $0.76 \mathrm{~m} / \mathrm{s}(2.5$ $\mathrm{ft} / \mathrm{sec})$. A slurry viscosity of $0.76 \mathrm{~m} / \mathrm{s}(2.5 \mathrm{ft} / \mathrm{sec})$ would therefore be a better choice than 0.46 $\mathrm{m} / \mathrm{s}(1.5 \mathrm{ft} / \mathrm{sec})$ when the transferred SY-101 waste contains solids.

Tables 5.25 and 5.26 summarize the required SY-101 cross-site transfer conditions to meet restrictions 1 through 5 . If there are no solids, a flow velocity at or below $0.46 \mathrm{~m} / \mathrm{s}(1.5 \mathrm{ft} / \mathrm{sec})$ would transfer the liquid waste without any dilution. However, when the SY-101 waste contains solids, a $0.76-\mathrm{m} / \mathrm{s}(2.5-\mathrm{ft} / \mathrm{sec})$ velocity is preferable to the other two velocities. At this velocity, dilution with water at 6 parts water to 1 part SY-101 slurry is required if the slurry consists of two-thirds SY-101 supernatant liquid and one-third nonconvective layer (sludge) waste (5.67 vol\% solids). If the slurry consists of one-third supernatant liquid and two-thirds nonconvective layer (sludge) waste (11.3 vol\% solids), it needs to be diluted with water at 7.2 parts water to 1 part SY-101 slurry. The slurry must be diluted with 8.5 parts water to 1 part slurry if the slurry consists entirely of nonconvective layer (sludge) waste (17.0 vol\% solids). 
Table 5.25. Summary of SY-101 Waste Transferable Conditions

\begin{tabular}{|c|c|c|c|}
\hline Case & $\begin{array}{c}\text { Solid concentration } \\
(\mathrm{vol} \%)\end{array}$ & $\begin{array}{c}\text { Required water dilution } \\
\text { (volume ratio) }\end{array}$ & $\begin{array}{c}\text { Slurry velocity } \\
(\mathbf{m} / \mathbf{s})\end{array}$ \\
\hline 1 & 0 & \multirow{4}{*}{$\begin{array}{c}100 \\
\text { to } \\
200\end{array}$} & \multirow{4}{*}{1.2} \\
\hline 2 & 5.67 & & \\
\hline 3 & 11,3 & & \\
\hline 4 & 17 & & \\
\hline 5 & 0 & 5.0 & \multirow{4}{*}{0.76} \\
\hline 6 & 5.67 & 6.0 & \\
\hline 7 & 11,3 & 6.9 & \\
\hline 8 & 17 & 8.1 & \\
\hline 9 & 0 & 0 & \multirow{4}{*}{0.46} \\
\hline 10 & 5.67 & 19 & \\
\hline 11 & 11,3 & 43 & \\
\hline 12 & 17 & 70 & \\
\hline 13 & 0 & \multirow{4}{*}{$\begin{array}{c}100 \\
\text { to } \\
200\end{array}$} & \multirow{4}{*}{1.2} \\
\hline 14 & 5.67 & & \\
\hline 15 & 11,3 & & \\
\hline 16 & 17 & & \\
\hline 17 & 0 & 5.0 & \multirow{4}{*}{0.76} \\
\hline 18 & 5.67 & 5.5 & \\
\hline 19 & 11,3 & 7.2 & \\
\hline 20 & 17 & 8.5 & \\
\hline 21 & 0 & 0 & \multirow{4}{*}{0.46} \\
\hline 22 & 5.67 & 0 & \\
\hline 23 & 11,3 & 22 & \\
\hline 24 & 17 & 30 & \\
\hline
\end{tabular}

Table 5.26. Near-Optimal SY-101 Slurry Conditions for Cross-Site Transfer

\begin{tabular}{|c|c|c|}
\hline $\begin{array}{c}\text { Solid concentration } \\
(\text { vol \%) }\end{array}$ & $\begin{array}{c}\text { Required water } \\
\text { dilution } \\
\text { (volume ratio) }\end{array}$ & $\begin{array}{c}\text { Slurry velocity } \\
(\mathbf{m} / \mathbf{s})\end{array}$ \\
\hline 0 (no sludge) & 0 & $\leq 0.46$ \\
\hline $5.67(1 / 3$ sludge) & 6.0 & \multirow{2}{*}{0.76} \\
\hline $11.3(2 / 3$ sludge) & 7.2 & \\
\hline 17.0 (sludge only) & 8.5 & \\
\hline
\end{tabular}

\subsubsection{SY-101 waste transfer with dilution to satisfy pipeline pressure restrictions}

As discussed in subsection 5.3.3.3, the most restrictive condition for waste transfer at $0.76 \mathrm{~m} / \mathrm{s}(2.5 \mathrm{ft} / \mathrm{sec})$ comes from a transfer pump head limit of $220 \mathrm{psi}$ (restriction 5). Thus we also evaluated how much dilution is needed for the same 21 cases if there is no restriction on the transfer pump's available head. Under this assumption (imposing restrictions 1 through 4 but not 5), the pipeline pressure restrictions (maximum pressures of 400 psi at Tank SY-101 and 180 psi at the vent station) are the main limitations to overcome by diluting the SY-101 waste with water 
while still satisfying restrictions 1 and 2 on slurry pipe flows (see Table 5.18). Similar to the dilution evaluation above, we examined the upper and lower bounds of the $95 \%$ confidence interval as well as the median.

Estimated dilution results in this case are shown in Tables 5.27 through 5.30 for both coarse and fine particles. As shown in Tables 5.27 and 5.29, a slurry velocity of $1.2 \mathrm{~m} / \mathrm{s}(4 \mathrm{ft} / \mathrm{sec})$ requires the SY-101 waste to be diluted 100 to 200 times by volume to satisfy the two pressure requirements and ensure that the waste can be transferred successfully through the cross-site transfer pipeline at UB 95 CI. This is not practical. As discussed in subsection 5.4.3.3, SY-101 liquid waste is not subject to the critical velocity and turbulence flow requirements (restrictions 1 and 2), and the liquid waste can be transferred at a much lower velocity to satisfy the pipeline pressure limitations (restrictions 3 and 4), as long as potential temperature reduction effects on the waste phase and properties are not considered.

With a slurry velocity of $0.76 \mathrm{~m} / \mathrm{s}(2.5 \mathrm{ft} / \mathrm{sec}), 0.79 \sim 4.7$ times dilution by volume will enable SY-101 waste to be transferred at UB 95 CI (see Tables 5.28 and 5.30). This dilution requirement is much smaller (roughly half) than the $6.9 \sim 8.5$ times dilution needed to satisfy the transfer pump limitation of 220 psi (restriction 5). For the coarse particle cases, up to approximately $20 \%$ of the slurry flow is transferred as Durand flow, potentially causing pressure fluctuations. For the fine particle cases, $99 \%$ is transferred as the vehicle; thus, no pressure fluctuations are expected.

If the slurry is set to the slowest velocity of $0.46 \mathrm{~m} / \mathrm{s}(1.5 \mathrm{ft} / \mathrm{sec}), \mathrm{SY}-101$ waste must be diluted 19 to 70 times by volume with water to ensure that the slurry flows are turbulent (see Tables 5.21 and 5.24-duplicated below). Because this dilution was dictated by satisfying restrictions 1 and 2 of the slurry pipe flows, elimination of transfer pump limitation does not affect the dilution requirement. As shown in these tables, these dilution requirements are much greater than the $3.0 \sim 4.7$ times dilution required at the flow velocity of $0.76 \mathrm{~m} / \mathrm{s}(2.5 \mathrm{ft} / \mathrm{sec})$.

Although we examined only three velocities $(1.2,0.76$, and $0.46 \mathrm{~m} / \mathrm{s})$, both the Reynolds number (to ensure the turbulence flow) and pipeline pressure limitations are satisfied very tightly at a velocity of $0.76 \mathrm{~m} / \mathrm{s}(2.5 \mathrm{ft} / \mathrm{sec})$. This implies that the $0.76-\mathrm{m} / \mathrm{s}(2.5-\mathrm{ft} / \mathrm{sec})$ velocity not only satisfies restrictions 1 through 4 but also seems to be very close to the optimal velocity for the SY-101 cross-site transfer when the transfer pump's available pressure limitation of 220 psi was eliminated (restriction 5).

Table 5.27. Required Water Dilution and Slurry Operational Conditions for Cases 1 through 4

\begin{tabular}{|c|c|c|c|c|c|c|c|c|}
\hline \multirow[t]{2}{*}{ Case } & \multirow{2}{*}{$\begin{array}{c}\text { Confidence } \\
\text { interval } \\
(\%)\end{array}$} & \multirow{2}{*}{$\begin{array}{c}\text { Required } \\
\text { water dilution } \\
\text { (volume ratio) }\end{array}$} & \multirow{2}{*}{$\begin{array}{c}\text { Slurry } \\
\text { flow rate } \\
(\text { gpm })\end{array}$} & \multicolumn{2}{|c|}{$\begin{array}{c}\text { Required } \\
\text { pressure drop } \\
\text { (psi) }\end{array}$} & \multirow{2}{*}{$\begin{array}{c}\text { Slurry } \\
\text { velocity } \\
(\mathbf{m} / \mathbf{s})\end{array}$} & \multirow{2}{*}{$\begin{array}{c}\text { Critical } \\
\text { velocity } \\
(\mathbf{m} / \mathbf{s})\end{array}$} & \multirow{2}{*}{$\begin{array}{c}\text { Pipe } \\
\text { Reynolds } \\
\text { No. }\end{array}$} \\
\hline & & & & $\begin{array}{r}\text { Total } \\
\text { system }\end{array}$ & \begin{tabular}{|c|} 
Vent \\
station
\end{tabular} & & & \\
\hline 1 & \multirow{4}{*}{ UB 95 CI } & \multirow{4}{*}{$\begin{array}{c}100 \\
\text { to } \\
200\end{array}$} & \multirow{4}{*}{87} & 335 & 164 & \multirow{4}{*}{1.2} & N/A & 113300 \\
\hline 2 & & & & 336 & 164 & & 0.32 & 112800 \\
\hline 3 & & & & 336 & 165 & & 0.36 & 112400 \\
\hline 4 & & & & 336 & 165 & & 0.39 & 112100 \\
\hline
\end{tabular}


Table 5.28. Required Water Dilution and Slurry Operational Conditions for Cases 5 through 8

\begin{tabular}{|c|c|c|c|c|c|c|c|c|}
\hline \multirow{2}{*}{ Case } & \multirow{2}{*}{$\begin{array}{c}\text { Confidence } \\
\text { interval } \\
(\%)\end{array}$} & \multirow{2}{*}{$\begin{array}{c}\text { Required } \\
\text { water dilution } \\
\text { (volume ratio) }\end{array}$} & \multirow{2}{*}{$\begin{array}{c}\text { Slurry } \\
\text { flow rate } \\
(\text { gpm })\end{array}$} & \multicolumn{2}{|c|}{$\begin{array}{c}\text { Required } \\
\text { pressure drop } \\
(\text { psi) }\end{array}$} & \multirow{2}{*}{$\begin{array}{c}\text { Slurry } \\
\text { velocity } \\
(\mathbf{m} / \mathbf{s})\end{array}$} & \multirow{2}{*}{$\begin{array}{c}\text { Critical } \\
\text { velocity } \\
(\mathbf{m} / \mathbf{s})\end{array}$} & \multirow{2}{*}{$\begin{array}{c}\text { Pipe } \\
\text { Reynolds } \\
\text { No. }\end{array}$} \\
\hline & & & & $\begin{array}{c}\text { Total } \\
\text { system }\end{array}$ & $\begin{array}{c}\text { Vent } \\
\text { station }\end{array}$ & & & \\
\hline \multirow{3}{*}{5} & UB 95 CI & \multirow{3}{*}{0.24} & \multirow{3}{*}{55} & 379 & 180 & \multirow{3}{*}{0.76} & N/A & 2,700 \\
\hline & Median & & & 233 & 93 & & N/A & 16,900 \\
\hline & LB 95 CI & & & 214 & 82 & & N/A & 24,200 \\
\hline \multirow{3}{*}{6} & UB 95 CI & \multirow{3}{*}{0.78} & \multirow{3}{*}{55} & 376 & 180 & \multirow{3}{*}{0.76} & 0.60 & 2,400 \\
\hline & Median & & & 238 & 98 & & 0.58 & 12,500 \\
\hline & LB 95 CI & & & 220 & 88 & & 0.55 & 17,500 \\
\hline \multirow{3}{*}{7} & UB 95 CI & \multirow{3}{*}{3.0} & \multirow{3}{*}{55} & 346 & 166 & \multirow{3}{*}{0.76} & 0.66 & 2,300 \\
\hline & Median & & & 216 & 89 & & 0.63 & 13,400 \\
\hline & LB 95 CI & & & 199 & 79 & & 0.61 & 19.300 \\
\hline \multirow{3}{*}{8} & UB 95 CI & \multirow{3}{*}{4.6} & \multirow{3}{*}{55} & 339 & 163 & \multirow{3}{*}{0.76} & 0.69 & 2,310 \\
\hline & Median & & & 213 & 88 & & 0.66 & 13.200 \\
\hline & LB 95 CI & & & 198 & 79 & & 0.63 & 19,000 \\
\hline
\end{tabular}

Table 5.21. Required Water Dilution and Slurry Operational Conditions for Cases 10-12

\begin{tabular}{|c|c|c|c|c|c|c|c|c|}
\hline \multirow[t]{2}{*}{ Case } & \multirow{2}{*}{$\begin{array}{c}\text { Confidence } \\
\text { interval } \\
(\%)\end{array}$} & \multirow{2}{*}{$\begin{array}{c}\text { Required water } \\
\text { dilution (volume } \\
\text { ratio) }\end{array}$} & \multirow{2}{*}{$\begin{array}{c}\text { Slurry } \\
\text { flow rate } \\
(\mathrm{gpm})\end{array}$} & \multicolumn{2}{|c|}{$\begin{array}{c}\text { Required } \\
\text { pressure drop } \\
(\text { psi) }\end{array}$} & \multirow{2}{*}{$\begin{array}{c}\text { Slurry } \\
\text { velocity } \\
(\mathbf{m} / \mathbf{s})\end{array}$} & \multirow{2}{*}{$\begin{array}{c}\text { Critical } \\
\text { velocity } \\
(\mathrm{m} / \mathrm{s})\end{array}$} & \multirow{2}{*}{$\begin{array}{c}\text { Pipe } \\
\text { Reynolds } \\
\text { No. }\end{array}$} \\
\hline & & & & $\begin{array}{c}\text { Total } \\
\text { system }\end{array}$ & $\begin{array}{c}\text { Vent } \\
\text { station }\end{array}$ & & & \\
\hline \multirow{3}{*}{10} & UB 95 CI & \multirow{3}{*}{19} & \multirow{3}{*}{33} & 113 & 31 & \multirow{3}{*}{0.46} & 0.46 & 2,390 \\
\hline & Median & & & 71 & 6 & & 0.44 & 15,000 \\
\hline & LB 95 CI & & & 67 & 4 & & 0.42 & 21,200 \\
\hline \multirow{3}{*}{11} & UB 95 CI & \multirow{3}{*}{43} & \multirow{3}{*}{33} & 111 & 30 & \multirow{3}{*}{0.46} & 0.46 & 2,470 \\
\hline & Median & & & 70 & 6 & & 0.44 & 11,500 \\
\hline & LB 95 CI & & & 66 & 3 & & 0.42 & 21,800 \\
\hline \multirow{3}{*}{12} & UB 95 CI & \multirow{3}{*}{70} & \multirow{3}{*}{33} & 110 & 30 & \multirow{3}{*}{0.46} & 0.46 & 2,490 \\
\hline & Median & & & 70 & 6 & & 0.44 & 15,700 \\
\hline & LB 95 CI & & & 66 & 3 & & 0.42 & 22,000 \\
\hline
\end{tabular}

Table 5.29. Required Water Dilution and Slurry Operational Conditions for Cases 13-16

\begin{tabular}{|c|c|c|c|c|c|c|c|c|}
\hline \multirow[t]{2}{*}{ Case } & \multirow{2}{*}{$\begin{array}{c}\text { Confidence } \\
\text { interval } \\
(\%)\end{array}$} & \multirow{2}{*}{$\begin{array}{c}\text { Required } \\
\text { water dilution } \\
\text { (volume ratio) }\end{array}$} & \multirow{2}{*}{$\begin{array}{c}\text { Slurry } \\
\text { flow rate } \\
\text { (gpm) }\end{array}$} & \multicolumn{2}{|c|}{$\begin{array}{c}\text { Required } \\
\text { pressure drop } \\
(\text { psi) }\end{array}$} & \multirow{2}{*}{$\begin{array}{c}\text { Slurry } \\
\text { velocity } \\
(\mathbf{m} / \mathbf{s})\end{array}$} & \multirow{2}{*}{$\begin{array}{c}\text { Critical } \\
\text { velocity } \\
(\mathbf{m} / \mathbf{s})\end{array}$} & \multirow{2}{*}{$\begin{array}{c}\text { Pipe } \\
\text { Reynolds } \\
\text { No. }\end{array}$} \\
\hline & & & & $\begin{array}{c}\text { Total } \\
\text { system }\end{array}$ & $\begin{array}{c}\text { Vent } \\
\text { station }\end{array}$ & & & \\
\hline 13 & \multirow{4}{*}{ UB 95 CI } & \multirow{4}{*}{$\begin{array}{c}100 \\
\text { to } \\
200\end{array}$} & \multirow{4}{*}{87} & 335 & 164 & \multirow{4}{*}{1.2} & N/A & 113300 \\
\hline 14 & & & & 336 & 164 & & 0.23 & 112800 \\
\hline 15 & & & & 336 & 165 & & 0.25 & 112400 \\
\hline 16 & & & & 336 & 165 & & 0.27 & 112100 \\
\hline
\end{tabular}


Table 5.30. Required Water Dilution and Slurry Operational Conditions for Cases 17-20

\begin{tabular}{|c|c|c|c|c|c|c|c|c|}
\hline \multirow{2}{*}{ Case } & \multirow{2}{*}{$\begin{array}{c}\text { Confidence } \\
\text { interval } \\
(\%)\end{array}$} & \multirow{2}{*}{$\begin{array}{c}\text { Required } \\
\text { water dilution } \\
\text { (volume ratio) }\end{array}$} & \multirow{2}{*}{$\begin{array}{c}\text { Slurry } \\
\text { flow rate } \\
\text { (gpm) }\end{array}$} & \multicolumn{2}{|c|}{$\begin{array}{c}\text { Required } \\
\text { pressure drop } \\
(\text { psi) }\end{array}$} & \multirow{2}{*}{$\begin{array}{c}\text { Slurry } \\
\text { velocity } \\
(\mathbf{m} / \mathbf{s})\end{array}$} & \multirow{2}{*}{$\begin{array}{c}\text { Critical } \\
\text { velocity } \\
(\mathbf{m} / \mathbf{s})\end{array}$} & \multirow{2}{*}{$\begin{array}{c}\text { Pipe } \\
\text { Reynolds } \\
\text { No. }\end{array}$} \\
\hline & & & & $\begin{array}{c}\text { Total } \\
\text { system }\end{array}$ & $\begin{array}{c}\text { Vent } \\
\text { station }\end{array}$ & & & \\
\hline \multirow{3}{*}{17} & UB 95 CI & \multirow{3}{*}{0.24} & \multirow{3}{*}{55} & 379 & 180 & \multirow{3}{*}{0.76} & N/A & 2,700 \\
\hline & Median & & & 233 & 93 & & N/A & 16,900 \\
\hline & LB 95 CI & & & 214 & 82 & & N/A & 24,200 \\
\hline \multirow{3}{*}{18} & UB 95 CI & \multirow{3}{*}{0.79} & \multirow{3}{*}{55} & 376 & 180 & \multirow{3}{*}{0.76} & 0.43 & 2,300 \\
\hline & Median & & & 242 & 101 & & 0.41 & 11,600 \\
\hline & LB 95 CI & & & 224 & 90 & & 0.39 & 15,700 \\
\hline \multirow{3}{*}{19} & UB 95 CI & \multirow{3}{*}{3.0} & \multirow{3}{*}{55} & 345 & 166 & \multirow{3}{*}{0.76} & 0.46 & 2,300 \\
\hline & Median & & & 218 & 90 & & 0.45 & 12.300 \\
\hline & LB 95 CI & & & 202 & 81 & & 0.43 & 17,100 \\
\hline \multirow{3}{*}{20} & UB 95 CI & \multirow{3}{*}{4.7} & \multirow{3}{*}{55} & 338 & 162 & \multirow{3}{*}{0.76} & 0.49 & 2,310 \\
\hline & Median & & & 216 & 89 & & 0.47 & 12,000 \\
\hline & LB 95 CI & & & 200 & 80 & & 0.45 & 16,500 \\
\hline
\end{tabular}

Table 5.24. Required Water Dilution and Slurry Operational Conditions for Cases 23 and 24

\begin{tabular}{|c|c|c|c|c|c|c|c|c|}
\hline \multirow[t]{2}{*}{ Case } & \multirow{2}{*}{$\begin{array}{c}\text { Confidence } \\
\text { interval } \\
(\%)\end{array}$} & \multirow{2}{*}{$\begin{array}{c}\text { Required } \\
\text { water dilution } \\
\text { (volume ratio) }\end{array}$} & \multirow{2}{*}{$\begin{array}{c}\text { Slurry } \\
\text { flow rate } \\
(\mathrm{gpm})\end{array}$} & \multicolumn{2}{|c|}{$\begin{array}{c}\text { Required } \\
\text { pressure drop } \\
(\text { psi) }\end{array}$} & \multirow{2}{*}{$\begin{array}{c}\text { Slurry } \\
\text { velocity } \\
(\mathbf{m} / \mathbf{s})\end{array}$} & \multirow{2}{*}{$\begin{array}{c}\text { Critical } \\
\text { velocity } \\
(\mathrm{m} / \mathrm{s})\end{array}$} & \multirow{2}{*}{$\begin{array}{c}\text { Pipe } \\
\text { Reynolds } \\
\text { No. }\end{array}$} \\
\hline & & & & $\begin{array}{c}\text { Total } \\
\text { system }\end{array}$ & $\begin{array}{c}\text { Vent } \\
\text { station }\end{array}$ & & & \\
\hline \multirow{3}{*}{23} & UB 95 CI & \multirow{3}{*}{22} & \multirow{3}{*}{33} & 115 & 32 & \multirow{3}{*}{0.46} & 0.36 & 2,300 \\
\hline & Median & & & 71 & 6 & & 0.35 & 13,900 \\
\hline & LB 95 CI & & & 66 & 3 & & 0.33 & 19,500 \\
\hline \multirow{3}{*}{24} & UB 95 CI & \multirow{3}{*}{30} & \multirow{3}{*}{33} & 114 & 32 & \multirow{3}{*}{0.46} & 0.37 & 2,300 \\
\hline & Median & & & 71 & 6 & & 0.36 & 13,800 \\
\hline & LB 95 CI & & & 66 & 3 & & 0.34 & 19,300 \\
\hline
\end{tabular}

Table 5.31 summarizes cross-site transfer conditions needed for SY-101 waste for all 24 cases examined in this study, if the transfer pump head limitation of 220 psi was assumed to be eliminated from the consideration. At a $0.46-\mathrm{m} / \mathrm{s}$ transfer velocity, no dilution is needed if there are no solids. As clearly shown in this table, a transfer velocity of $0.76 \mathrm{~m} / \mathrm{s}(2.5 \mathrm{ft} / \mathrm{s})$ is preferable to the other two velocities under this assumption if the waste contains solids.

The near-optimal conditions for SY-101 cross-site transfer at a velocity of $0.76 \mathrm{~m} / \mathrm{s}$ are shown in Table 5.32. When the slurry consists of $2 / 3$ SY-101 supernatant liquid and $1 / 3$ nonconvective layer sludge, the waste must be diluted with water at 0.79 part water to 1 part SY-101 slurry. If the slurry consists of $1 / 3$ supernatant liquid and $2 / 3$ nonconvective layer sludge, it needs to be diluted at 3 parts water to 1 part SY-101 slurry. The slurry must be diluted at 4.7 parts water to 1 part SY-101 slurry if it consists entirely of nonconvective layer (sludge) waste. These dilution requirements are much less than those imposed by the 220-psi transfer pump head limitation. 
Table 5.31. Summary of SY-101 Waste Transferable Conditions

\begin{tabular}{|c|c|c|c|}
\hline Case & $\begin{array}{l}\text { Solid concentration } \\
\text { (vol\%) }\end{array}$ & $\begin{array}{l}\text { Required water } \\
\text { dilution } \\
\text { (volume ratio) }\end{array}$ & $\begin{array}{c}\text { Slurry velocity } \\
(\mathbf{m} / \mathbf{s})\end{array}$ \\
\hline 1 & 0 & \multirow{4}{*}{$\begin{array}{l}100 \\
\text { to } \\
200\end{array}$} & \multirow{4}{*}{1.2} \\
\hline 2 & 5.67 & & \\
\hline 3 & 11,3 & & \\
\hline 4 & 17 & & \\
\hline 5 & 0 & 0.24 & \multirow{4}{*}{0.76} \\
\hline 6 & 5.67 & 0.78 & \\
\hline 7 & 11,3 & 3.0 & \\
\hline 8 & 17 & 4.6 & \\
\hline 9 & 0 & 0 & \multirow{4}{*}{0.46} \\
\hline 10 & 5.67 & 19 & \\
\hline 11 & 11,3 & 43 & \\
\hline 12 & 17 & 70 & \\
\hline 13 & 0 & \multirow{4}{*}{$\begin{array}{c}100 \\
\text { to } \\
200\end{array}$} & \multirow{4}{*}{1.2} \\
\hline 14 & 5.67 & & \\
\hline 15 & 11,3 & & \\
\hline 16 & 17 & & \\
\hline 17 & 0 & 0.24 & \multirow{4}{*}{0.76} \\
\hline 18 & 5.67 & 0.79 & \\
\hline 19 & 11,3 & 3.0 & \\
\hline 20 & 17 & 4.7 & \\
\hline 21 & 0 & 0 & \multirow{4}{*}{0.46} \\
\hline 22 & 5.67 & 0 & \\
\hline 23 & 11,3 & 22 & \\
\hline 24 & 17 & 30 & \\
\hline
\end{tabular}

Table 5.32. Near-Optimal SY-101 Slurry Conditions for Cross-Site Transfer

\begin{tabular}{|c|c|c|}
\hline $\begin{array}{c}\text { Solid concentration } \\
\text { (vol\%) }\end{array}$ & $\begin{array}{c}\text { Required water } \\
\text { dilution } \\
\text { (volume ratio) }\end{array}$ & $\begin{array}{c}\text { Slurry velocity } \\
\text { (m/s) }\end{array}$ \\
\hline 0 (no sludge) & 0 & $\leq 0.46$ \\
\hline 5.67 (1/3 sludge) & 0.79 & \multirow{2}{*}{0.76} \\
\hline 11.3 (2/3 sludge) & 3.0 & \\
\hline 17.0 (sludge only) & 4.7 & \\
\hline
\end{tabular}




\subsection{Summary and Conclusions}

We evaluated the feasibility of transferring waste currently stored in Hanford Tank SY-101 in the 200 West Area to a storage tank in the 200 East Area through a 6.2-mile-long, 3-inchdiameter stainless steel supernate pipeline. The Wasp slurry pipeline transport model (Wasp 1963) was used for this assessment. We validated the Wasp model with experimental data and applied the Wasp model to calculate the critical velocity and expected pressure drop to determine 1) whether current SY-101 waste can be transferred through the existing pipeline without additional dilution with water, and 2) if it is not possible, how much dilution is needed to make it possible. The evaluation was subject to the following five restrictions:

Restriction 1 The slurry velocity must be greater than the critical velocity at above which all solids are suspended during the transfer.

Restriction 2 The slurry flow must be turbulent.

Restriction 3 The pipeline pressure must not exceed 400 psi in any part of the pipeline.

Restriction 4 The pipeline pressure at the vent station must be less than 180 psi.

Restriction 5 The required transfer pump pressure must not exceed 220 psi.

Restrictions 1 and 2 are those imposed to the slurry flow, restrictions 3 and 4 are imposed by the pipeline, and restriction 5 is imposed by the transfer pump.

We evaluated 24 cases, combining two SY-101 solid size distributions (fine and coarse), three slurry transfer velocities $(0.46,0.76$, and $1.2 \mathrm{~m} / \mathrm{s})$, and four solids concentrations (varying from liquid-only to sludge-only waste). For each of the 24 cases, we conducted Monte Carlo simulations by running the Wasp Model 5,000 times to obtain statistically valid results. Cases were acceptable if they satisfied all five restrictions at the upper bound of the $95 \%$ confidence interval. These results are subject to the uncertainty of the data used in the assessment, potential Wasp model prediction errors and limitations, potential unsteadiness of the slurry bed load, current pipeline pressure restrictions, and the available head of the transfer pump already installed in Tank SY-101.

We concluded that only the liquid waste (without any solids) could be transferred at or below the pipe flow velocity of $0.46 \mathrm{~m} / \mathrm{s}(1.5 \mathrm{ft} / \mathrm{sec})$ without additional dilution with water. When the $\mathrm{SY}-101$ waste contains solids, a transfer velocity of $0.76 \mathrm{~m} / \mathrm{s}(2.5 \mathrm{ft} / \mathrm{sec})$ requires the least amount of dilution compared with the other two velocities. We did not consider the chemical effects of added water on waste phases and properties (e.g., solids dissolution and precipitation). As summarized in Table 6.1, required dilution at a slurry velocity of $0.76 \mathrm{~m} / \mathrm{s}(2.5 \mathrm{ft} / \mathrm{sec})$ is:

- dilution of the waste at 6.2 parts water to 1 part SY-101 waste by volume if the waste consists of 2/3 supernatant liquid and 1/3 nonconvective layer (sludge) waste.

- dilution of the waste at 7.2 parts water to 1 part SY-101 waste by volume if the waste consists of $1 / 3$ supernatant liquid and $2 / 3$ nonconvective layer (sludge) waste.

- dilution of the waste at 8.5 parts water to 1 part SY-101 waste by volume if the waste consists entirely of nonconvective layer (sludge) waste. 
Table 6.1. Required SY-101 Slurry Conditions for Cross-Site Transfer

\begin{tabular}{|c|c|c||}
\hline $\begin{array}{c}\text { Solid concentration } \\
(\mathbf{v o l} \%)\end{array}$ & $\begin{array}{c}\text { Required water } \\
\text { dilution } \\
\text { (volume ratio) }\end{array}$ & $\begin{array}{c}\text { Slurry velocity } \\
(\mathbf{m} / \mathbf{s})\end{array}$ \\
\hline 0 (no sludge) & 0 & $\leq 0.46$ \\
\hline $5.67(1 / 3$ sludge) & 6.0 & \multirow{2}{*}{0.76} \\
\hline $11.3(2 / 3$ sludge) & 7.2 & \\
\hline 17.0 (sludge only) & 8.5 & \\
\hline
\end{tabular}

Because the most restrictive condition for waste transfer at $0.76 \mathrm{~m} / \mathrm{s}(2.5 \mathrm{ft} / \mathrm{sec})$ comes from the transfer pump head limitation of 220 psi (Restriction 5), we also evaluated how much dilution is needed if there is no restriction on the transfer pump's available head. Under this assumption, dilution requirements are $0.79 \sim 4.7$ parts water to 1 part SY-101 waste by volume and are about half or less of the $6.0 \sim 8.5$ times dilution requirements to meet restriction 5 (compare Table 6.1 and 6.2). Moreover, both the Reynolds number (to ensure the turbulent flow) and the pipeline pressure limitations are very tightly satisfied at a velocity of $0.76 \mathrm{~m} / \mathrm{s}$ $(2.5 \mathrm{ft} / \mathrm{sec})$. This implies that the $0.76-\mathrm{m} / \mathrm{s}(2.5-\mathrm{ft} / \mathrm{sec})$ velocity not only satisfies the restrictions but also is very close to optimal for the SY-101 cross-site transfer. For those cases in which the coarse particle size distribution was assigned, pressure fluctuations may occur as significant portions of the slurry flow may be transferred as Durand (heterogeneous) flow. For fine particle size cases, over $99 \%$ of the solids would be transferred as a vehicle (homogeneous flow), thus the pipeline pressure would remain steady.

Table 6.2. Near-Optimal SY-101 Slurry Conditions for Cross-Site Transfer

\begin{tabular}{|c|c|c|}
\hline $\begin{array}{c}\text { Solids concentration } \\
(\text { vol \%) }\end{array}$ & $\begin{array}{c}\text { Required water } \\
\text { dilution } \\
\text { (volume ratio) }\end{array}$ & $\begin{array}{c}\text { Slurry velocity } \\
(\mathbf{m} / \mathbf{s})\end{array}$ \\
\hline 0 (no sludge) & 0 & $\leq 0.76$ \\
\hline $5.67(1 / 3$ sludge) & 0.79 & \multirow{2}{*}{0.76} \\
\hline $11.3(2 / 3$ sludge) & 3.0 & \\
\hline 17.0 (sludge only) & 4.7 & \\
\hline
\end{tabular}




\subsection{References}

Brantley WM. 1994. Replacement of Cross-Site Transfer System, Functional Design Criteria. WHC-SD-W058-FDC-001, Westinghouse Hanford Company, Richland, Washington.

Condolios E and EE Chapus. 1963. "Solids Pipelines - 2: Designing Solids Handling Pipelines." Chem. Eng., Vol. 70, pp. 131-138.

DiCenso AT, LC Amato, and WI Winters. 1995. Tank Characterization Report for Double-Shell Tank 241-SY-102, WHC-SD-WM-ER-366 Rev. 0, Westinghouse Hanford Company, Richland, Washington.

Domnoske-Rauch LA and KA White. 1998. Hydraulic Calculations for Cross-Site Transfer System and Selected Physically Connected Routes. HNF-3612 Rev 0, Lockheed Martin Hanford Corp., Richland, Washington.

Durand R. 1953a. "Hydraulic Transport of Coal and Sand Materials in Pipes." Proceedings of a Colloquium on the Hydraulic Transport of Coal, November 5-6, 1952. National Coal Board, London, pp. 39-52.

Durand R. 1953b. "Basic Relationship of the Transportation of Solids in Pipes - Experimental Research." Proceedings of Minnesota International Hydraulics Convention. Minneapolis, pp. 89-103.

Ebadian MA, CX Lin, PV Skudarnov, Y Sukegawa, HJ Kang, M Allen, and R Silva. 2001. Plugging Prevention and Unplugging of Waste Transfer Pipelines; Part 2, Slurry Transport Experiments in the Flow Loop. Florida International University, Miami.

Fowler KD. 1999. Tank Farm Waste Transfer Compatibility Program. HNF-SD-WM-OCD015 Rev. 2, Lockheed Martin Hanford Corp., Richland, Washington.

George Grant Construction. 1997. Cross-Site Transfer System: System Training Class Notes. 2073CLS0.WPD. Programmable Control Services, Inc., Richland, Washington.

Govier GW and K Aziz. 1977. The Flow of Complex Mixtures in Pipes. Robert E. Krieger Publishing Company, Inc., Malabar, Florida.

Hanks RW. 1986. "Principles of Slurry Pipeline Hydraulics." Chapter 6 in Encyclopedia of Fluid Mechanics, Volume 5, Slurry Flow Technology, NP Cheremisinoff, ed. Gulf Publishing Company, Houston.

Herting DL. 1997. Results of Dilution Studies with Waste from Tank 241-AN-105. HNF-SDWM-DTR-046 Rev. 0, Numatec Hanford Corp., Richland, Washington.

Herting DL. 1998. Results of Dilution Studies with Waste from Tank 241-AN-104. HNF-3352 Rev. 0, Numatec Hanford Corp., Richland, Washington. 
Herting DL. 1999. Results of Dilution Studies with Waste from Tank 241-AW-101. HNF-4964 Rev. 0, Numatec Hanford Corp., Richland, Washington.

Ismail H. 1952. "Turbulent transfer mechanism and suspended sediment in closed channels." Tran. ASCE, Vol. 117, pp. 409-447.

Johnson GD, NW Kirch, RE Bauer, JM Conner, CW Stewart, BE Wells, and JM Grigsby. 2000. Evaluation of Hanford High-Level Waste Tank 241-SY-101. RPP-6517 Rev. 0, CH2M HILL Hanford Group, Inc., Richland, Washington.

Julyk LJ, TC Oten, and WL Willis. 2000. Waste Feed Delivery Transfer System Analysis. RPP5346 Rev 1. CH2M Hill Hanford Group, Inc., Richland, Washington.

Landel RF, BG Moser, and AJ Bauman. 1963. Proceedings of Fourth International Congress on Rheology, Part 2, p. 663. Interscience Publishers, New York.

Oroskar AR and RM Turian. 1980. The critical velocity in pipeline flow of slurries. AIChE J., 26 , pp. 550-558.

Pacquet A. 1998. Preoperational Test Report, Cross-Site Transfer System Integrated Test. HNF-2504 Rev. 0, Numatec Hanford Co., Richland, Washington.

Rassat SD, CW Stewart, BE Wells, WL Kuhn, ZI Antoniak, JM Cuta, KP Recknagle, G Terrones, VV Viswanathan, JH Sukamto, and DP Mendoza. 2000. Dynamics of Crust Dissolution and Gas Release in Tank 241-SY-101. PNNL-13112, Pacific Northwest National Laboratory, Richland, Washington.

Reynolds DA. 1993. Tank 101-SY Window E Core Sample: Interpretation of Results. WHC-EP0628. Westinghouse Hanford Company, Richland, Washington.

Reynolds DA. 1992. Tank 101-SY Window C Core Sample Results and Interpretation. WHCEP-0589. Westinghouse Hanford Company, Richland, Washington.

Reynolds BA, EA Daymo, JGH Getting, and J Zhang. 1996. Instrument Validation Project. PNNL-11221. Pacific Northwest National Laboratory, Richland, Washington.

Rose HE and RA Duckworth. 1969. The Engineer, 227(5903):392; (5904):430; (5905):478.

Ryan GW. 1995. Tank Characterization Report for Double Shell Tank 241-AZ-102. WHC-SDWM-ER-411 Rev. 0, Westinghouse Hanford Company, Richland, Washington.

Shook CA. 1969. Pipelining Solids: The Design of Short-Distance Pipelines. Presented at the Symposium on Pipeline Transport of Solids. Canadian Society for Chemical Engineering, Toronto. 
Sinclair CG. 1962. "The Limit Deposit Velocity of Heterogeneous Suspensions." Proceedings of the Symposium on Interaction Between Fluids and Particles, pp. 78-86. European Federation of Chemical Engineers, London.

Spell KE. 1955. "Correlation for Use in Transport of Aqueous Suspensions of Fine Solids through Pipes." Trans-Inst., Chem. Eng., Vol. 33, pp. 79-84.

Stewart CW, CL Shepard, JM Alzheimer, TI Stokes, and G Terrones. 1995. In Situ Determination of Rheological Properties and Void Fraction in Hanford Waste Tank 241-SY-101. PNL-10682, Pacific Northwest National Laboratory, Richland, Washington.

Tingey JM, PR Bredt, and EH Shade. 1994. The Effects of Heating and Dilution on the Rheological and Physical Properties of Tank 241-SY-101 Waste. PNL-10198, Pacific Northwest National Laboratory, Richland, Washington.

Thomas DG. 1965. "Transport characteristics of suspensions: Part VII. A note on the viscosity of Newtonian suspensions of uniform spherical particles.” J. Colloid Sci., Vol. 20, p. 267.

Vanoni VA ed. 1975. Sedimentation Engineering. "Manuals and Reports in Engineering." Brochure No. 54, American Society of Civil Engineers, New York.

Wani GA, MK Sarkar, and BP Mani. 1982. "Velocity in Multisize Particle Transportation through Horizontal Pipes." J. of Pipelines, Vol. 2, pp. 57-62.

Wasp EJ. 1963. “Cross Country Coal Pipe Line Hydraulics.” Pipeline News, pp. 20 - 28.

Wasp EJ, JP Kenny, and RL Gandhi. 1977. Solid-Liquid Flow Slurry Pipeline Transportation. Trans Tech Publications.

Whyatt GA, RJ Serne, SV Mattigold, Y Onishi, MR Powell, JH Westik Jr, LM Liljegren, GR Golcar, KP Recknagle, PM Doctor, VG Zhirnov, and J Dixon. 1996. Potential for Criticality in Hanford Tanks Resulting from Retrieval of Tank Waste. PNNL-11304, Pacific Northwest National Laboratory, Richland, Washington.

Zandi I and G Govatos. 1967. "Heterogeneous Flow of Solids in Pipelines." J. Hydr. Div., ASCE, 93:HY3, Proc. Paper 5244, pp. 145-159. 


\section{Distribution}

No. of

Copies

Offsite

M. Katona

Department of Civil and Environmental Engineering

Washington State University

Pullman, WA 99164

E J Wasp

STI International Associates

134 El Condor Court

San Rafael, CA 94903

R Srivastava

Florida International University

10555 W. Flagler St

CEAS 2100

Miami, FL 33174

JS Lindner

Diagnostic Instrumentation and

Analysis Laboratory

Mississippi State University

205 Research Blvd.

Starkville, MS 39759-9374

2 Oak Ridge National Laboratory

PO. Box 2008

Oak Ridge, TN 37831

Attn: CP McGinnis

TD Welch
No. of

Copies

33 Hanford Contractors

WB Barton

RE Bauer (6)

S7-73

JR Biggs

S7-07

RJ Cash

S7-73

JW Cammann

T4-08

PJ Certa

R3-73

A-MF Choho

R3-73

JM Conner

R2-11

TJ Conrads

R3-83

DW Crass

S7-90

SD Estey

R2-11

PW Gibbons

K9-91

CE Grenard

R3-73

C Hanson

R4-09

DL Herting

T6-07

JL Jewett

G3-43

GD Johnson

S7-73

LJ Julyk

R3-83

NW Kirch

R2-11

JG Kristofzski

R2-39

CE Leach

R1-44

EW Martinen

R3-47

RE Raymond

R2-50

DA Reynolds

R2-11

CA Rieck

R3-47

DB Smet

S7-90

WT Thompson

S7-90

JE Van Beek

60 Pacific Northwest National Laboratory

\section{Onsite}

5 DOE Richland Operations Office

J Cruz

H6-60

JJ Davis

H6-60

CA Groendyke

H6-60

DH Irby

H6-60

JS Shuen

H6-60

JA Bamberger

K7-15

JM Bates

$\mathrm{K} 7-15$

SQ Bennett

$\mathrm{K} 7-90$

JW Brothers (3)

K9-20

SK Cooley (5)

K5-12

CW Enderlin

K7-15

PA Gauglitz

K6-28

SA Hartley (5)

K5-12

Distr.1 
No. of

Copies

JL Huckaby

WL Kuhn

PA Meyer

Y Onishi (30)

CW Stewart

WC Weimer

BE Wells (5)

Information Release (2)
K7-15

K7-15

K7-15

K7-15

K7-15

K9-09

K7-15

K1-06 